\title{
Air Sampler Performance At Ford's Farm Range
}

J. A. Glissmeyer

J. W. Johnston

July 1984

Prepared for the U.S. Army under a Related Services Agreement with the U.S. Department of Energy

Contract DE-AC06-76RLO 1830

Pacific Northwest Laboratory Operated for the U.S. Department of Energy by Battelle Memorial Institute 


\title{
DISCLAIMER
}

This report was prepared as an account of work sponsored by an agency of the United States Government. Neither the United States Government nor any agency thereof, nor any of their employees, makes any warranty, express or implied, or assumes any legal liability or responsibility for the accuracy, completeness, or usefulness of any information, apparatus, product, or process disclosed, or represents that its use would not infringe privately owned rights. Reference herein to any specific commercial product, process, or service by trade name, trademark, manufacturer, or otherwise, does not necessarily constitute or imply its endorsement, recommendation, or favoring by the United States Government or any agency thereof. The views and opinions of authors expressed herein do not necessarily state or reflect those of the United States Government or any agency thereof.

\author{
PACIFIC NORTHWEST LABORATORY \\ operated by \\ BATTELLE \\ for the \\ UNITED STATES DEPARTMENT OF ENERGY \\ under Contract DE-AC06-76RLO 1830
}

\begin{tabular}{|c|c|}
\hline \multicolumn{2}{|c|}{ Printed in the United States of America } \\
\hline \multicolumn{2}{|c|}{ Available from } \\
\hline \multirow{2}{*}{\multicolumn{2}{|c|}{$\begin{array}{l}\text { National Technical Information Service } \\
\text { United States Department of Commerce }\end{array}$}} \\
\hline & \\
\hline \multicolumn{2}{|c|}{5285 Port Royal Road } \\
\hline \multicolumn{2}{|c|}{ Springfield, Virginia 22161} \\
\hline \multirow{2}{*}{\multicolumn{2}{|c|}{$\begin{array}{l}\text { NTIS Price Codes } \\
\text { Microfiche A01 }\end{array}$}} \\
\hline & \\
\hline \multicolumn{2}{|c|}{ Printed Copy } \\
\hline & Price \\
\hline Pages & Codes \\
\hline $001-025$ & A02 \\
\hline 026-050 & $\mathrm{A} 03$ \\
\hline 051-075 & $\mathrm{A} 04$ \\
\hline 076-100 & A05 \\
\hline $101-125$ & A06 \\
\hline $126-150$ & A07 \\
\hline $151-175$ & A 08 \\
\hline $176-200$ & $A 09$ \\
\hline $201-225$ & A010 \\
\hline $226-250$ & A011 \\
\hline $251-275$ & A012 \\
\hline $276-300$ & A013 \\
\hline
\end{tabular}


AIR SAMPLER PERFORMANCE

AT FORO'S FARM RANGE

J. A. Glissmeyer

J. W. Johnston

July 1984

Prepared for the U.S. Army under a Related Services Agreement with the U.S. Department of Energy Contract OE-AC06-76RLO 1830

Pacific Northwest Laboratory

Richland, Washington 99352 
, 
SUMMARY

The performance of an air-sampling system for a large-caliber depleted uranium (DU) penetrator firing range was tested during the ten initial test shots at the range. The range's target bay is enclosed and ventilated with fresh air for worker protection. The ventilation air is filtered to remove DU particles before discharge. The air-sampling system includes continuous realtime dust concentration monitors inside the target bay and at the ventilation air discharge. After the ventilation system achieves a low dust concentration in the target bay following a test shot, the bay doors are opened and two additional dust-concentration monitors are used inside, one with a 30-min sampling interval and the other with a 2-min interval. Additionally, particle samples are collected from the air discharge into membrane filters for quantitative analysis of radionuclides.

The main test objectives were: 1) to determine the bias between the monitor readings and actual DU concentrations and 2) to determine if the target bay real-time monitor tracks a decaying dust concentration as seen following a test firing. The test procedure was to operate both total and respirable airborne particle samplers adjacent to both target bay monitors for a series of ten test firings. A series of air samples was also sequentially taken after the test firings adjacent to the target bay real-time dust monitor. Exhaust particle samples were collected for each test shot. Particle samples were analyzed for gross alpha, gross beta, and uranium content. The sample analyses were then used to compare against the monitor readouts.

The analysis of the rate of concentration depletion as determined by the sequential samples showed good correlation $(0.977)$, with the target bay realtime monitor indicating that the monitor accurately indicates the rate of change in DU concentration. The real-time monitor readings are generaliy somewhat lower than the DU concentrations. Average concentration from this monitor did not correlate with either the long-term total or respirable sampler DU concentrations. Therefore, to more accurately estimate worker exposure, long-term particle samplers in the workplace are recommended. Of the other target bay dust monitors, the monitor used to quickly confirm a low dust concentration 
when the door is opened correlated well (0.810) with the real-time monitor. The other target bay dust monitor did not correlate with either the other monitors or the air samples; its use should be discontinued.

In the ventilation discharge, the long-term average monitor readings did not correlate very well with DU concentrations, probably because the concentrations were very close to the instrument's zero and were on the order of noise and zero drift. The exhaust monitor detected a dust discharge for each test firing usually lasting $<20 \mathrm{~min}$ and sometimes exceeding the weekly average control limit. The accuracy of the monitor's response to these brief emissions was not tested.

Smearable surface-contamination samples from 33 locations inside the target bay were obtained and analyzed. The highest contamination was located on the equipment on the gravel floor and the exhaust air intake. The average (over the 10 rounds) concentrations in the smears varied by a factor of ten between locations. The location air-intake contamination increased over the first three rounds. Contamination was reduced by a low-pressure water spray washdown to about the same concentration as after the second round, then remained at about twice the level as after the third round for rounds 4 through 10. 


\section{CONTENTS}

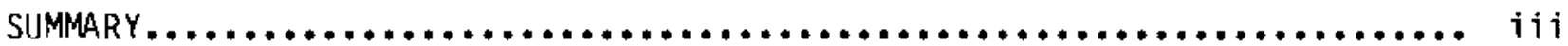

1.0 INTRODUCTION........................................ 1..1

2.0 TEST PROCEDURES...................................... 2.1

2.1 DESCRIPTION OF AIR-SAMPLING SYSTEM.................... 2.1

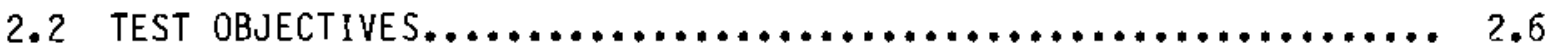

2.2.1 Inlet Respirable Sampler......................... 2.7

2.2.2 Inlet and Workplace Total Particulate Samplers.......... 2.7

2.2.3 Sequential Sampler........................... 2.8

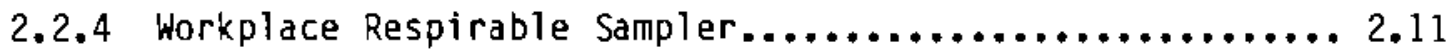

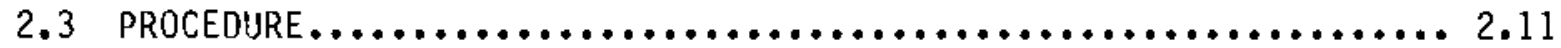

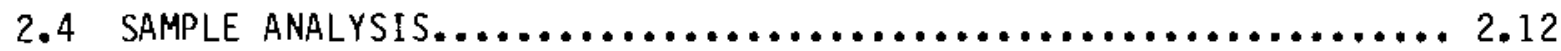

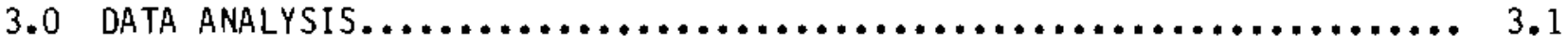

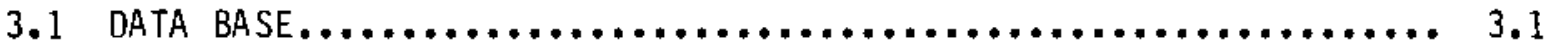

3.2 CDMPARISON OF EXPOSED FILTER CONCENTRATIONS AND BLANK

3.3 COMPARISON OF EXHAUST RAM-1 AND EXHAUST FILTERS $\ldots \ldots \ldots \ldots \ldots \ldots \ldots$

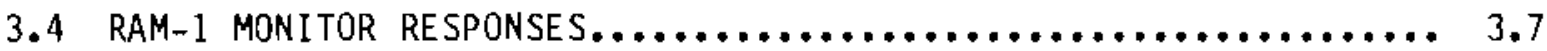

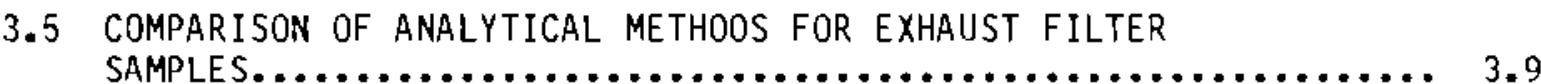

3.6 COMPARISON OF INLET RAM-1 WITH INLET AND WORKPLACE
FILTER RESUILTS $\ldots \ldots \ldots \ldots \ldots \ldots \ldots \ldots \ldots \ldots \ldots \ldots \ldots \ldots \ldots \ldots \ldots \ldots \ldots \ldots \ldots \ldots \ldots \ldots$

3.7 COMPARISON OF SEQUENTIAL RAM-1 AND FILTER RESULTS $\ldots \ldots \ldots \ldots \ldots \ldots \ldots .17$

3.8 RESULTS FOR THE RDM-3D1 MONITOR....................... 3.27

3.9 COMPARISONS OF RESULTS FOR THE TSI-35DO AND OTHER

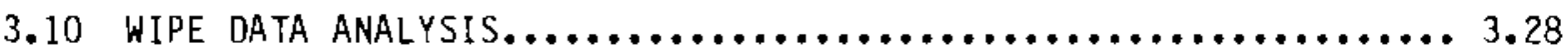


4.0 CONCLUSTONS AND RECOMMENDATIONS $. \ldots \ldots \ldots \ldots \ldots \ldots \ldots \ldots \ldots \ldots \ldots \ldots, 4.1$

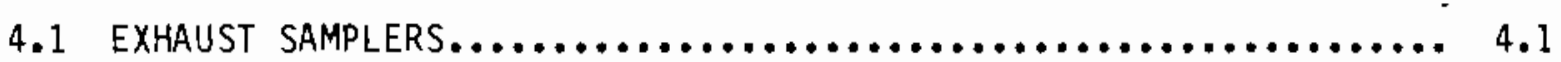

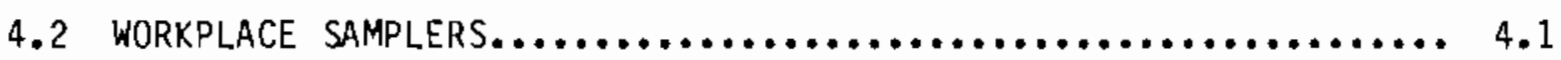

4.3 SMearable surface contamination........................ 4.2

4.4 RECOMMENDATIONS..................................... 4.3

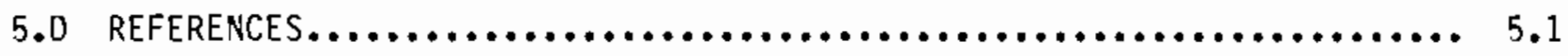

APPENDIX A - BASIC DATA FOR FORO'S FARM......................... A.I

APPENDIX B - BLANK ADJUSTMENT FOR TEMPORARY SAMPLERS $\ldots \ldots \ldots \ldots \ldots \ldots \ldots \ldots$ B.2

APPENDIX C. 1 - LISTING OF BETA-GAMMA DATA FROM WIPES................ C1.1

APPENDIX C.2 - PLOTS OF BETA-GAMMA DATA FROM WIPES BY ROUND NATURAL LOGARITHM OF DATA......................... C2.? 


\section{FIGURES}

2.1 Top View of Target Enclosure and Location of Samplers............ 2.2

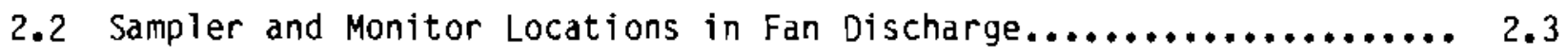

2.3 Air Samplers at Exhaust Duct Inlet........................ 2.8

2.4 Workplace Samplers..................................... 2.9

2.5 Locations of Workplace and Inlet Sampler Clusters................ 2..10

3.1 Relationships Between Total Particulates and Airborne DU in the Exhaust Stream........................................ 3.7

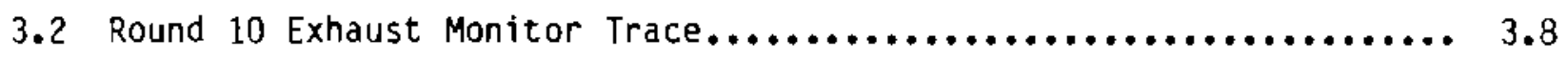

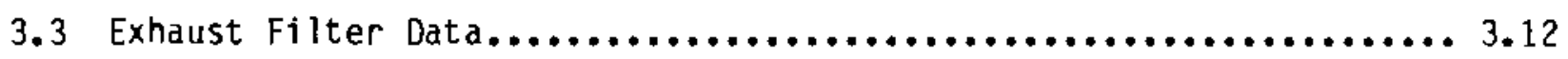

3.4 Alpha and Beta Counts Versus Average Uranium...........................

3.5 Least-Squares Fits of Counting Results to Fluorimetry Results...... 3.15

3.6 Comparison of Inlet RAM-1 and Inlet and Workplace filter 0ata...... 3.17

3.7 Sequential Sample Duration for Rounds 5 to 7,9 and $10 \ldots \ldots \ldots \ldots . . . .19$

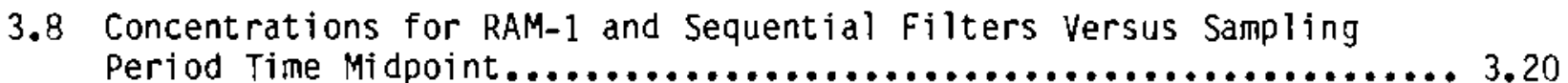

3.9 Comparison of Depletion Rates for Sequential RAM-1 and Filters..... 3.24

3.10 Least-Squares fit of Sequential filter to RAM $-1 \log _{e}$ (DATA) ....... 3.25

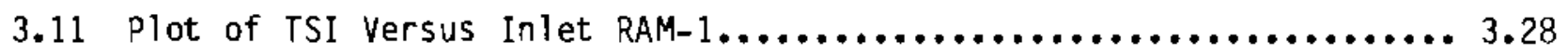

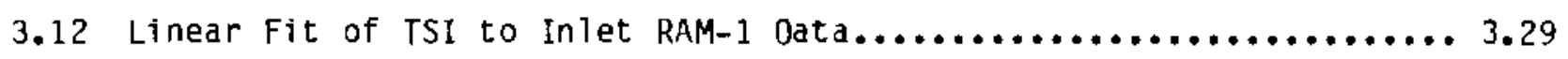

3.13 Sampling Locations with Average Thousand Counts per Minute......... 3.30 


\section{IABLES}

2.1 Air-Sampling Program for Ford's Farm........................ 2.5

3.1 Sampler Identification................................. $3 . \ldots$ ?

3.2 Field Blank Filter Analyses.............................. 3.3

3.3 Data for Comparison of Exhaust RAM-1 and Exhaust Filters......... 3.6

3.4 Monitor Responses..................................... 3.9

3.5 Exhaust Filter Data........................................

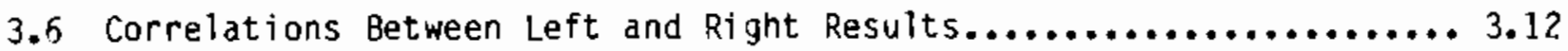

3.7 Sumnary of Least-Squares Regressions for Exhaust Filter

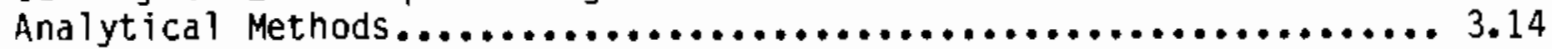

3.8 Data for Inlet RAM-1 Comparison with Inlet and Workplace

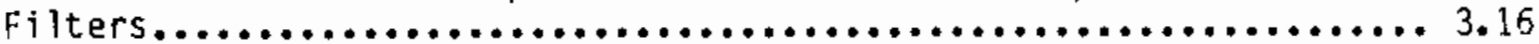

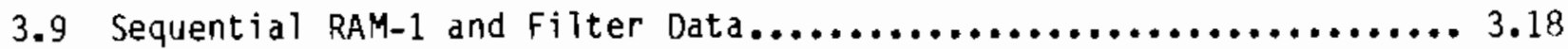

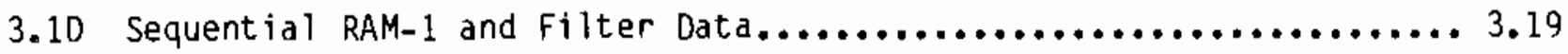

3.11 Duration of Sampling and Rates of Depletion for RAM-1 and

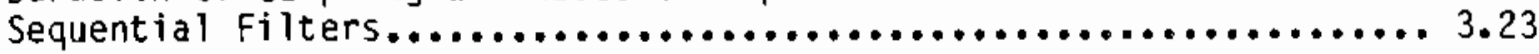

3.12 Minimum and Maximum for Wipe Data and Averages.....................31

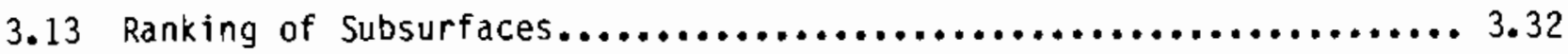

3.14 Wipe Summary.......................................... 3.32

4.1 Correlations for Comparisons of Major Interest................. 4.3 


\subsection{INTRODUCTION}

The objective of this report is to evaluate the performance of an airmonitoring system at the Ford's Farm Range where large-caliber depleted uranium (DU) munitions are test fired. The range is located at Aberdeen Proving Ground, Maryland, and is operated by the U.S. Army Material Testing Directorate (MTD). The target bay houses the test target and is continuously ventilated with fresh air to control worker exposure to inhalable DU-containing particles. The ventilation air is filtered to remove Du-containing particles prior to discharging the air.

A radiation monitoring program, including air monitoring, is required for worker protection and effluent control. The objectives of the target bay airmonitoring system are to:

- collect a representative sample of the particulate effluent for subsequent radionuclide analysis

- continuously monitor the particles present in the exhaust for loss of filter integrity

- indicate when the particle concentration in the enclosure after a test firing has decreased to a level safe for personnel entry

- indicate, while personnel are in the enclosure, when the concentration in the workplace exceeds a set action level

- record the particle concentration in exhaust and workplace.

Experiments were conducted in 1980 during the first ten DU test firings at the range to test whether these objectives were achieved. This report details the experimental method and the results of the data analyses. Additionally this report analyzes surface-contamination data collected by MTD concurrently with these experiments. 
, 


\subsection{TEST PROCEDURES}

The air-monitoring system for the Ford's Farm target bay has been described in detail by Glissmeyer and Halverson (1980). The test procedure was described initially in the application (1980) to the U.S. Nuclear Regulatory Commission for operation of the range. These two topics will be summarized below.

\subsection{DESCRIPTION OF AIR-SAMPLING SYSTEM}

Air sampling is performed both at the workplace inside the target bay and in the ventilation exhaust. The five sampling instruments and their purposes are as follows:

- exhaust sampler for collecting representative samples of particles in the filtered exhaust air for subsequent radionuclide analys is

- exhaust monitor for detecting a loss of effective air filtration

- inlet monitor at the inlet of the ventilation duct in the enclosure for indicating the decline of particle air concentration in the enclosure after a test firing or a concentration increase when the enclosure is occupied

- workplace monitor to indicate when the airborne uranium concentration in the enclosure, when it is occupied, exceeds a set level

- back-up sampler used to quickly measure air concentration in any location when other systems fail or to verify that the enclosure is safe for personnel entry.

The instruments are located in the target bay as shown in the plan view, Figure 2.1.

The exhaust sampler collects particles on membrane filters(a) contained in two in-stack filter holders located in regions of average velocity in the fan discharge as seen in Figure 2.2. Sampler flow rate (56.6 standard liters per

(a) $47 \mathrm{~mm}$ diameter, 3 micron pore, Model AN-3000, Gelman Sciences, Inc., Ann Arbor, Michigan. 


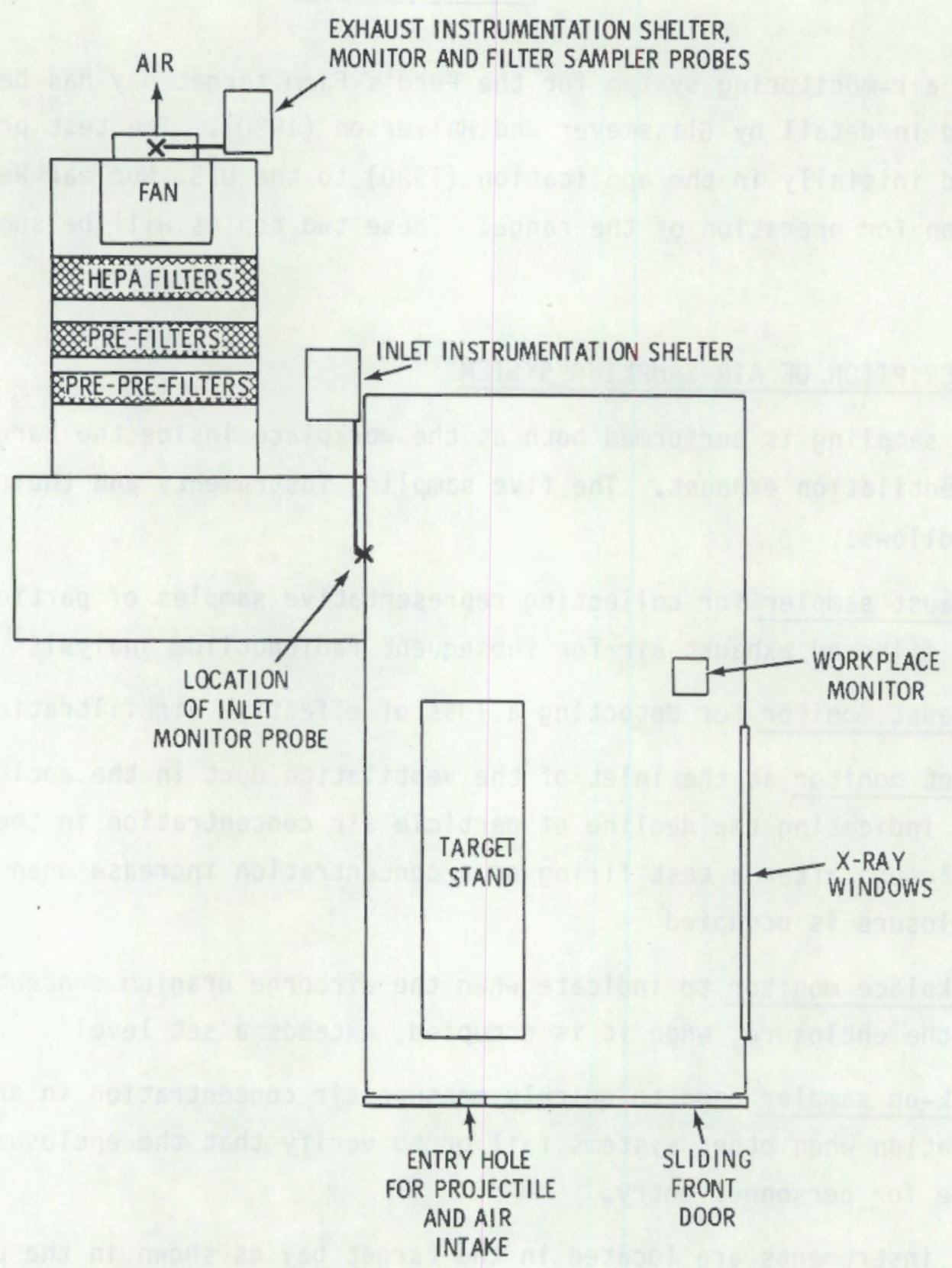

FIGURE 2.1. Top View of Target Enclosure and Location of Samplers (drawing not to scale; enclosure is $\sim 20 \mathrm{ft}$ by $40 \mathrm{ft}$ )

minute [slpm] each) and nozzle sizes were selected for isokinetic sampling. The filter holders are designated as left and right reflecting their relative position when viewed from the duct discharge. The sampler is operated concurrently with the ventilation system, and samples are changed weekly. 


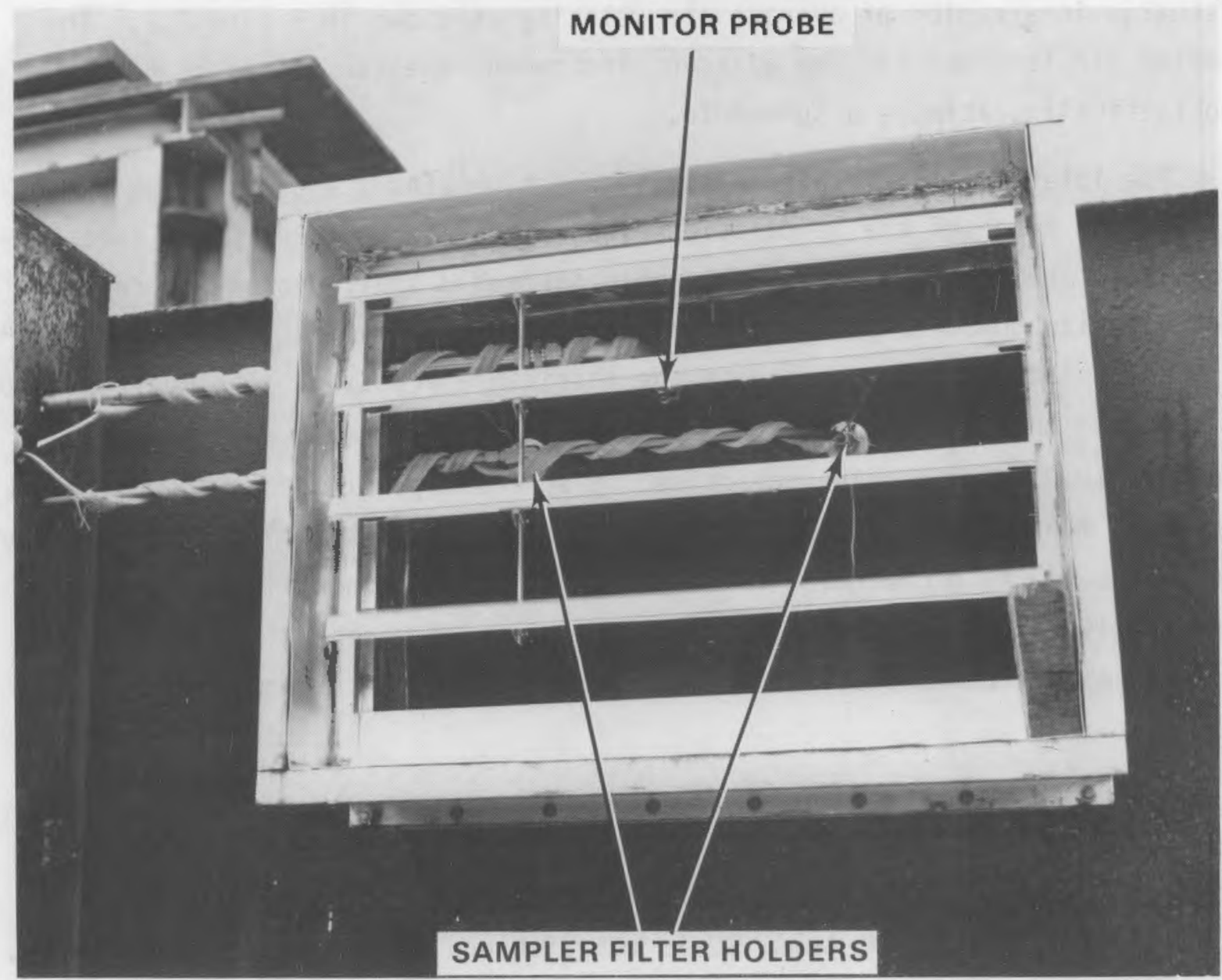

FIGURE 2.2. Sampler and Monitor Locations in Fan Discharge

The exhaust monitor is a real-time aerosol monitor (RAM-1) (a) used to indicate change in particle concentration such as might occur when a ventilation filter fails. The instrument, which operates on a light-scattering principle, does not distinguish DU from other dusts. Its measurement should give a conservative estimate of radiological hazard. The output of the instrument is continuously recorded and alarms are activated when a concentration limit is exceeded. An dir sample is withdrawn isokinetically from the fan

(a) Product of GCA Incorporated, Bedform, Massachusetts. 
discharge in a region of average air velocity as shown in Figure 2.2. The sampled air is piped into an adjacent instrument shelter where the RAM-1 isokinetically extracts a subsample.

The inlet monitor is also a RAM-1, which obtains its sample from a manifold on the front of the ventilation exhaust port in the target bay (see Figure 2.1). The manifold draws its sample through a small cyclone operated at a particle-size cutpoint of 3.5 microns aerodynamic equivalent diameter (AED)(a) so the sampled particle represents the respirable fraction. The monitor output is recorded on a strip chart that activates an alarm when a control limit is exceeded $\left(0.05 \mathrm{mg} / \mathrm{m}^{3}\right)$. The advertised measurement precision is $\pm 0.005 \mathrm{mg} / \mathrm{m}^{3}$. The inlet monitor is operated concurrently with the ventilation system or when the target bay is occupied. The sampling manifold is back-flushed with clean air briefly during the test firing. When the inlet monitor indicates an acceptable dust concentration after a test firing, the target bay door is opened.

A workplace aerosol monitor is used in the target bay only when it is occupied. It is mounted on a cart, which is wheeled into the position indicated in Figure 2.1. This instrument is an RDM-301, (b) which measures dust impacted on a mylar film; thus, DU is not distinguished from the other dusts. The monitor samples air at two lpm (1iters per minute) through a cyclone such that only respirable dust is monitored. Concentration measurements covered 30-min intervals for which the monitor has an advertised measurable concentration of $0.02 \mathrm{mg} / \mathrm{m}^{3}, \pm 25 \%$.

The back-up sampler measures dust concentration using a piezoelectric mass sensor on which respirable particles are deposited by an electrostatic precipitator. This instrument, TSI-3500 piezobalance, $(c)$ is compact and portable allowing a measurement of respirable dust concentration down to $0.01 \mathrm{mg} / \mathrm{m}^{3}$ at any work station with a 2 min sampling time. It is principally used to verify

(a) The diameter of a sphere of water that behaves aerodynamically the same as the real particles being sampled. The AED is an important parameter affecting a particle's behavior and its probability of being retained in the respiratery system. For spherical particles, AED $=$ diameter $x$ $\checkmark$ specific gravity.

(b) Product of GCA Incorporated, Bedform, Massachusetts.

(c) Product of Thermosystems Incorporated, St. Paul, Minnesota. 
an acceptable concentration in the target bay as the door is opened. The user carries the instrument and makes a 2 -min walking traverse of the target bay. The advertised accuracy is $\pm 10 \%$ of reading or $\pm 0.01 \mathrm{mg} / \mathrm{m}^{3}$, whichever is greater.

The function of each air sampler, readout, and frequency of use are summarized in Table 2.1.

TABLE 2.1. Air-Sampling Program for Ford's Farm

\section{Function}

Exhaust Air:

1. Average concentration in exhaust air
Equipment by Function

Operation Frequency
1. and 4. Isokinetic in stack filters
In stack filters: Continuous when air exhausts, with weekly change

2. Real-time air concentration

with alarm activation

3. Continuous record of realtime air concentration

2., 3., and 4. RAM-1

Monitor: Continuous when air exhausts

4. Monitor filter integrity

Enclosure Workplace:

1. Safe to open door, real time

1. RAM-1

1., 2. Continuous

2. Continuous record of realtime air concentration with alarm activation

3. Confirm safe to enter enclosure, short term

4. Short-term air concentration at fixed station with alarm

2. RAM-1 actuation

3. TSI -3500

3. When door opened

4. RDM- 301

4. When personnel in enclosure

5. Short-term portable workplace concentration

5. TSI -3500

5. Intermittent when personnel in enciosure 
The air-sampling system described in Table 2.1 is unusual in that the concentration monitors are not specific for radioactive particles, which are the chief concern. In situations where the hazardous particles are radioactive, the typical monitoring instrumentation continuously collects a particle sample on a filter that is observed by a detector designed for alpha or beta-gamma radiation. This type of monitor then observes an integrated sample because particles are not removed from the detection geometry once they are collected. This integrated dose monitor renders it impractical for indicating decreasing as well as increasing concentrations. Also, the monitor's longer response time in detecting a low concentration following a very high concentration increases the time between test shots. We chose to use real-time or short-response-time instruments that monitor aerosol concentration rather than DU.

\subsection{TEST OBJECTIVES}

The general objective of the proof testing was to determine what correlations and biases exist between the response of the different monitors and DU concentrations as measured by analysis of particles collected on filters. More specific objectives were to investigate correlations between the following air concentration data:

$\begin{array}{ll}\text { Exhaust RAM-1 } & \text { vs. Exhaust DU Sample } \\ \text { Inlet RAM-1 } & \text { vs. Inlet DU as function of time } \\ \text { Inlet RAM-1 } & \text { vs. Inlet DU } \\ \text { Inlet RAM-1 } & \text { vs. Inlet respirable DU } \\ \text { RDM- } 301 & \text { vs. Workplace DU } \\ \text { RDM- } 301 & \text { vs. Workplace respirable DU } \\ \text { TSI-3500 } & \text { vs. Inlet RAM-1 } \\ \text { TSI-3500 } & \text { vs. RDM-301 }\end{array}$


Using measurements of DU concentration as a function of time at the inlet location, we also wanted to investigate what would be a reasonable alarm set point for the Inlet RAM-1 to indicate an acceptable DU concentration according to regulatory guidelines. (a)

To obtain the needed DU concentration data, additional air-sampling equipment was operated during the first ten test firings. Total and respirable particulate samplers collecting particles on filters were operated adjaceņt to the inlet and workplace monitoring positions as shown in Figures 2.3, 2.4, and 2.5. Figure 2.3 also shows a device for sequentially sampling total particulates adjacent to the Inlet RAM-1.

\subsubsection{Inlet Respirable Sampler}

For the inlet sampler, the air first passed through a Bendix Model 240 cyclone, identical to that of the Inlet RAM-1, at a flow rate of 75 slpm to maintain a respirable cutpoint of 3.5 microns AED. Particles were collected on a membrane filter and sampled air passed to a calibrated rotameter, valve, and pump. In-line temperature and pressure gauges assisted in reading the flowmeter in terms of standard volume at $70^{\circ} \mathrm{C}$ and 1 atmosphere pressure.

\subsubsection{Inlet and Workplace Total Particulate Samplers}

The inlet and workplace total-particulate samplers consisted of a membrane filter in a holder, critical orifice, valve, and pump. The flowrate was calibrated with a filter in-place at $50.5 \mathrm{slpm}$.

(a) Code of Federal Regulations, Title 10, Part 20, Appendix B, Footnote 4 states that for soluble mixtures of DU isotopes the occupational ( $40 \mathrm{hr}$ ) and nonoccupational ( $168 \mathrm{hr}$ ) average maximum permissible concentrations (MPC) are 0.2 and $0.007 \mathrm{mg} / \mathrm{m}^{3}$ of air, respectively. If the specific activity is unknown, the regulation directs the use of $3.6 \times 10^{-7} \mathrm{Cj} / \mathrm{g}$. The limits translated into units of radioactivity are then $7.2 \times 10^{-11}$ and $2.5 \times 10^{-12} \mu \mathrm{Ci} / \mathrm{ml}$, respectively. These limits are essentially the same as those stated in the regulagtion of $238 \mathrm{U}$ except that the nonoccupational $238 \mathrm{U}$ limit is $0.0083 \mathrm{mg} / \mathrm{m}^{3}$ using the above specific activity. During the experiments $0.008 \mathrm{mg} / \mathrm{m}^{3}$ was used as the nonoccupational limit because the 0.007 MPC did not exist at that time. The regulation assumes an individual inhales material at the concentration in which he is present. 


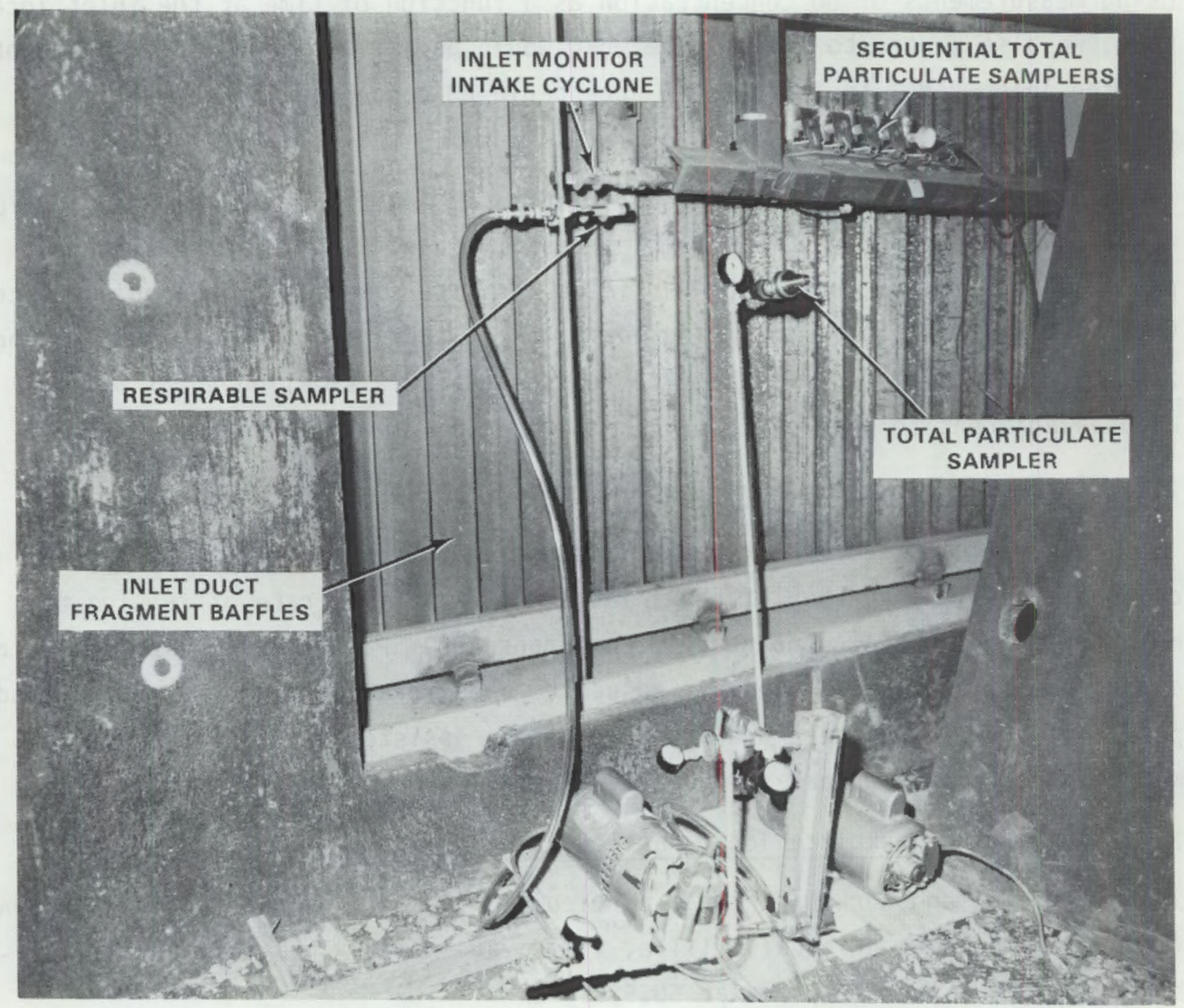

FIGURE 2.3. Air Samplers at Exhaust Duct Inlet

\subsubsection{Sequential Sampler}

The sequential sampler used for rounds 4 to 10 is shown in Figure 2.3. The sampler had five identical sampling heads mounted on a common manifold. Each head consisted of a membrane filter and a solenoid valve. Airflow passed through the sample filter, solenoid valve, manifold, critical orifice, valve, and a pump. A vacuum gauge was mounted on the pump and when operated at vacuum $>1 / 2$ atmosphere, the flow rate measured through each filter was determined to be 27 slpm. Each filter holder was covered with a spring-loaded flapper, which 


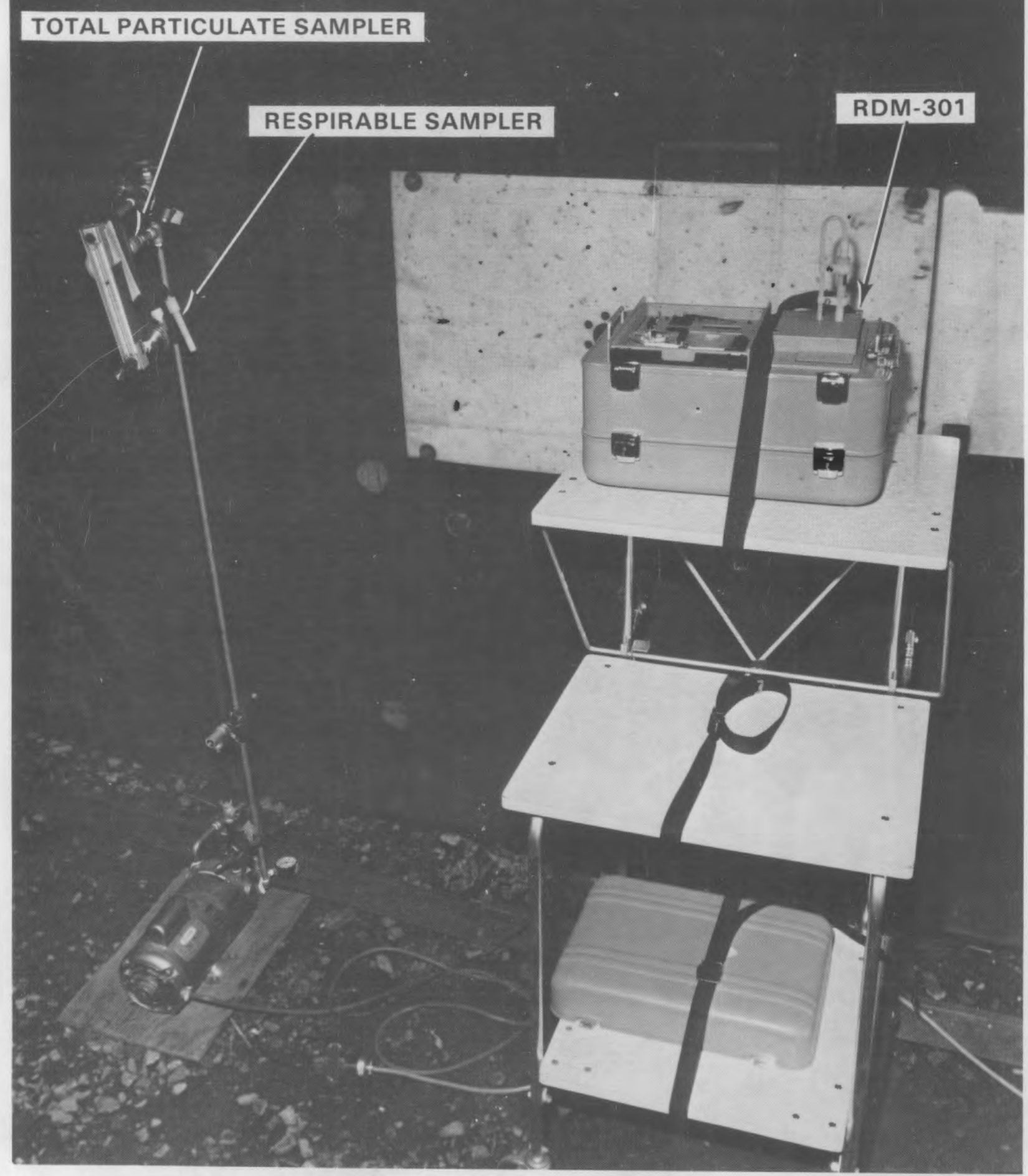

FIGURE 2.4. Workplace Samplers 


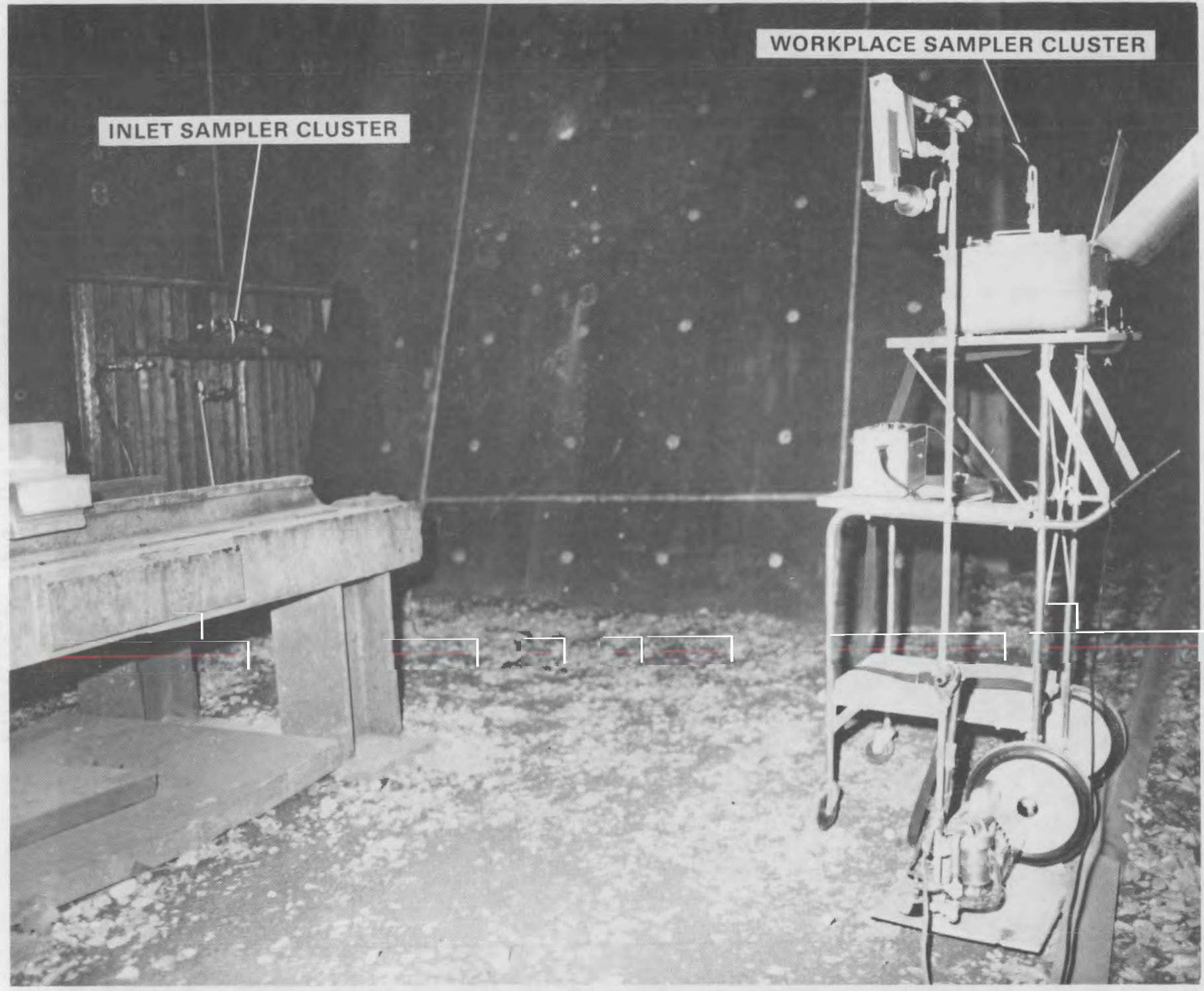

FIGURE 2.5. Locations of Workplace and Inlet Sampler Clusters 
was pulled back remotely to uncover the filter for sampling. The flapper served to protect the filter from fragments.

The inlet sequential sampler used during rounds 2 and 3 had only two filter holders. Each filter holder had its own orifice and the flow rates with filters in-place were 31 and $28 \mathrm{slpm}$. No sequential sampler was used during round 1.

Because the exhaust flow rate fluctuated considerably, the inlet samplers did not sample isokinetically. During sampling with the target bay door open the air velocity at the inlet ranged from 0.75 to $3.00 \mathrm{~m} / \mathrm{s}$. The face velocity at the total particulate, sequential, and respirable samplers were $2.83,0.35$, and $1.93 \mathrm{~m} / \mathrm{s}$, respectively.

\subsubsection{Workplace Respirable Sampler}

Air in the workplace respirable sampler first passed through a cyclone at a rate of 2 slpm yielding a respirable particle cutpoint of 3.5 micron AED. The cyclone was a 10-mm-diameter nylon type identical to that used on the RDM-301. After passing the cyclone, respirable particles were collected on a membrane filter and the sample air went through a calibrated rotometer, valve, and pump. In-line temperature and vacuum gauges corrected flow to standard conditions. For rounds 1 to 3 the vacuum pump produced an oil smoke, which was detected by the TSI-3500 and the inlet RAM-1. The pump was then replaced.

\subsection{PROCEDURE}

The permanent air-sampling system was operated as described by Glissmeyer and Halverson (1980) with the exception that the exhaust air sample filters were changed out before each test firing. For rounds 1 to 4 , the inlet RAM- 1 was operated on only one concentration range, 0 to 2 or 0 to $20 \mathrm{mg} / \mathrm{m}^{3}$, for the entire test. It read off-scale for several minutes after the shot, and the purge air was turned off. For rounds 5 to 10, the inlet RAM-1 was sequenced from the 0 to 200,0 to 20,0 to $2 \mathrm{mg} / \mathrm{m}^{3}$ ranges to obtain data during the entire sampling period.

The target bay door was opened when the inlet RAM-1 showed a concentration below $0.2 \mathrm{mg} / \mathrm{m}^{3}$ or when 30 min had elapsed after the test shot, whichever came 
last. A confirmatory concentration reading was taken with the TSI-3500 with a 2-min traverse inside the bay. The inlet and workplace sampler clusters were then installed and put into operation for at least $30 \mathrm{~min}$. The RDM-301 was started with a sampling interval of $30 \mathrm{~min}$. During the 30 -min sampling period, readings were periodically taken with the $T S I-3500$ in the target bay.

The sequential sampler was operated as follows during rounds 4 to 10: 1) sample $A$ for the first 5 min after the shot, 2) sample $B$ for the second $5 \mathrm{~min}, 3$ ) sample $C$ for the third $5 \mathrm{~min}$, 4) sample $D$ approximately until the inlet RAM-1 read $<0.2 \mathrm{mg} / \mathrm{m}^{3}$, and 5 ) sample $E$ until it was convenient to shut it off. During rounds 2 to 3, sample A was started within 5 min after the shot; sample $B$ took over after the Inlet RAM- 1 read $<0.2 \mathrm{mg} / \mathrm{m}^{3}$ and operated until the other temporary target bay samplers started.

During rounds 3 to 9 the air sampling in the target bay was done while routine target and $x-r a y$ film handling was performed. No routine activities occurred during the round 10 sampling period. Because alpha and beta sample analyses from rounds 1 and 2 showed several values below detection limits, it was decided to operate the samplers for two rounds before changing samples. This caused some data analysis problems for rounds 3 to 6 . After round 6 , samples were again changed every shot.

\subsection{SAMPLE ANALYSIS}

All sample filters except the exhaust sample were weighed before and after sampling under controlled environmental conditions. An analysis of the field blanks and other blanks showed that a collected mass under 1 to $2 \mathrm{mg}$ was unmeasurable. Because most blank samples fell into that category, a further analysis of the weighing data is not addressed in this report.

Each sample filter was analyzed for gross alpha, gross beta-gamma, and uranium by an MTD contractor. Gross alpha and gross beta-gamma were determined by direct counting of the filter using standard techniques to account for background and radon/thoron daughters. Uranium was determined by sample dissolution, ion exchange on an aliquot, column elution, electroplating, and counting. Each result was reported along with the $95 \%$ confidence limits. If the confidence limits exceeded $100 \%$, the result was reported as less than the minimum 
detectable level or lower limit of detection. Variability in the "less than" values was largely due to variable sample aliquot size.

The average RAM-l readings corresponding to various time intervals were determined from the strip chart records. For long time intervals, a reading was made every $3 \mathrm{~min}$. For short intervals, or when the concentration was rapidly changing, readings were made as often as every 0.3 min. Accounting for suspected zero drift during averages over 20 min was a problem. If the trace drifted below the recorder's zero, the values were interpreted as $0.000 \mathrm{mg} / \mathrm{m}^{3}$ rather than as a negative concentration. If the trace baseline drifted slight ly higher than the recorder's zero, it could be interpreted as either zero drift or a positive concentration. In calculating averages we assumed the latter, possibly biasing the results particularly if the average was below 0.001 to $0.005 \mathrm{mg} / \mathrm{m}^{3}$. Time constants could be selected as $0.5,2,8$, or $32 \mathrm{~s}$, the latter being used most often. The long time constant significantly dampened out noise in the trace and sensitivity to a rapid concentration fluctuation.

During the testing, several blank filters were submitted to observe the precision of methods and the background content of uranium. These filters were handled in the same fashion as exposed filters including their installation in filter holders and handling in the field. At least one such blank was handled during rounds 4 to 10 . 


\section{,}




\subsection{DATA ANALYSIS}

\subsection{DATA BASE}

Data from routine monitoring and additional temporary air-sampling equipment were collected for 10 rounds fired at Ford's Farm during February 1980. The samplers used are summarized in Table 3.1. Data from the air samplings are listed in Appendix A.

The basic data of Appendix A create several problems in answering the questions of interest. First, many data values are missing (indicated by dashes in Appendix A, Tables A.2, A.4, and A.5), particularly for the first three rounds. Of the 41 missing values, 25 are in the first three rounds. Second, there are 12 values reported as "less than," indicating a detection limit value. These are preceded by a minus sign in Appendix A, Tables A.l and A.5. Third, inlet and workplace total and respirable samples filters were not renewed between rounds 3 and 4 and 5 and 6 . Thus, only two analytical results for each of these samplers represent the concentrations for four rounds. These problems in the data base make routine analysis difficult to interpret. For example, a correlation coefficient between AC.C and the workplace cyclone would be based on only two, not ten valid data pairs.

\subsection{COMPARISON OF EXPOSED FILTER CONCENTRATIONS AND BLANK VALUES}

A single field blank (unexposed filter) was submitted to the analytical lab with the filters for each of rounds 4 through 10 . The resulting data are given in Table 3.2 .

The average and standard deviation of the total activity of the blank filters were calculated to check the consistency of the blanks. It would be expected that uncontaminated blanks should produce results in fairly close agreement, even when analyzed over a period of weeks. The standard deviation relative to the mean is $180 \%$, indicating considerable lack of agreement. The range of activities, 0.06 to $16.00 \mathrm{pCi}$, with an intervening detection limit value of $<0.24 \mathrm{pCi}$, also demonstrates a lack of consistency. The standard deviation is large enough that the average, $3.19 \mathrm{pCi} / \mathrm{m}^{3}$, could not be judged 
TABLE 3.1. Sampler Identification

\begin{tabular}{|c|c|c|c|c|c|}
\hline Rout ine & $\begin{array}{l}\text { Sampler } \\
\text { Name }\end{array}$ & $\begin{array}{c}\text { Sampler } \\
\text { Type }\end{array}$ & $\begin{array}{r}\text { Sampler } \\
\text { Location }\end{array}$ & $\begin{array}{l}\text { Medi um } \\
\text { Sampled }\end{array}$ & $\begin{array}{c}\text { Analytical } \\
\text { Units }\end{array}$ \\
\hline 1. & EXH.M & RAM-1 & Exhaust duct & $\begin{array}{l}\text { Total } \\
\text { particulates }\end{array}$ & $\mathrm{mg} / \mathrm{m}^{3}$ dust \\
\hline 2. & EXH.L\&R & Filters & Exhaust duct & $\begin{array}{l}\text { Total } \\
\text { particulates }\end{array}$ & $\mathrm{aCi} / \mathrm{ml}$ DU \\
\hline 3. & INLET & RAM-1 & $\begin{array}{l}\text { Before } \\
\text { exhaust grill }\end{array}$ & $\begin{array}{l}\text { Respirable } \\
\text { particulates }\end{array}$ & $\mathrm{mg} / \mathrm{m}^{3}$ dust \\
\hline 3a. & $S E Q \cdot A-E$ & RAM-1 & $\begin{array}{l}\text { Before } \\
\text { exhaust grill }\end{array}$ & $\begin{array}{l}\text { Respirable } \\
\text { particulates }\end{array}$ & $\begin{array}{l}\text { Averagge } \\
\mathrm{mg} / \mathrm{m}^{3}\end{array}$ \\
\hline 4. & RDM & RDM- 301 & $\begin{array}{l}\text { Cart near } \\
\text { door }\end{array}$ & $\begin{array}{l}\text { Respirable } \\
\text { particutates }\end{array}$ & $\mathrm{mg} / \mathrm{m}^{3}$ dust \\
\hline 5. & TSI & TSI -3500 & $\begin{array}{l}\text { Workplace } \\
\text { traverse }\end{array}$ & $\begin{array}{l}\text { Respirable } \\
\text { particulates }\end{array}$ & $\mathrm{mg} / \mathrm{m}^{3}$ dust \\
\hline
\end{tabular}

Temporary

6.

INFILT Filters

Before

Total

$\mathrm{aCi} / \mathrm{ml}$ DU

exhaust grill

particulates

7. INCYCL

Filters

with

cyclone

Before

exhaust grill

Respirable

$\mathrm{aCi} / \mathrm{ml} \mathrm{DU}$ particulates

8. WKFILT Filters Near dọor

total

particulates

$\mathrm{aCj} / \mathrm{mI} \quad \mathrm{DU}$

9. WKCYCL

Filters Near door

Respirable particulates

$\mathrm{aCi} / \mathrm{ml} \quad \mathrm{DU}$

with

cyclone

10. SEQ.A-E Filters

Before

exhaust grill

Total

particulates

$\mathrm{fCi} / \mathrm{ml}$ DU

Other

Measurements

11.

Field

Filters

Unexposed

filters

PCi DU per

blanks

12.

A 11

Flow

meter

Air flow rate $m^{3} / m i n$

13.

A11 Clock ---

Time of filter min exposure 
TABLE 3.2. Field Blank Filter Analyses

\begin{tabular}{|c|c|c|}
\hline Round & $\begin{array}{l}\text { pCi DU/ } \\
\text { Filter }\end{array}$ & $\begin{array}{l}\text { Two Standard } \\
\text { Deviations }\end{array}$ \\
\hline 4 & 1.20 & 0.80 \\
\hline 5 & 0.35 & 0.31 \\
\hline 6 & 3.20 & 1.30 \\
\hline 7 & $<0.24$ & -- \\
\hline 8 & 1.30 & 1.00 \\
\hline 9 & 0.06 & 0.04 \\
\hline 10 & 16.00 & 3.00 \\
\hline Mean & 3.1829 & \\
\hline $\begin{array}{l}\text { Standard } \\
\text { Deviation }\end{array}$ & 5.7474 & \\
\hline
\end{tabular}

(a) According to counting statistics.

statistically different from zero. The conclusion is that an average blank correction could not be used. The data for each round should be corrected for its accompanying blank.

The blank correction is complicated since the total activities in Ci per blank filter need to be converted to concentrations, in effective $\mathrm{Ci} / \mathrm{l}$. This was done by dividing the $p c i$ per blank filter by the volume of air sampled. Let

$x_{i j}$ be the $\mathrm{C} i / m l$ for sampler $i$ and round $j$

$V_{i j}$ be the corresponding volume, $\mathrm{m}^{3}$, of air sampled

$b_{j}$ be the $\mathrm{pC} i$ for the blank filter associated with round $j$.

Then the blank correction was calculated as

$$
b_{i j}=\left(b_{j} \times 10^{-12} \mathrm{ci}\right) /\left[v_{i j} \times 10^{6}\right] \mathrm{ml} / \mathrm{m}^{3}=\left(b_{j} / v_{i j}\right) \times 10^{-18}
$$

and the blank corrected concentration was

$$
x_{i j}=x_{i j}-b_{i j}
$$


The large blank corrections for round 10 caused 4 of the 11 samples to go negative, and 2 of the round 6 values were swamped by their blanks. These considerations lead to the somewhat subjective conclusion that all but the round 10 blank value (16 pCi) are reasonable. It was decided to blank correct all of the filter data, using the blank filter results for rounds 4 through 9 . The average of the blanks for rounds 4 through $9,(1.0583 \mathrm{pCi})$ was used to correct the data for rounds $1,2,3$, and 10. Another operating decision was to treat the "less than" values as actual concentrations.

The results of these calculations are given in Appendix $B$. The $x_{i j}$ block of data (Table B.4) are the blank adjusted data to be used in subsequent calculations. The ten negative values are the values for which the blank correction was greater than the exposed filter concentration. Seven of these negative values are for the cyclone samples. The nine parenthesized values are the adjusted values for the "less than" detection limit concentrations.

Appendix B, Table B.5, also has the background as a percentage of the unadjusted $\mathrm{Ci} / \mathrm{ml}$ data; i.e.,

$$
p_{i j}=100 \frac{b_{i j}}{x_{i j}}
$$

The percentage background is followed by the grams of DU per cubic meter of air, in Table 8.6 , calculated by

$$
U_{i j}=\left(x_{i j} / 0.36\right)
$$

which results in $\mathrm{mg} / \mathrm{m}^{3}$ for the sequential samplers and micrograms $\left(\mu \mathrm{g} / \mathrm{m}^{3}\right)$ for the other filter samples. This calculation puts the temporary samplers into the same units as the routine samplers. Finally, the natural logarithms of these data are given in Table 8.7 . 


\subsection{COMPARISON OF EXHAUST RAM- 1 AND EXHAUST FILTERS}

The exhaust RAM- 1 measured the total dust particulates in $\mathrm{mg} / \mathrm{m}^{3}$ air. The exhaust filters (right and left sides of the exhaust stream) were analyzed for attocuries due to DU per milliliter of air ( $\left.\mathrm{Ci} \times 10^{-18} / \mathrm{ml}\right)$. The DU activity was corrected for blanks (as explained previously) and transformed to micrograms of DU per cubic meter of air sampled $\left(\mu \mathrm{g} \mathrm{DU} / \mathrm{m}^{3}\right)$, using $3.6 \times 10^{-7} \mathrm{Ci} / \mathrm{g}$ of DU. The resulting data are given in Table 3.3 , where $\overline{E X H F}$ is the average of the left and right exhaust filters. The negative value for EXHL in round 6 is due to a large blank.

The main interest in this comparison is to determine how the uranium concentration measured for the filters relates to the total dust-particulate concentration measured by the RAM-1. The stated criterion for exhaust air is $3 . \mathrm{D} \times 1 \mathrm{D}^{-12} \mu \mathrm{Ci} / \mathrm{ml}$, or $8.33 \mu \mathrm{g} \mathrm{DU} / \mathrm{m}^{3}$. The average for the fitters is $2.368 \mu \mathrm{g} \mathrm{DU} / \mathrm{m}^{3}$; for the RAM-1 it is $1.880 \mu \mathrm{g}$ dust $/ \mathrm{m}^{3}$. The average filter $\mu \mathrm{g} \mathrm{DU} / \mathrm{m}^{3}$ is $28 \%$ of the criterion value and the RAM-1 dust is $23 \%$ of the criterion. None of the observed concentrations are as great as the criterion.

The fact that the average DU concentration $\left(2.368 \mu \mathrm{g} / \mathrm{m}^{3}\right)$ is typically greater than the dust concentration $\left(1.880 \mu \mathrm{g} / \mathrm{m}^{3}\right)$ goes against the logic of the part being less than the whole. The column of differences in Table 3.3 shows that the EXH.M (dust particles) result was greater than the $\overline{\text { EXHF }}$ DU concentration only for round 3 and the three rounds with EXH.M at its detection limit value. When the five $1.0 \mu \mathrm{g} / \mathrm{m}^{3} \mathrm{EXH} . \mathrm{M}$ values are removed, the average difference is $1.11 \mathrm{\mu g} / \mathrm{m}^{3}$. This difference is significantly different from zero, using a t-test at the $90 \%$ critical value. These results indicate some relative bias in the sampling DU-concentration analysis. The problem is most likely with the RAM-1 calibration because of zero drift and the technique used in calculating the EXH.M average value from the strip chart.

Despite these anomalies in the data, a linear regression was done to see if a relationship existed between the dust and DU data. The results are summarized in Figure 3.1. When all 10 rounds were used, the correlation between EXH.M and $\overline{\text { EXHF }}$ was a respectable 0.83 , and there was a linear relationship. However this relationship depended on "anchoring" by the five 1.0 values. 


\begin{tabular}{|c|c|c|c|c|c|}
\hline Round & EXH.L & EXH.R & EXXHF & EXH.M & EXHF-EXH.M \\
\hline 1 & 4.69 & 6.63 & 5.660 & 2.40 & 3.260 \\
\hline 2 & 0.86 & 0.659 & 1.00 & 1.00 & -0.341 \\
\hline 3 & 1.11 & 1.55 & 1.329 & 2.00 & -0.671 \\
\hline 4 & 3.52 & 4.35 & 3.936 & 3.50 & 0.436 \\
\hline 5 & 3.78 & 4.06 & 3.922 & 3.00 & 0.922 \\
\hline 6 & -0.54 & 0.91 & 0.185 & $1.00^{(a)}$ & -0.815 \\
\hline 7 & 0.72 & 0.94 & 0.827 & $1.00(a)$ & -0.713 \\
\hline 8 & 2.57 & 1.35 & 1.963 & 1.00 & 0.963 \\
\hline 9 & 0.56 & 0.79 & 0.674 & $1.00^{(a)}$ & -0.326 \\
\hline 10 & 4.38 & 4.66 & 4.521 & 2.90 & 1.621 \\
\hline verage & 2.166 & 2.570 & 2.368 & 1.880 & 0.488 \\
\hline $\begin{array}{l}\text { Standard } \\
\text { Deviation }\end{array}$ & 1.85 & 2.16 & 1.96 & 1.00 & 1.2566 \\
\hline
\end{tabular}

(a) These values were reported as $<1.0$, indicating detection limit values.

The steeper line shows the best least-squares linear fit to all the data. When the five 1.0 EXH.M values were removed, the correlation dropped to 0.39 and the relationship was not different from assigning the average EXH.M value, $2.76 \mu \mathrm{Ci} / \mathrm{m}^{3}$, for any $\overline{E X H F}$ value. The dashed lines show the intersection of the average values for each data set.

The data do not support the expected relationship between the exhaust monitor total dust particulates and the filter Du concentrations. An explanation is that at this low end of the RAM-1's range the readings are below the manufacturer's claimed precision $\left(5 \mu \mathrm{g} / \mathrm{m}^{3}\right)$ and stability. The test result does not invalidate the usefulness of the RAM- 1 in detecting an abnormally high concentration caused by filter bank leakage or extremely high concentration upstream of the filters. The RAM-l should not be used to estimate weekly averages below $5 \mu \mathrm{g} / \mathrm{m}^{3}$. 


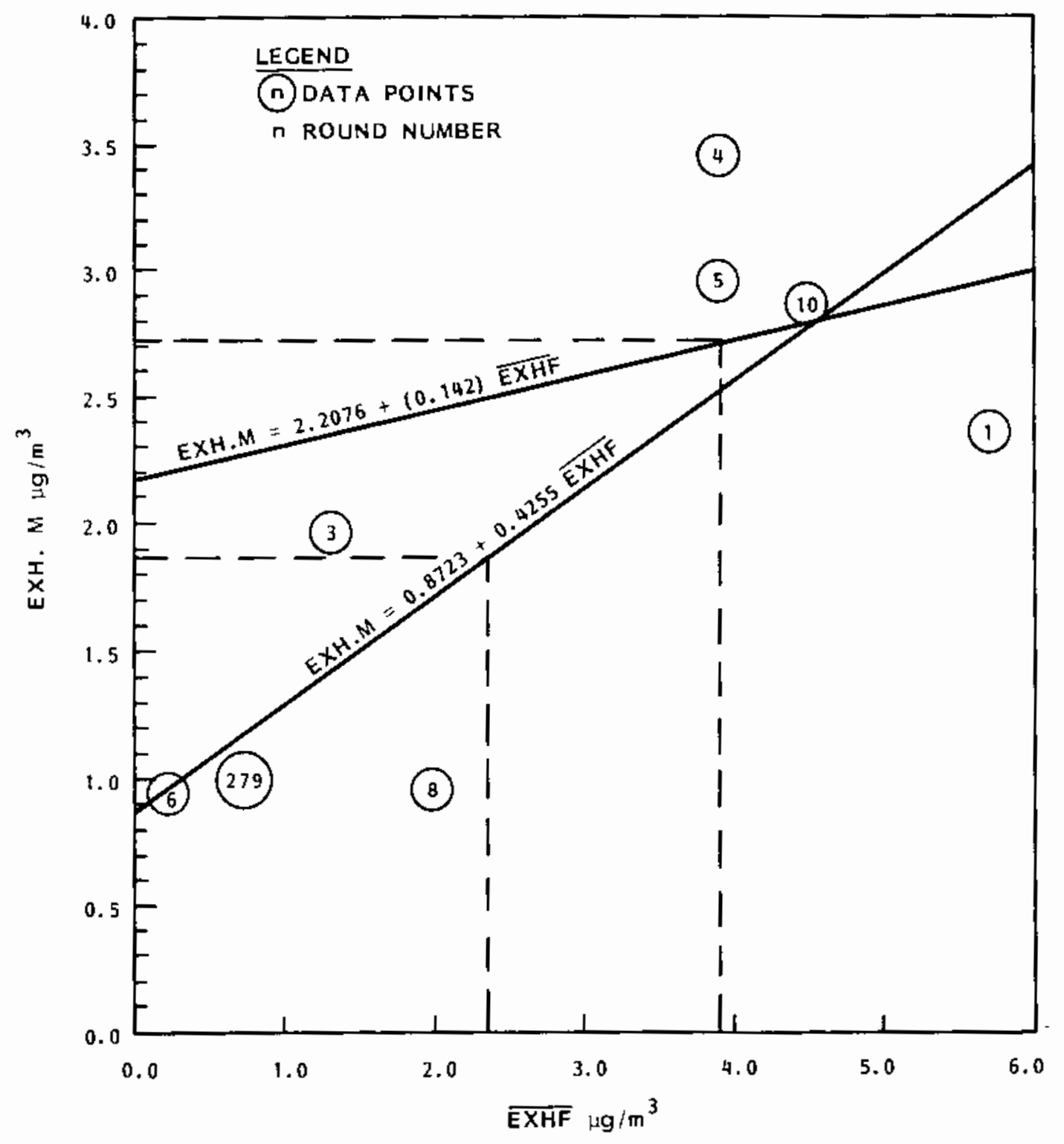

FIGURE 3.1. Relationships Between Total Particulates (EXH.M) and Airborne DU (EXHF) in the Exhaust Stream

\subsection{RAM-1 MONITOR RESPONSES}

The experiment was not properly designed to test the functioning of the monitor under conditions of abnormal release where the concentrations present are beginning to be in the useful range of the instrument. An example of the 
exhaust monitor's response is shown in Figure 3.2. Exhaust air samples with the same duration as the release would probably allow assessing the accuracy of the monitor's response in these situations.

Some of the inlet and exhaust RAM-l responses are summarized by round in Tabie 3.4. The clearance time is the interval between the shot and dust clearance to a concentration of $0.05 \mathrm{mg} / \mathrm{m}^{3}$ for the inlet RAM-1. The exhaust alarm duration is the interval over which the exhaust monitor's reading exceeded $0.008 \mathrm{mg} / \mathrm{m}^{3}$. Of interest to the ventilation filter performance is the

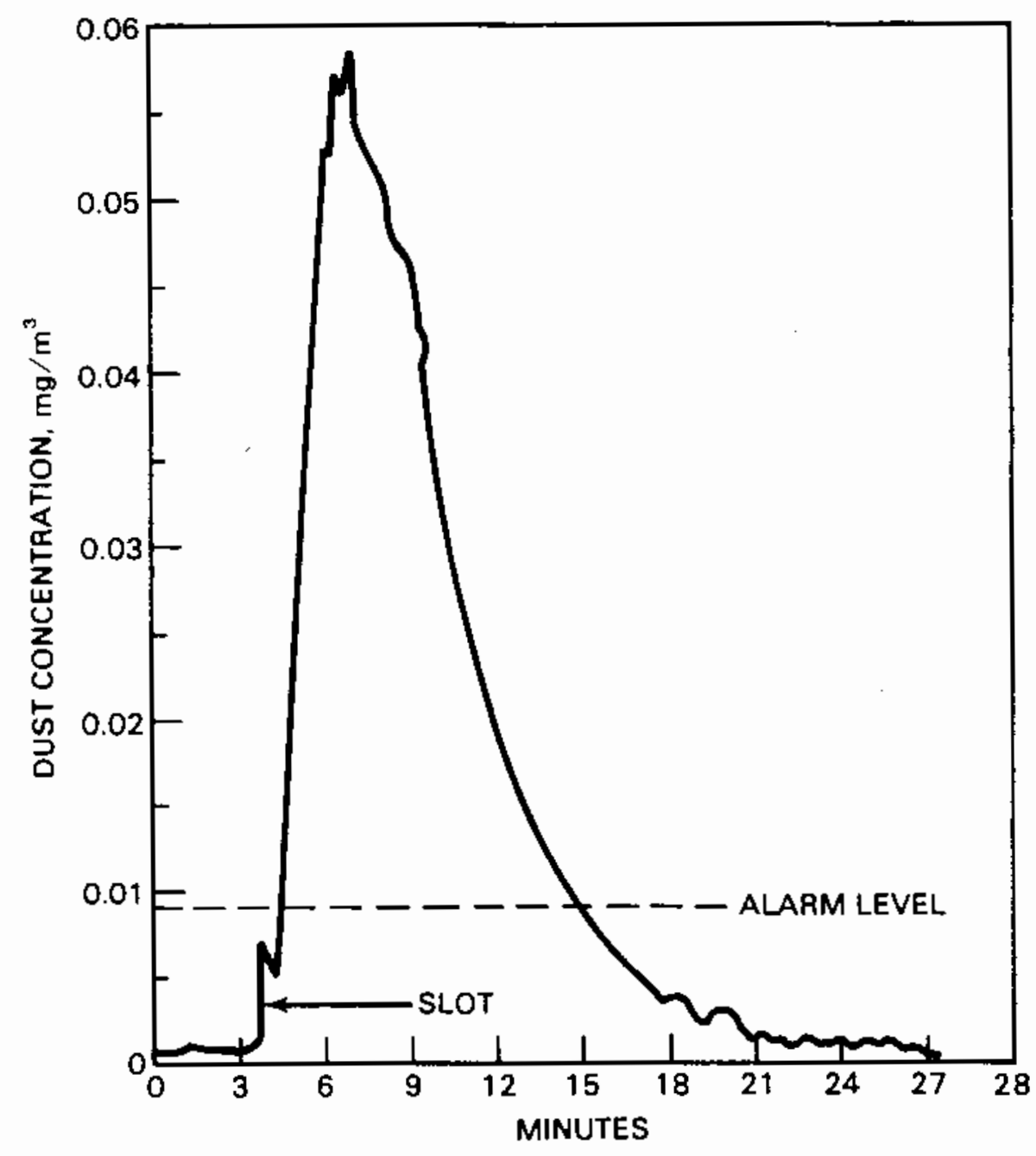

FIGURE 3.2. Round 10 Exhaust Monitor Trace 
TABLE 3.4. Monitor Responses

\begin{tabular}{|c|c|c|c|c|c|}
\hline Round & $\begin{array}{c}\text { Exhaust Alarm } \\
\text { Duration } \\
\text { (min) } \\
\end{array}$ & $\begin{array}{c}\text { Exhaust } 20-m i n \\
\text { Average } \\
\left(\mathrm{mg} / \mathrm{m}^{3}\right)\end{array}$ & $\begin{array}{l}\text { Exhaust } \\
\text { Peak } \\
\left(\mathrm{mg} / \mathrm{m}^{3}\right) \\
\end{array}$ & $\begin{array}{l}\text { Inlet Peak }(a) \\
\text { After Purge } \\
\left(\mathrm{mg} / \mathrm{m}^{3}\right) \\
\end{array}$ & $\begin{array}{l}\text { Inlet } \\
\text { Clearance } \\
\text { Time (min) } \\
\end{array}$ \\
\hline 1 & 8.4 & 0.0082 & 0.021 & OS & 22 \\
\hline 2 & 0.5 & 0.0024 & 0.028 & OS & 17 \\
\hline 3 & 4.2 & 0.0109 & 0.115 & OS & 19 \\
\hline 4 & 12.0 & 0.0132 & 0.028 & OS & 33 \\
\hline 5 & 15.0 & 0.0161 & 0.038 & 182 & 66 \\
\hline 6 & none & 0.0013 & 0.006 & 12 & 23 \\
\hline 7 & none & 0.0010 & 0.005 & 55 & 20 \\
\hline 8 & none & 0.0030 & 0.008 & 53 & 35 \\
\hline 9 & none & D. 0010 & 0.004 & 62 & 17 \\
\hline 10 & 11.4 & $\underline{0.0182}$ & 0.059 & $\underline{92}$ & 32 \\
\hline Average & 5.2 & 0.0075 & 0.031 & 76 & 28 \\
\hline
\end{tabular}

(a) OS means concentration was off scale of the RAM-1.

exhaust monitor average and peak reading during the first 20 min after each shot. The peak reading of the inlet monitor after purging is listed for cases when the reading was not off-scale. The averages of the data are also given.

A typical exhaust monitor readout is shown in figure 3.2. The exhaust monitor traces for 9 out of 10 rounds exhibited a leading peak followed by a more gradual release either higher or lower than the leading peak. The leading peak is believed to be the release resulting from the pressure wave passing through the exhaust system. The dust released at that time is either from the round's impact or resuspension from the ductwork or filter media. The remainder of the release occurs during normal airflow and is probably due to filter leakage or the very high concentration upstream of the filters.

\subsection{COMPARISON OF ANALYTICAL METHODS FOR EXHAUST FILTER SAMPLES}

The exhaust air stream was sampled by a pair of filters for each round, one in the right and one in the left sector of the exhaust duct. The total uranium was determined by fluorimetry, alpha counts, and beta-gamma counts in 
microcuries $\times 10^{-12} / \mathrm{ml}$. Since alpha and beta-gamma counts are less accurate (precision and bias sense), but cheaper than fluorimetry, it is of interest to determine any relationship between the analytical methods.

The data, ordered by the rank of the average of the right and left uranium values, and the averages and standard deviation (sd) are given in Table 3.5 . Despite high concentrations based on the counting data, the round 3 uranium (fluorimetry) values were at the detection limits $(0.52$ and 0.68$)$; the reverse situation was observed for round 4 . The effect of these anomalies is shown in Figure 3.3. When two or more analytical results are separated by less than the plotting interval (about $0.15 \times 10^{-12} \mu \mathrm{Ci} / \mathrm{ml}$ for Figure 3.3 ), the number of coinciding points is plotted. Note also, in Table 3.5, that both the alpha and beta-gamma counts are low relative to the fluorimetry result for round 1 , the round with the largest average fluorimetry uranium value. Rounds 3 and 4 will be removed from the following analyses and results for all three data sets will be reported.

It is obvious in Figure 3.3 that the alpha and beta counts tend to increase with average uranium. (When two or more points coincide, the number of coincident points is used as the plotting symbol.) The averages without rounds 3 and 4 show that results on the left side were slightly greater than those on the right side. However, the differences of 0.1 to $0.2 \times 10^{-12 \mu \mathrm{Ci} / \mathrm{ml}}$ were not statistically significant. Correlations between the left-and rightside results for each analytical method are given in Table 3.6. Removal of round 3 significantly improved the alpha correlation by removing the (3.170, 0.458 ) point. Removal of round 4 caused the beta correlation to drop because the identical detection limit values $[(2.2,2.2)$, the largest beta values after the removal of round 3] were removed. Analysis of variance and individual regression on these data confirmed that it would be reasonable in subsequent analysis to use the average of the right and left data for each method. These averages are plotted in Figure 3.4. The averages for rounds 3 and 4 are joined by a vertical line. Table 3.7 has the results for the analysis of the averages.

The correlations show that removal of round 3 improved the relationship between $U$ and alpha and $U$ and beta counts. Subsequent removal of round 4 
TABLE 3.5. Exhaust Filter Data, $\mu \mathrm{Ci} / \mathrm{ml} \times 10^{-12}$

\begin{tabular}{|c|c|c|c|c|c|c|c|c|c|}
\hline \multirow[b]{2}{*}{ Round } & \multirow{2}{*}{$\begin{array}{l}\text { Average } \\
\text { Uranium } \\
\end{array}$} & \multicolumn{3}{|c|}{ Right } & \multicolumn{3}{|c|}{ Left } & \multirow{2}{*}{$\begin{array}{c}\text { Rank EXH.M } \\
\text { Concentration } \\
\end{array}$} & \multirow{2}{*}{$\begin{array}{c}\text { Rank INLET + TSI } \\
\text { Concentration } \\
\end{array}$} \\
\hline & & U & $\alpha$ & $B$ & U & $\alpha$ & $\bar{B}$ & & \\
\hline 9 & 0.25 & 0.210 & 0.118 & $<0.100$ & 0.290 & 0.362 & 0.241 & 3 & 6 \\
\hline 7 & 0.33 & 0.290 & $<0.030$ & 0.162 & 0.370 & 0.508 & 0.309 & 3 & 4 \\
\hline 2 & 0.34 & 0.413 & 0.561 & 0.088 & 0.267 & 0.317 & $<0.090$ & 3 & 9 \\
\hline 6 & 0.45 & 0.190 & 0.256 & 0.128 & 0.710 & 0.731 & 0.556 & 3 & 2 \\
\hline$(3)$ & 0.60 & $<0.52$ & 3.170 & 2.720 & $<0.68$ & 0.458 & 2.530 & 6 & 1 \\
\hline 8 & 0.88 & 1.10 & 1.020 & 0.795 & 0.66 & 0.823 & 0.535 & 3 & 7 \\
\hline 5 & 1.45 & 1.40 & 1.830 & 1.170 & 1.50 & 1.75 & 1.200 & 9 & 8 \\
\hline (4) & 1.65 & 1.50 & $<0.810$ & $<2.200$ & 1.80 & $<0.81$ & $<2.200$ & 10 & 10 \\
\hline 10 & 1.75 & 1.70 & 1.610 & 0.923 & 1.80 & 1.91 & 1.040 & 8 & 3 \\
\hline 1 & 2.25 & 1.90 & 1.000 & 1.010 & 2.60 & 1.89 & 1.670 & 7 & 6 \\
\hline Average & 0.9950 & 0.9223 & 1.0405 & 0.8286 & 1.0677 & 0.9559 & 1.0371 & & \\
\hline \multirow[t]{2}{*}{ sd } & 0.721 & 0.668 & 0.958 & 0.915 & 0.802 & 0.642 & 0.853 & & \\
\hline & \multicolumn{7}{|c|}{ Without Round 3} & & \\
\hline Average & 1.0389 & 0.9670 & 0.8039 & 0.7307 & 1.1108 & 1.0112 & 0.8712 & & \\
\hline \multirow[t]{2}{*}{ sd } & 0.750 & 0.693 & 0.634 & 0.704 & 0.838 & 0.655 & 0.714 & & \\
\hline & \multicolumn{7}{|c|}{ Without Rounds 3 and 4} & & \\
\hline Average & 0.9625 & 0.9004 & 0.8031 & 0.5470 & 1.0246 & 1.0364 & 0.7051 & & \\
\hline sd & 0.763 & 0.709 & 0.678 & 0.469 & 0.852 & 0.896 & 0.546 & & \\
\hline
\end{tabular}




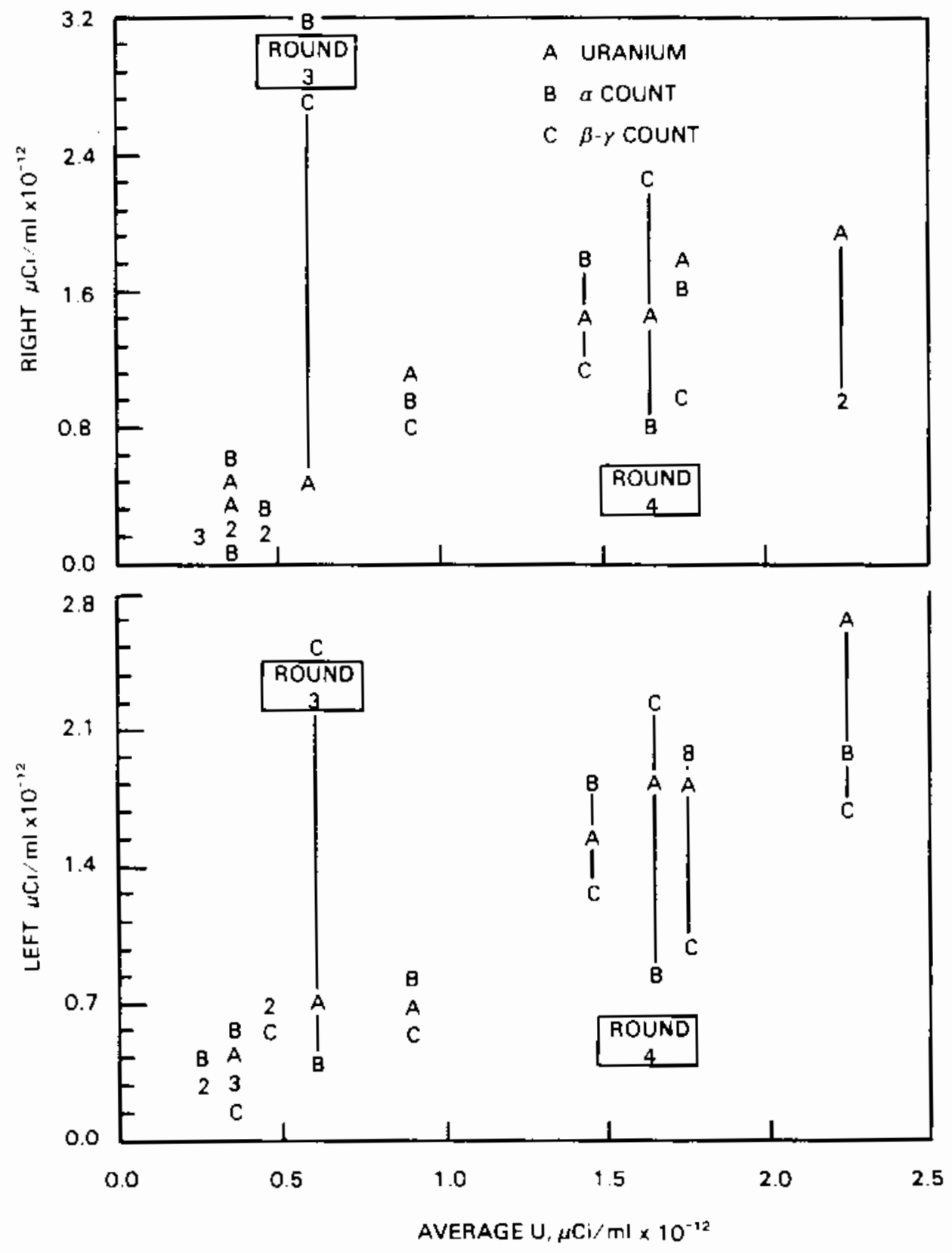

FIGURE 3.3. Exhaust Filter Data

TABLE 3.6. Correlations Between Left and Right Results

\begin{tabular}{|c|c|c|c|}
\hline \multirow[b]{2}{*}{ Method } & \multirow[b]{2}{*}{ All } & \multicolumn{2}{|c|}{ Removed } \\
\hline & & Round 3 & Rounds 3 and 4 \\
\hline Fluorimetry & 0.922 & 0.920 & 0.912 \\
\hline Alpha & 0.288 & 0.833 & 0.839 \\
\hline Bet a-Gamma & 0.955 & 0.930 & 0.860 \\
\hline
\end{tabular}




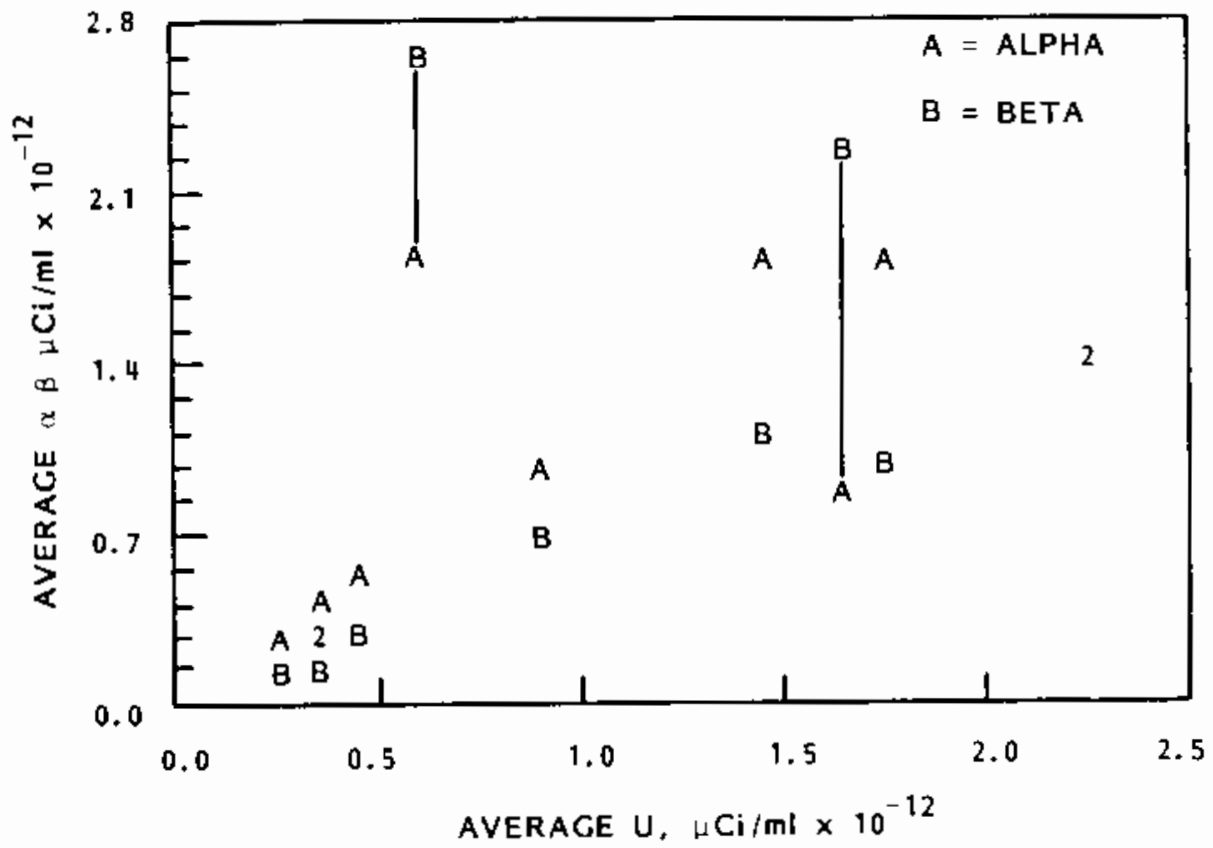

FIGURE 3.4 Alpha and Beta Counts versus Average Uranium

improved the relationship between alpha and beta counts. The resulting leastsquares fits of the counting averages to the uranium average is shown in Figure 3.5. The round numbers for the (alpha, uranium) points are also plotted. If the counting and fluorimetry results were the same $(\alpha=\beta=U)$ then the intercept, $a$, in

$$
\alpha=a+b U
$$

would be zero and the slope, b, would be unity. The results for rounds 3 and 4 removed, in Table 3.7, show that the intercepts are not different from zero. When the intercept is forced through zero, the slope for the alpha data changes from 0.7783 to 0.8926 , which is not statistically different from unity. But, for the beta data, the slope changes from 0.6176 to 0.6388 , both of which are significantly less than unity. The final result is that the alpha-counting results are slightly less than the fluorimetry and the beta results significantly underestimate the fluometry values. 
TABLE 3.7. Summary of Least-Squares Regressions for Exhaust Filter Analytical Methods

\begin{tabular}{|c|c|c|c|c|}
\hline \multirow[b]{2}{*}{ Statistic } & \multirow[b]{2}{*}{$\mathrm{All}$} & \multicolumn{3}{|c|}{ Removed } \\
\hline & & Round 3 & Rounds $3 \& 4$ & Rounds $3 \& 4$ \\
\hline Correlations & & & & Intercept \\
\hline$r(U, \alpha)$ & 0.654 & 0.839 & 0.902 & Set $=0.0$ \\
\hline$r(1), \beta)$ & 0.487 & 0.833 & 0.963 & \\
\hline$r(\alpha, \beta)$ & 0.674 & 0.567 & 0.931 & \\
\hline
\end{tabular}

Regressions

\begin{tabular}{|c|c|c|c|c|c|c|c|c|}
\hline$\underline{a}=a+b U$ & & & & & & & $\alpha=$ bU & \\
\hline Intercept & 0. & 126 & $(0.1$ & $99)^{(a)}$ & $(0.17$ & $6)^{(a)}$ & 0.0 & \\
\hline Slope & 0. & 884 & 0.6 & & 0.77 & & 0.8926 & \\
\hline sd (slope) & 0. & & 0.1 & & 0.15 & & 0.0898 & \\
\hline sd (resid) & 0. & 206 & 0.3 & & 0.30 & & 0.3040 & \\
\hline $\mathrm{R}^{2}$ & 42. & & 70.4 & & 81.4 & & & \\
\hline $\mathrm{R}^{2}(\operatorname{adj})$ & 35. & & 66.2 & & 78.3 & & & \\
\hline$\beta=a+b U$ & & & & & & & $B=b U$ & \\
\hline Intercept & 0. & 954 & $(-0.0$ & $28)^{(a)}$ & 10.03 & $6)^{(a)}$ & 0.0 & \\
\hline Slope & 0. & 908 & 0.7 & & 0.61 & & 0.6388 & \\
\hline sd (s lope) & 0. & 74 & 0.1 & & 0.07 & & 0.0395 & \\
\hline sd (resid) & 0.8 & 1096 & 0.4 & & 0.14 & & 0.1340 & \\
\hline $\mathrm{R}^{2}, \%$ & 23. & & 69.4 & & 92.7 & & & \\
\hline$R^{2}(\operatorname{adj})$ & 14 & & 65.0 & & 91.5 & & & \\
\hline Fitted values & $a$ & $B$ & $\alpha$ & $B$ & $\alpha$ & $\vec{\beta}$ & $a$ & $\bar{B}$ \\
\hline $\mathrm{U}=0.0$ & 0.41 & 0.40 & 0.19 & -0.00 & 0.17 & 0.03 & 0.0 & 0.0 \\
\hline $\mathrm{U}=1.0$ & 1.00 & 0.99 & 0.88 & 0.77 & 0.95 & 0.65 & 0.98 & 0.64 \\
\hline $\mathrm{U}=2.5$ & 1.88 & 1.87 & 1.92 & 1.93 & 2.12 & 1.48 & 2.23 & 1.60 \\
\hline
\end{tabular}

(a) Parenthesized values are not statistically different from zero.

[CAUTION: These results, based on questionable 2-yr old data, should not be used for adjusting alpha or beta counts for the apparent bias relative to fluorimetry results.] 


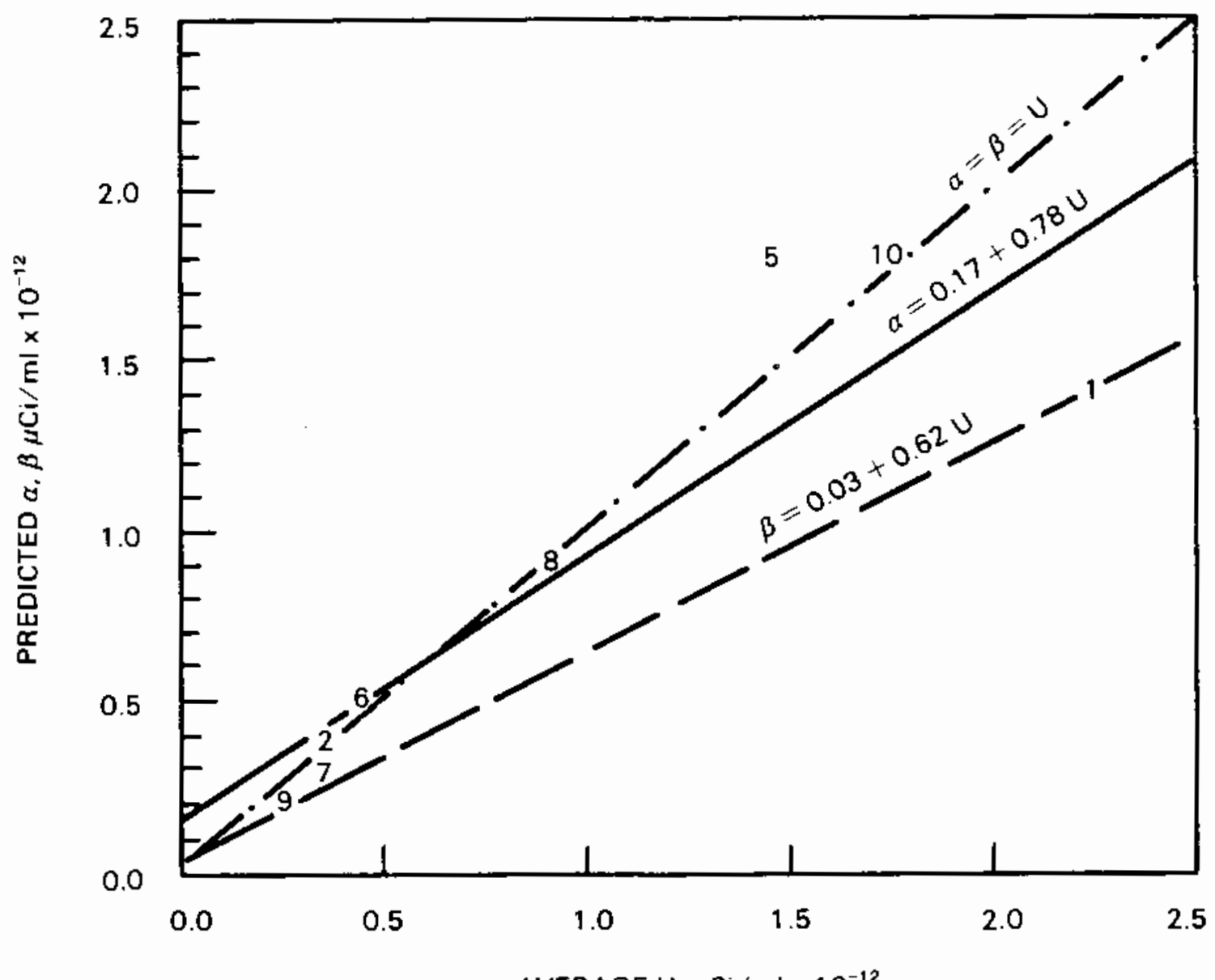

AVERAGE $\mathrm{U}, \mu \mathrm{Ci} / \mathrm{ml} \times 10^{-12}$

FIGURE 3.5. Least-Squares Fits of Counting

Results to Fluorimetry Results

\subsection{COMPARISON OF INLET RAM-1 WITH INLET AND WORKPLACE FILTER RESULTS}

After workers are allowed in the building, the Inlet RAM-l monitors the dust concentration in lieu of a radiation-monitoring device. The MPC is $0.2 \mathrm{mg} / \mathrm{m}^{3}$ of DU, $\left(7.0 \times 10^{-11} \mu \mathrm{Ci} / \mathrm{ml}\right)$ for occupational exposure. The Ford's Farm study used four filter samplers to measure the uranium concentration related to the RAM-1: open-faced filters near the RAM-1 and the workplace entrance (INLET and WKFILT), and respirable cut (3.5 microns AEO cyclone) filters near the open-faced filters (INCYC and WKCYC).

The data are given in Table $3.8 \mathrm{in} \mu \mathrm{g} / \mathrm{m}^{3}$. Six of the ten workplace cyclone samples gave results below analytical detection limits (d in Table 3.8) 
TABLE 3.8. Data for Inlet RAM-1 Comparison with Inlet and Workplace Filters, $\mu \mathrm{g} / \mathrm{m}^{3}$

\begin{tabular}{|c|c|c|c|c|c|}
\hline Round & INLET & INF ILT & INCYC & WKF ILT $(a)$ & $W K C Y C(a)$ \\
\hline 1 & 30 & -1.1150 & -0.5023 & $0.3914 d$ & 6.858 \\
\hline 2 & 45 & 6.7179 & -0.1495 & 3.5434 & $46.905 d$ \\
\hline 3 & 17 & 18.1670 & 1.8332 & 10.4127 & $-3.048 d$ \\
\hline 4 & 140 & 18.0590 & 1.7612 & 10.3003 & $-5.787 d$ \\
\hline 5 & 34 & 68.0587 & 1.7204 & 49.4024 & 61.620 \\
\hline 6 & 15 & 65.8223 & 0.2124 & 46.7982 & -4.352 \\
\hline 7 & 17 & 2.3170 & 1.4259 & 0.6545 & 71.839 \\
\hline 8 & 25 & 72.6243 & 21.4506 & 42.0687 & $-58.407 d$ \\
\hline 9 & 20 & 6.5570 & 2.4616 & 2.1681 & $33.333 d$ \\
\hline 10 & 19 & 21.6555 & -0.0118 & 54.6861 & 139.179 \\
\hline
\end{tabular}

(a) "d" indicates the value was based on "less than detection limit" result reported by the lab.

and/or were made negative by the blanks. Other anomalies in the data are: the $140-\mu \mathrm{g} / \mathrm{m}^{3}$ value for the Inlet RAM-1 for round 4 and the $21.45-\mu \mathrm{g} / \mathrm{m}^{3}$ values for the INCYC on round 7 .

The correlations of the filter data with the Inlet RAM-1 are not statistically different from zero and are all negative: -0.130 with INFILT, -0.075 with INCYC, -0.213 with WKFILT, and -0.209 with WKCYC. Removing round 4 data only brings the correlations closer to zero. The highest correlation among all the variables is $0.818(0.816$ without round 4$)$ between the WKFILT and INFILT data. The next highest is $0.540(0.537)$ between the INFILT and INCYC data. The WKCYC and INCYC data have a negative correlation $-0.578(-0.609)$. None of the other correlations are above 0.3 in absolute value. A correlation coefficient of at least 0.549 is necessary to judge the correlation coefficient to be greater than zero, allowing a 1 in 20 chance of being wrong.

The data do not support a 1 inear relationship between the Inlet RAM-1 and the filter results. The problem is evident in Figure 3.6, which plots the INFILT and WKFILT data against the Inlet RAM-1 data with round 4 renoved. Any 


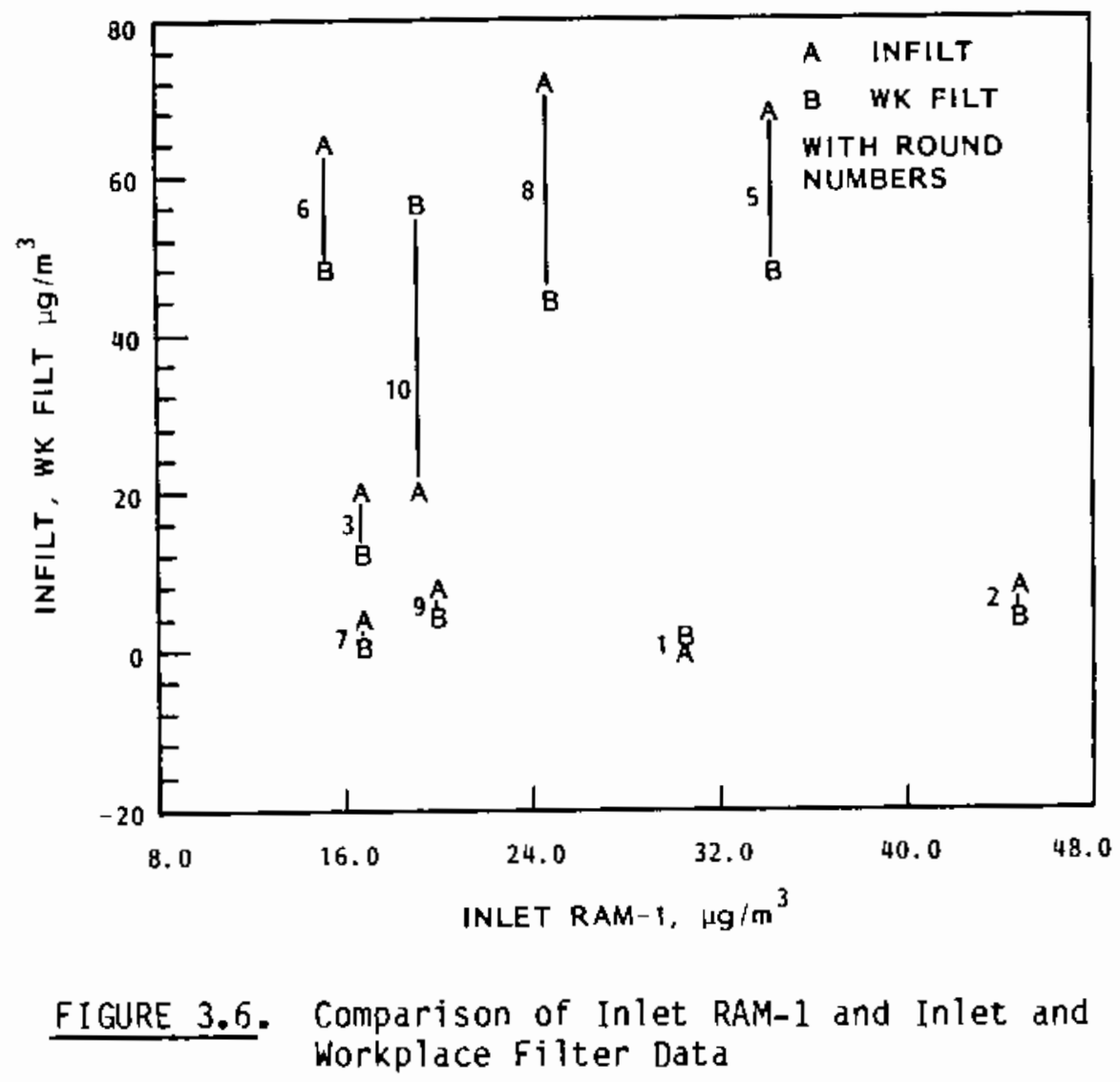

attempt at fitting a straight line is doomed by the high-filter data for round 6 or the low-filter data for rounds 1 and 2 .

\subsection{COMPARISON OF SEQUENTIAL RAM-1 AND FILTER RESULTS}

The continuous readout from the Inlet RAM-1 was averaged over time periods corresponding to the sequential open-faced filter sampler's periods of exposure. The questions of interest expected to be answered by these data were:

- Does the concentration decrease at the same rate for both types of samples?

- Can the sequential filters and RAM-1 results provide a relationship for setting a RAM-1 (dust) concentration corresponding to the MPC for uranium measured by the sequential filters? 
The pairs of data are listed in Table 3.9. The sequential filters were not operable for rounds 1 and 8 ; these rounds are not 1 isted. The only data listed for the remaining rounds are those for which both the RAM-1, $R$, and sequential filters, $F$, had results. These data were transformed by taking their natural logarithms given in Table 3.10. Except for round 5, this transformation tended to linearize the relationship over time periods. Typically, sequences $A, B$, and $C$ were 5 min long; sequence D varied from 2 to 16 min; and sequence $\varepsilon$ from 15 to $60 \mathrm{~min}$. Figure 3.7 shows the duration of the sampling times for each round. Figure 3.8 gives plots of the logarithmic data against the time midpoints for the sampling periods. Round 5 had the highest concentration at edch period, about twice as large as round 10 at sequence $B$, and more than four times as large at sequence $E$. (Round 5 had missing data for sequence $C_{.}$) The sequence $C$ filter for round 10 declined only slightly from

TABLE 3.9. Sequential RAM-1 and Filter Data, $\mathrm{mg} / \mathrm{m}^{3}$

\begin{tabular}{|c|c|c|c|c|c|c|}
\hline \multirow{2}{*}{\multicolumn{2}{|c|}{ Round }} & \multicolumn{5}{|c|}{ Sequence } \\
\hline & & A & \multirow[t]{2}{*}{$B$} & $\mathrm{C}$ & $\bar{D}$ & $E$ \\
\hline \multirow[t]{2}{*}{2} & Ram-1 & --- & & $\rightarrow$ & -- & $=--$ \\
\hline & Filter & --- & 0.007 & --- & $\rightarrow-$ & -- \\
\hline \multirow[t]{2}{*}{3} & $R$ & --- & 0.017 & $-\infty$ & -- & $\ldots$ \\
\hline & $\mathrm{F}$ & --- & 0.012 & --- & -- & -- \\
\hline \multirow[t]{2}{*}{4} & $\mathrm{R}$ & -- & --- & 13.100 & $-\infty$ & -- \\
\hline & $\mathrm{F}$ & --- & -- & 9.419 & --- & $\cdots$ \\
\hline \multirow[t]{2}{*}{5} & $\mathrm{R}$ & --- & 77.000 & -- & 22.000 & 2.700 \\
\hline & $F$ & --- & 91.659 & -- & 30.537 & 4.999 \\
\hline \multirow[t]{2}{*}{6} & $R$ & -- & 5.699 & -- & 0.260 & 0.032 \\
\hline & $\mathrm{F}$ & -- & 19.639 & --- & 0.181 & -0.003 \\
\hline \multirow[t]{2}{*}{7} & $R$ & $\cdots$ & 9.100 & 1.049 & 0.055 & 0.017 \\
\hline & $\mathrm{F}$ & --- & 12.217 & 1.633 & 0.037 & 0.002 \\
\hline \multirow[t]{2}{*}{9} & $\mathrm{R}$ & 37.000 & 4.199 & 0.380 & 0.059 & 0.020 \\
\hline & $\mathrm{F}$ & 69.443 & 4.998 & 0.637 & 0.132 & 0.006 \\
\hline \multirow[t]{2}{*}{10} & $\mathrm{R}$ & --- & 34.000 & 6.000 & 0.170 & 0.024 \\
\hline & $\mathrm{F}$ & --- & 49.978 & 42.211 & 2.114 & 0.801 \\
\hline
\end{tabular}


IABLE 3.10. Sequential RAM-1 and Filter Data, $\log _{\mathrm{e}}\left(\mathrm{mg} / \mathrm{m}^{3}\right)$

\begin{tabular}{|c|c|c|c|c|c|c|}
\hline \multirow{2}{*}{\multicolumn{2}{|c|}{ Round }} & \multicolumn{5}{|c|}{ Sequence } \\
\hline & & $\bar{A}$ & $B$ & $\mathrm{C}$ & D & $E$ \\
\hline \multirow[t]{2}{*}{2} & $\mathrm{R}$ & $\rightarrow-$ & -3.8167 & --- & -- & -- \\
\hline & $F$ & --- & -4.9257 & $\cdots$ & --- & - \\
\hline \multirow[t]{2}{*}{3} & $R$ & --- & -4.0745 & --- & -- & -- \\
\hline & $\mathrm{F}$ & -- & -4.3848 & --- & --- & $-\infty$ \\
\hline \multirow[t]{2}{*}{4} & $R$ & -- & $-\infty$ & 2.5726 & --- & --- \\
\hline & $\mathrm{F}$ & -- & --- & 2.2428 & -- & -- \\
\hline \multirow[t]{2}{*}{5} & $\begin{array}{l}R \\
F\end{array}$ & -- & 4. 3438 & $-\infty$ & 3.0910 & 0.9932 \\
\hline & F & $-\infty$ & 4.5180 & - & 3.4189 & 1.6093 \\
\hline \multirow[t]{2}{*}{6} & $R$ & $\cdots$ & 1.7404 & -- & -1.3470 & -3.4420 \\
\hline & $\mathrm{F}$ & -- & 2.9775 & --- & -1.7079 & $\rightarrow-$ \\
\hline \multirow[t]{2}{*}{7} & $R$ & --- & 2.2082 & 0.0487 & -2.9004 & -4.0745 \\
\hline & $\mathrm{F}$ & -- & 2.5028 & 0.4910 & -3.2875 & -5.8751 \\
\hline \multirow[t]{2}{*}{9} & $R$ & 3.6109 & 1.4350 & -0.9675 & -2.8134 & -3.9120 \\
\hline & $\mathrm{F}$ & 4.2405 & 1.6091 & -0.4504 & -2.0226 & -5.0724 \\
\hline \multirow[t]{2}{*}{10} & $R$ & --- & 3.5263 & 1.7917 & -1.7719 & -3.7297 \\
\hline & $F$ & --- & 3.9115 & 3.7426 & 0.7490 & -0.2217 \\
\hline
\end{tabular}

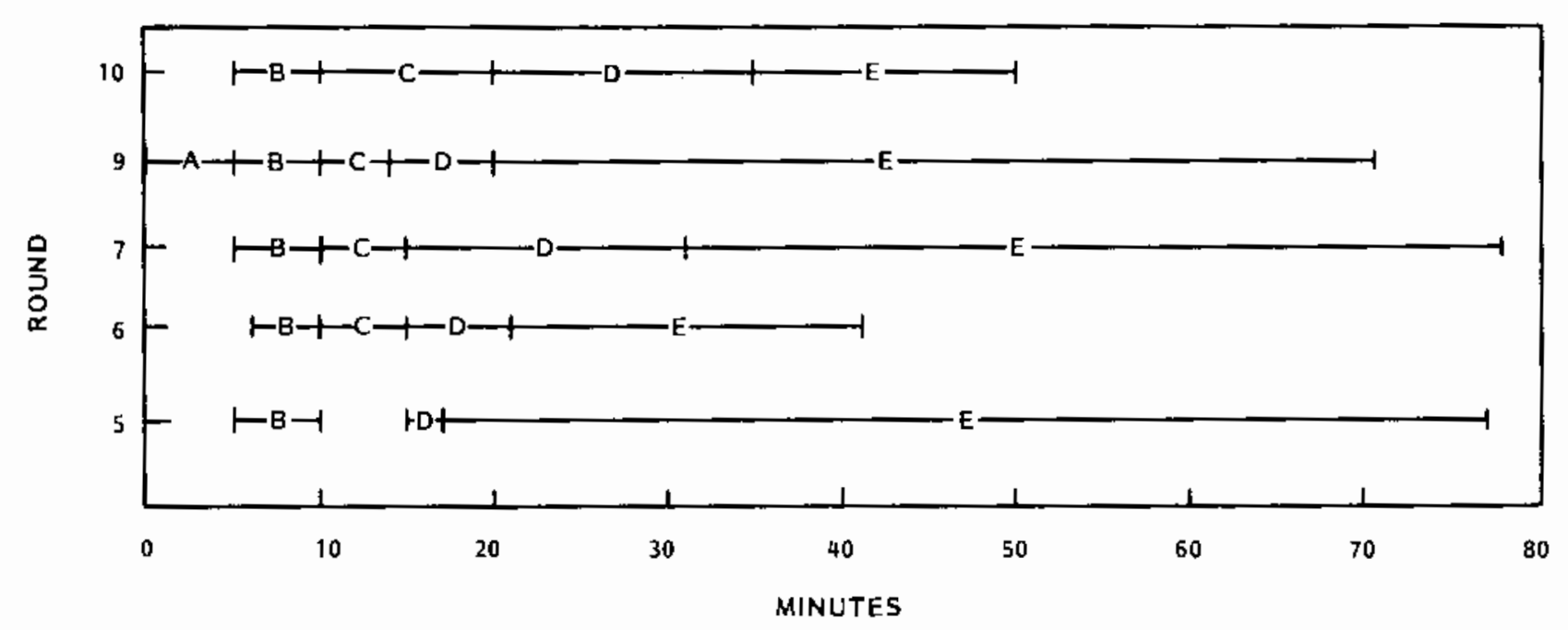

FIGURE 3.7. Sequential Sample Ouration for Rounds 5 to 7,9 and 10 


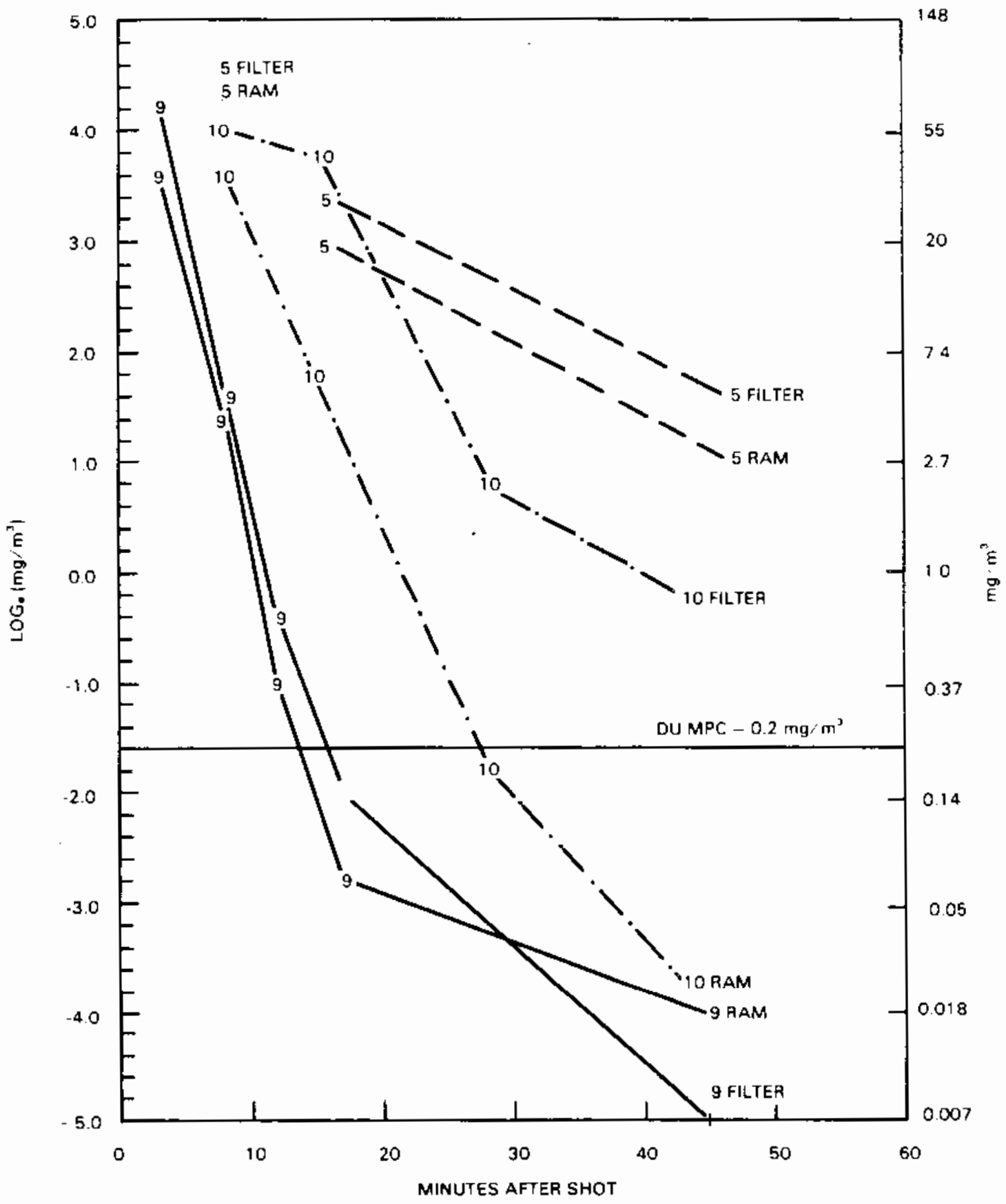

A

FIGURE 3.8. Concentrations for RAM-1 and Sequential filters Versus Sampling Period Time Midpoint, with Round Numbers:

(a) Rounds 5, 9, and 10 . 


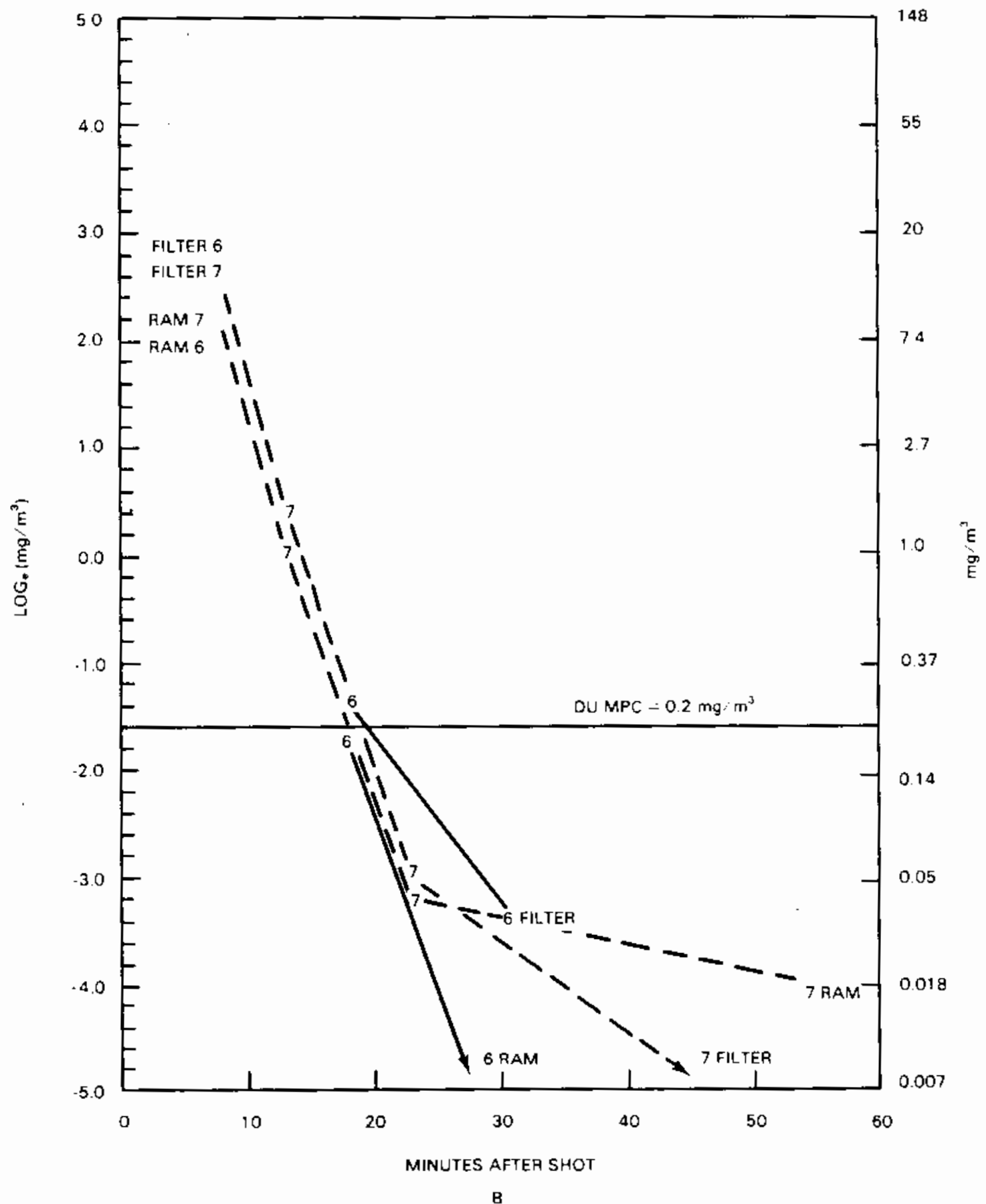

FIGURE 3.8 (contd). Concentrations for RAM-1 and Sequential Filters Versus Sampling Period Time Midpoint, with Round Numbers: (b) Rounds 6, 7 . 
sequence $B$ (from 59.978 to $42.211 \mathrm{mg} / \mathrm{m}^{3}$ ). For round 6 , the sequence $E$ point was negative due to the blank correction and was treated as missing on the logarithmic scale. Rounds 2,3 , and 4 had only one data pair and are not included in the plot.

The differences in duration of sampling for the same sequence complicates the interpretation of the results. The sequence A sampling commenced almost simultaneously with the round's striking the target, and most RAM-l readings were off-scale. Since particulate concentration is depleted rapidly from various initial concentrations $\left(4\right.$ to $95 \mathrm{mg} / \mathrm{m}^{3}$ for rounds 5 through 10 for sequence $B$ ), comparison of rates of depletion from round to round may depend on the time the sampler was turned on after the shot or when averaging started. The rates of depletion on the logarithmic scale over the first four sampling periods appear to be linear, except for the round $10 \mathrm{filter}$, sequence $C$, as shown by Figure 3.8. Except for round 10, the RAM-1 and filter results compare closely on both depletion rate and concentration level, at least through sequence D. As with the inlet and workplace filters, the RAM-1 results are lower than the filter results except for sequence $E$ of rounds 7 and 9 .

The rate of decline was calculated as:

$$
\mathrm{DT}_{s i, j+1}=\left(x_{s i j}-x_{s i j, j+1}\right) / t_{i, j+1}
$$

where:

$D_{S i, j+1}$ is the rate of decline per minute over period $j+1$ in Round $i$, for the sampler Type $s$

$$
\begin{aligned}
& x_{s i j} \text { is the } \mathrm{mg} / \mathrm{m}^{3} \text { for } s_{i j} \\
& t_{i, j+1} \text { is the duration of sampling, }
\end{aligned}
$$

and subscripts

$$
\begin{aligned}
& s=1 \text { for RAM-1, or } 2 \text { for filters, } \\
& \mathbf{i}=5,6,7,9,10, \text { the round number, } \\
& j=B, C, D, E \text { for sampling sequence. }
\end{aligned}
$$

The results of this calculation are given in Table 3.11. The correlation coefficient between RAM-1 (R) and Sequential Filter (F) data in the celis of 


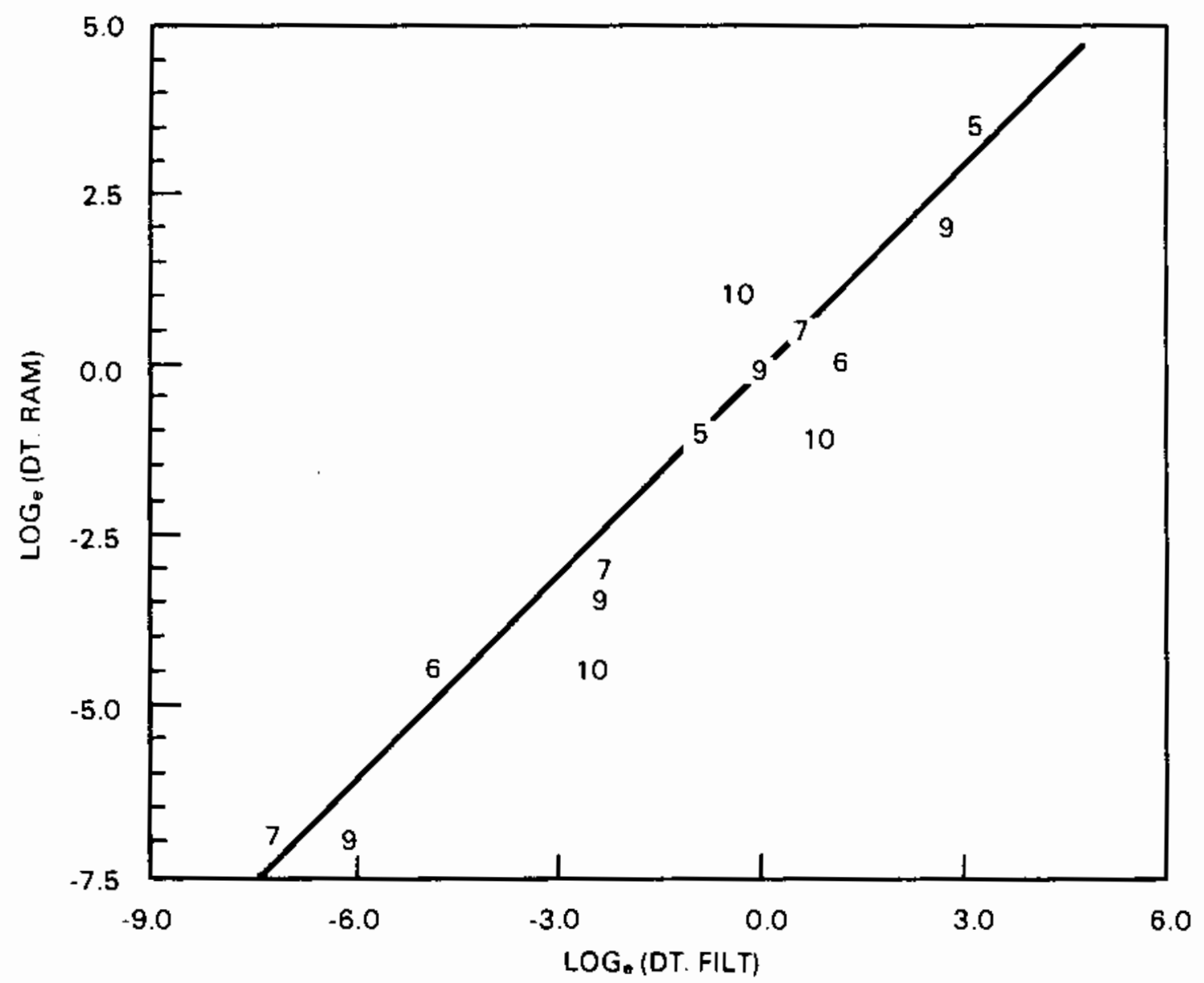

FIGURE 3.9. Comparison of Depletion Rates for Sequential RAM-1 and Filters

This relationship was based on the 16 data pairs left after round 10 , and the round 7 , sequence $E$ points were removed. Figure 3.10 is a plot of the data and the fitted line. The round 10 and round 7.E points are circled as a reminder that they were not included in the fit. When they were included in the fit, $87.4 \%$ of the variability in the filter data was accounted for by the fit to the RAM-1 data. This $R^{2}$ improved to $97.2 \%$ when the five unusual points were removed. The correlation coefficients were 0.935 with all 21 data points and 0.986 with the 16 data points.

The logarithmic scale complicates use of the relationship but is necessary to prevent the few high concentrations (20 $\mathrm{mg} / \mathrm{m}^{3}$ and above) from determining the relationship. A plot of the untransformed data would have 14 points in the 


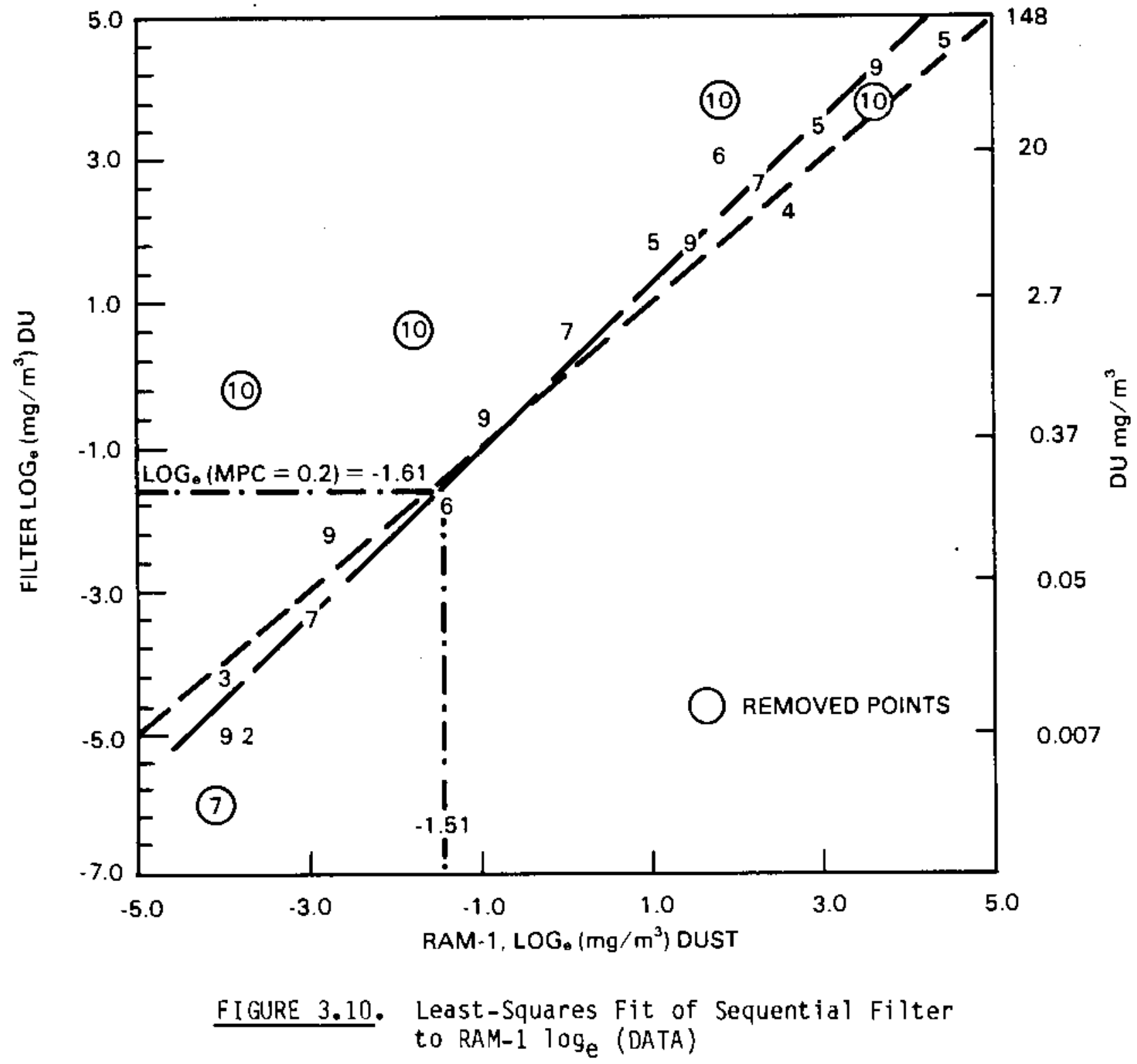

0- to $5-\mathrm{mg} / \mathrm{m}^{3}$ sector with the other 8 points sparsely distributed out toward the $100-\mathrm{mg} / \mathrm{m}^{3}$ extremes. On the logarithmic scale the relationship is not far from $\log _{e}(F)=\log _{e}(R)$, as indicated by the dashed line in Figure 3.10. The intercept, 0.095 , is not statistically significantly different from zero, but the slope is statistically greater than unity. Since these differences are on the logarithmic scale, they become practically significant when exponentiated to transform back to the $\mathrm{mg} / \mathrm{m}^{3} \mathrm{scale.} \mathrm{Use} \mathrm{of} \mathrm{the} \mathrm{logarithmic} \mathrm{scale} \mathrm{implies}$ that the underlying relationship is 


$$
F=a^{-} R^{b}
$$

so that

$$
\log _{e}(F)=\log _{e} a^{-}+b \log _{e}(R)
$$

The fit gave the estimates

$$
a=\log _{e} a^{\prime}=0.0949
$$

and

$$
b=1.12668
$$

Then

$$
a^{\prime}=\exp (0.0949)=1.10 \mathrm{mg} / \mathrm{m}^{3}
$$

and, for example, if a RAM-1 result were $10 \mathrm{mg} / \mathrm{m}^{3}$,

$$
\hat{F}=1.10(10)^{1.12668}=14.73 \mathrm{mg} / \mathrm{m}^{3} \text { of DU. }
$$

Using the relationship inversely at the MPC we have,

$$
\log _{e}(R)=\left[\log _{e}(0.2)-0.0949\right] / 1.12668=-1.5127
$$

and

$$
\exp (-1.5127)=0.2203 \mathrm{mg} / \mathrm{m}^{3} \text { of dust. }
$$

Since both the RAM-1 and filter analyses are subject to imprecision on the order of 10 to $20 \%$ of the reported values and since a relative bias is apparent between the two measurement methods, these point estimates and the applicability of the statistical methods used to get them are questionable.

The final conclusion is that the expected qualitative relationship between the RAM-1 and sequential filter data is confirmed, but the fit is not accurate enough to "calibrate" the RAM-1 to give grams of 0U. The inverse calculation does indicate that $0.5 \mathrm{mg} / \mathrm{m}^{3}$ for respirable particles is conservative, since the $0.2 \mathrm{mg} / \mathrm{m}^{3}$ DU MPC corresponds to $0.22 \mathrm{mg} / \mathrm{m}^{3}$ of dust. 


\subsection{RESULTS FOR THE RDM-301 MONITOR}

This instrument did not provide sufficient data for comparisons with other measuring instruments. Two rounds had no results. Rounds 2, 7, 9, and 10 had $0.0 \mathrm{mg} / \mathrm{m}^{3}$ reported and the results for rounds 3 and 4 are suspect due to an adjacent air sampler.

\subsection{COMPARISONS OF RESULLTS FOR THE TSI-3500 AND OTHER SAMPLERS}

The hand-held TSI-3500 is used as a back-up check on the Inlet Monitor (RAM-1). The measurements from these two instruments have a correlation of 0.810 , indicating a fairly strong relationship. The scatterplot of Figure 3.11 shows that round 4 strongly influences the relationship. The correlation improves slightly to 0.845 with round 4 removed. Figure 3.11 suggests a quadratic relationship between the TSI and Inlet RAM-1 results, but this is based on the single round 4 point. With all ten rounds included

$$
T S I=0.012+0.3755(\text { INLET }) \text {, }
$$

but with round 4 removed

$$
\text { TSI }=-0.0069+1.1561(\text { INL.ET }) .
$$

This last relationship, with an intercept not significantly different from zero and a slope near unity, is more in line with expectations for instruments sampling respirable particulates. The line estimated with round 4 removed is plotted in Figure 3.12. No other sampler, either routine or special filters, had a meaningful correlation with the TSI results. It might be expected that the RAM SEq.E data would be related, but the correlation was onty 0.132 . Other correlations with TSI were:

$\begin{array}{ccccc}\text { Sampler } & \text { INFILT } & \text { WKFILT } & \text { INCYC } & \text { WKCYC } \\ r & 0.080 & -0.121 & 0.226 & -0.585\end{array}$




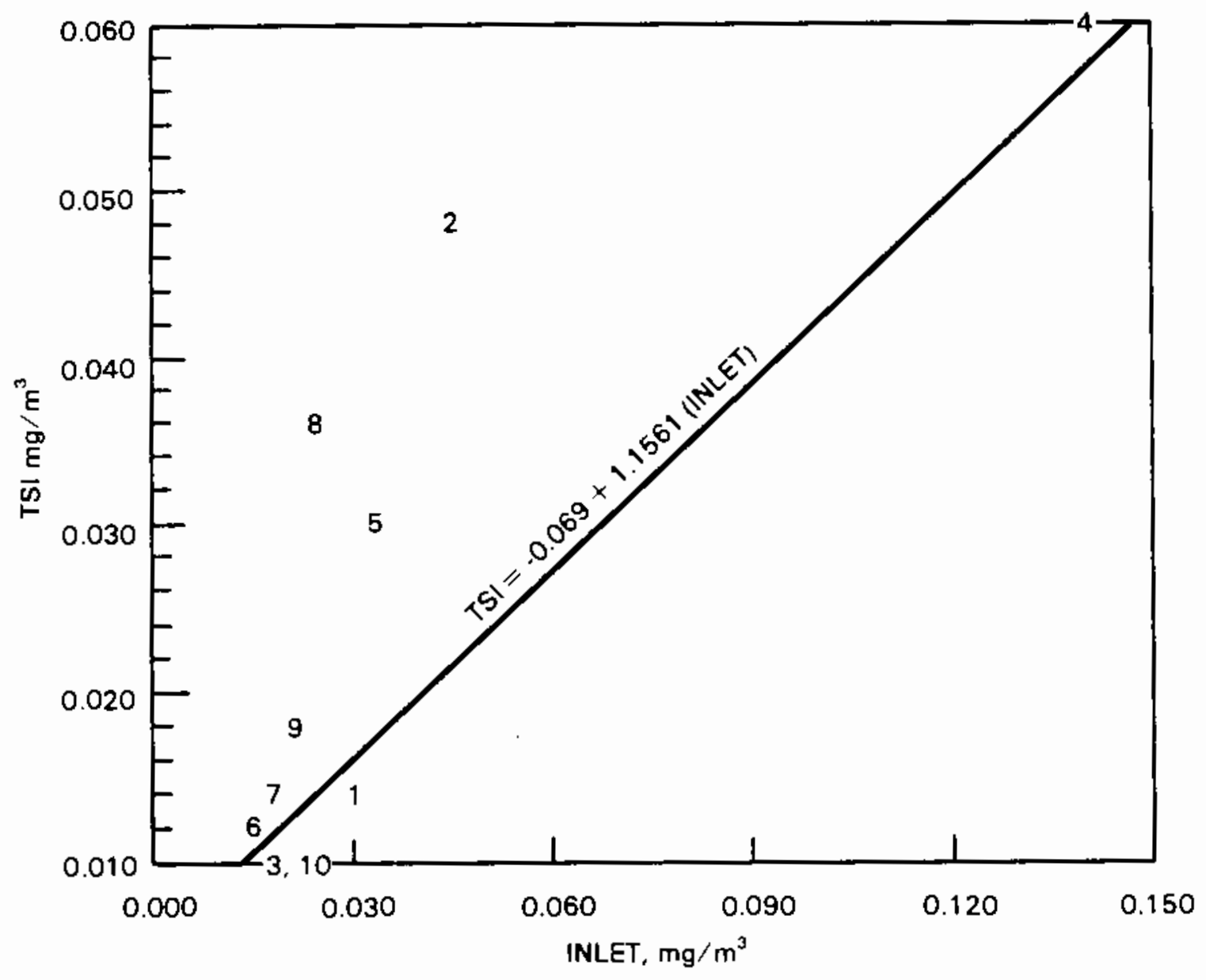

FIGURE 3.11. Plot of TSI versus Inlet RAM-1, with Round Number

The sequential-filter samples $D$ and $E$ had correlations of 0.911 and 0.875 due to the large values for round 4 (30.5 for sequence $D$ and 5.0 for sequence $E$ ). Without round 4 these correlations dropped to -0.756 and -0.751 , respectively, based on four data points.

\subsection{WIPE DATA ANALYSIS}

The wipe data from Ford's Farm were analyzed to determine if counts increased from the wipes over the series of 10 rounds and to discover the degree of variability in the amount of material deposited on the various surfaces within the building. The beta-gamma counts were used for the analysis. 


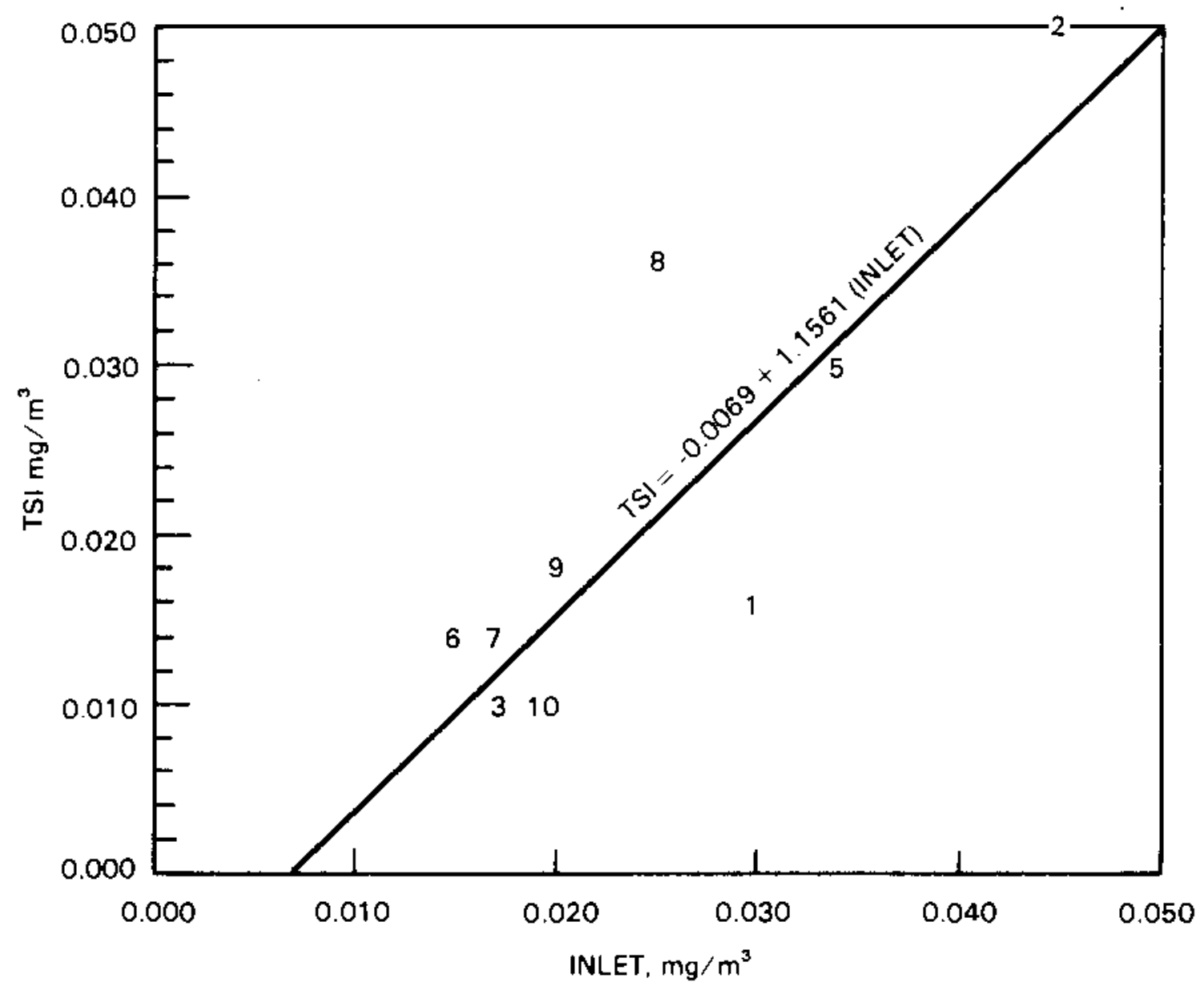

FIGURE 3.12. Linear Fit of TSI to Inlet Data, round 4 Removed, with Round Number

The wipe data were for five surfaces: target and $x$-ray film apparatus on the floor, exhaust side wall, x-ray side wall, rear wall, and front wall. Wipes were taken from four to nine locations on each of these surfaces after each round and after the decontamination wash-down between Rounds 3 and 4 . Not all locations were wiped after each round; for example, round 1 had beta-gamma wipes for only 3 of the 33 locations.

The beta-ganma data in counts per minute, are given in Appendix $C$. The locations where the wipe samples were taken are given in Figure 3.13. The average counts over the 10 rounds and the decontamination for each location and the whole surface is also shown. For the exhaust wall, the averages combining all wipes in the exhaust duct and the other three locations are given separately. There were no beta-gamma data for location 24 on the $x$-ray wall. 


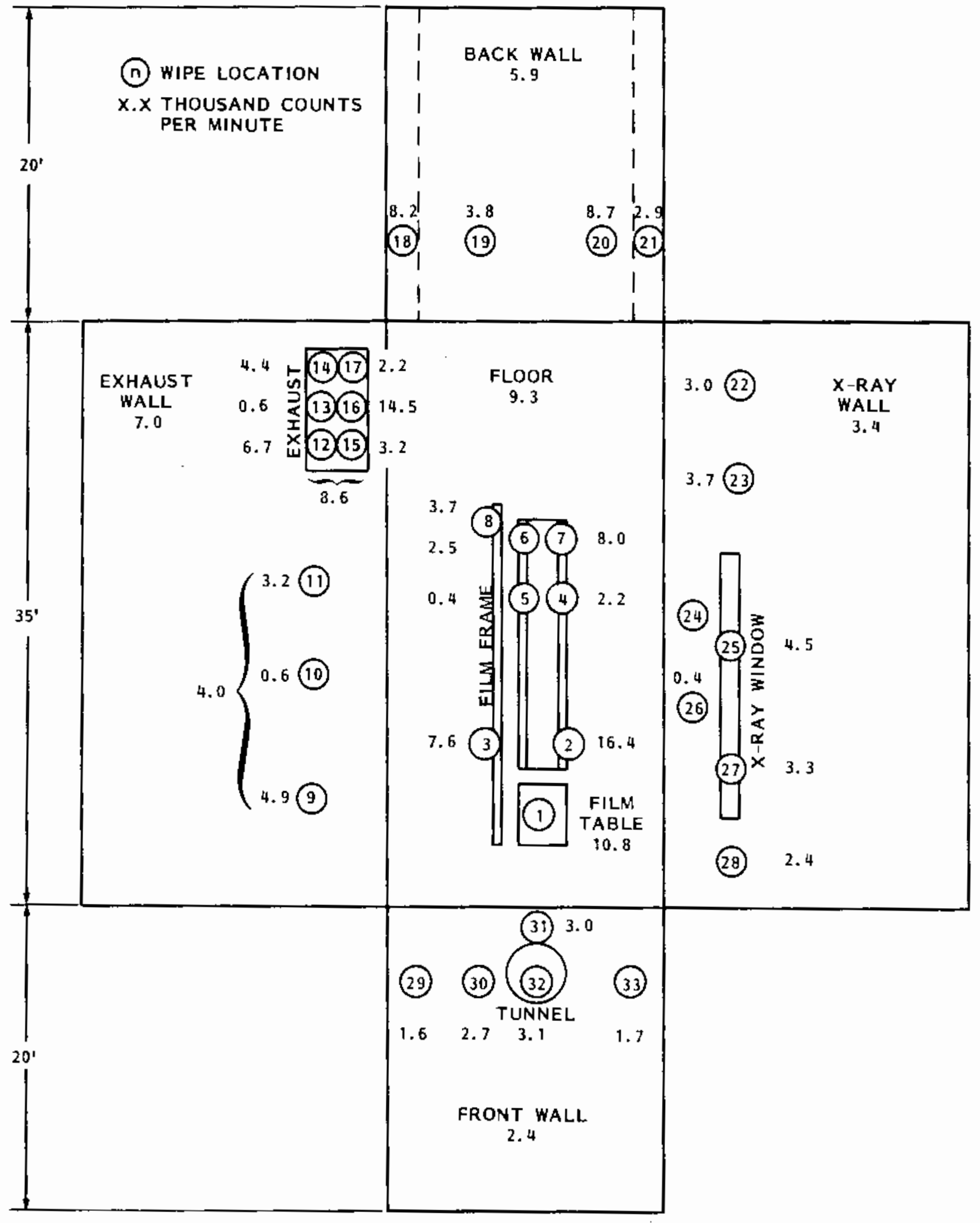

FIGURE 3.13. Sampling Locations with Average Thousand Counts per Minute 
Table 3.12 gives the ranges of averages and data for the surfaces with the most extreme differences. The average of all wipes for the five locations on the front wall was 2.4 thousand counts and for the equipment on the "floor," 9.3 thousand. For each of these surfaces, the extreme averages are given for specific locations with at least four wipes on the surface. For example, on the front wall, wipe location 29 has 1.6 thousand and location 32 has 3.1 thousand beta-gamma counts (Figure 3.13). These averages over the shots indicate how the locations on a surface might be expected to vary. The round-to-round row gives the minimum and maximum concentration observed for the rounds at the specific location.

Table 3.12 shows that the floor equipment had about four times as much contamination as the front wall. The averages in Table 3.13 show the ranking of the subsurfaces and indicate a significant concentration difference for the areas defined, a 6.9 thousand count difference overall. The exhaust entry area is almost as contaminated as the floor equipment; a significant drop to the rear wall average is followed by less pronounced changes for the other vertical surfaces.

The ranking of the rounds based on beta-gamma counts and Inlet RAM-1 concentrations are compared at the bottom of Table 3.14. There is fair agreement among ranks, the Spearman rank correlation coefficient being 0.706. However rounds 5 and 10 do have quite different rankings based on the two measurement methods.

TABLE 3.12. Minimum and Maximum for Wipe Data and Averages (thousands of $\beta, Y$ counts)

\begin{tabular}{|c|c|c|c|c|}
\hline Surface & \multicolumn{2}{|c|}{ Front Wall } & \multicolumn{2}{|c|}{ Floor } \\
\hline Surface Average & 2. & & & \\
\hline Location on Surface & 29 Left & 32 Tunnel & $\begin{array}{c}\text { Front } \\
\text { 8 Film Frame } \\
\end{array}$ & $2 \operatorname{Rail}$ \\
\hline Average & 1.6 & 3.1 & 3.7 & 16.4 \\
\hline $\begin{array}{l}\text { Round-to-Round Range } \\
\text { After Decontamination }\end{array}$ & 1.3 to 3.7 & 1.6 to 6.4 & 0.2 to 8.3 & 10 to 62.6 \\
\hline
\end{tabular}


TABLE 3.13. Ranking of Subsurfaces

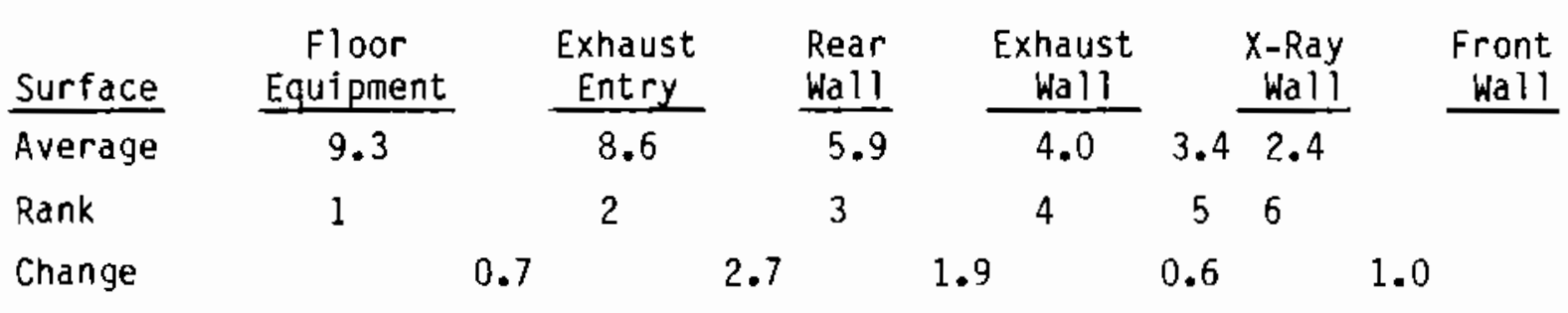

TABLE 3,14. Wipe Summary

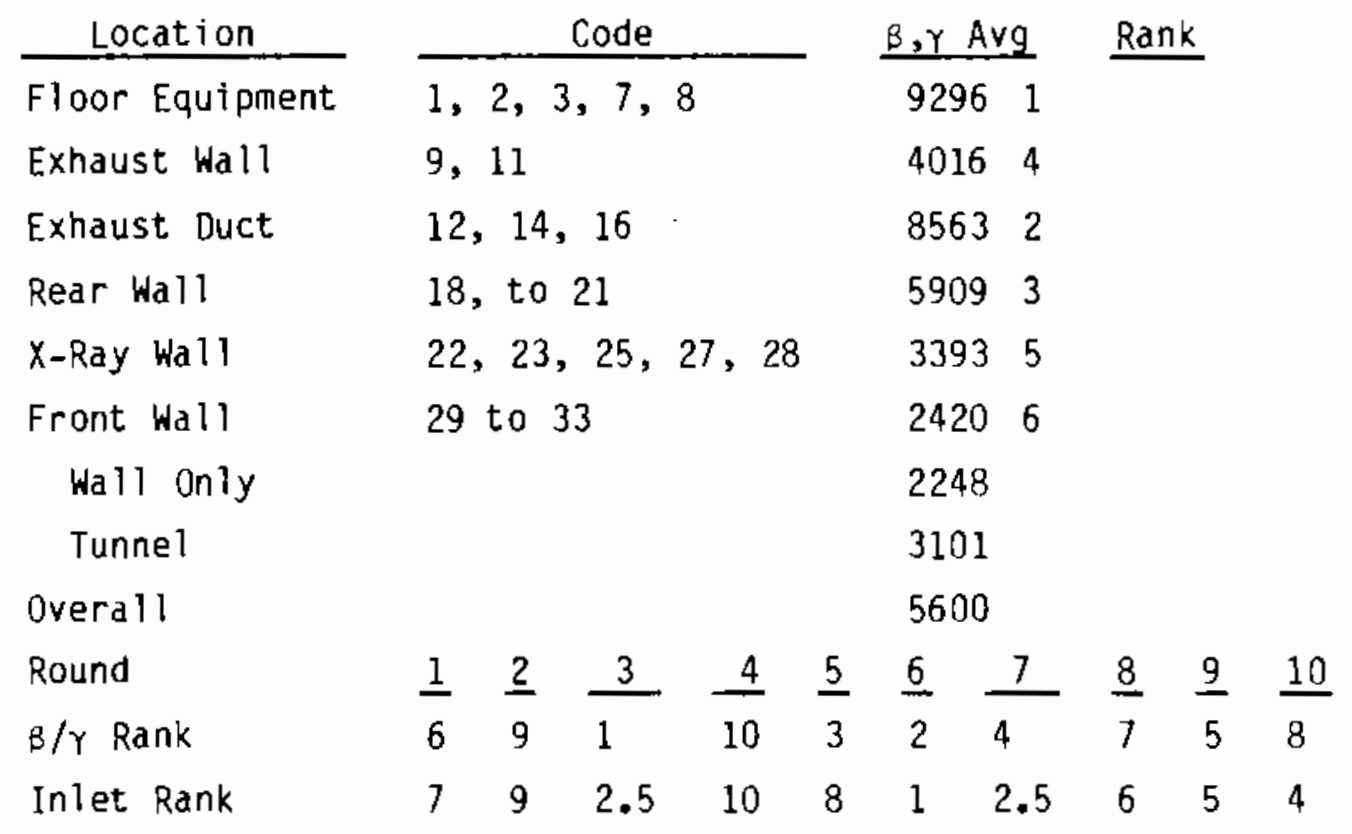

The counts for round 3 were greater than those for round 2. The building was washed down (decontaminated) after round 3 ; however, the counts were greater after round 4 than after round 3 , and stayed at roughly the same level for rounds 4 through 10. This pattern is evident in the plots of the natural logarithms of the data given in Appendix C.2. These plots mark the time of decontamination with a vertical line. Aside from the initial effect, seen in the first three rounds, the wipe data do not indicate a build-up in deposited material over successive rounds. The logarithmic scale of the plots masks the magnitudes of the differences in counts. The average of the natural log data for round 3 was about 7.82. After decontamination the average dropped to 6.24 and for rounds 4 through 10 it was 8.44. Exponentiating these averages (to 
base e), gives the geometric mean of the counts. These were, roughly: 2500 counts for round 3 (500 counts after decontamination), and 4600 for rounds 4 through 10. Decontamination decreased the smearable contamination by a factor of five, but the next shot raised it to about twice the level for round 3 , where it remained for the next 5 rounds. The trend slightly increased over rounds 4 through. 10 for the back wall. 


\subsection{CONCLUSIONS AND RECOMMENDATIONS}

Based on the analysis of the data, several conclusions are drawn that are relevant to the operation of the sampling system and the use of the results obtained. The section with supporting discussion is referenced in parenthesis.

\subsection{EXHAUST SAMPLERS}

1. For the exhaust particle sampler the gross alpha analyses only slightly underestimate the DU content as determined by radiochemical analysis. $(3.5)$

2. The exhaust concentration should be calculated as the average of the left and right samples. The results of the left and right samples correlated well. (3.5)

3. The observed average DU-exhaust concentrations were $<0.006 \mathrm{mg} / \mathrm{m}^{3}$. These do not correlate well with the long-term exhaust monitor averages. We conjecture that this is because of the procedure used for deriving the average from the strip charts and because the values are at the very bottom of the monitor's range and are imbedded in signal noise and zero drift. This means that the RAM-1 is not a suitable instrument for monitoring exhaust concentrations. It may be useful for monitoring filter integrity. (3.3)

4. The exhaust monitor indicated concentration excursions exceeding $0.008 \mathrm{mg} / \mathrm{m}^{3}$ for 6 out of 10 test rounds. The excursions averaged $8.4 \mathrm{~min}$, and none exceeded $15 \mathrm{~min}$ in duration. The concentrations were characterized by a sharply inclined pulse when the shot was fired, followed by a longer gradually declining release lasting no more than 20 min. (3.4).

\subsection{WORKPLACE SAMPLERS}

1. Data were insufficient for comparing the RDM-301 readings with any of the other samplers because most readings were recorded as below detection limits. $(3.8)$ 
2. No significant relationships between the inlet monitor and any other target bay sampler except the sequential filter samples are apparent. (3.6 and 3.7 )

3. The rates-of-concentration decline of the inlet monitor and the sequential samples showed significant correlation, the rates being nearly the same. Monitor respirable-dust concentration readings were lower than the sequential samplers' total DU concentrations. Depletion rates declined with sequence and varied from round to round. This shows that the monitor indicates a concentration change at the correct time and rate within the time resolution of the sequential samples, and probably quicker than that. (3.7)

4. The analysis of the limited data predicts that on the average the inlet monitor readings would be about 0.220 and $0.064 \mathrm{mg} / \mathrm{m}^{3}$ for DU concentrations of 0.200 and $0.050 \mathrm{mg} / \mathrm{m}^{3}$ respectively (the two action levels potentially of interest). (3.7)

5. The TSI-3500 readings when the target bay door was opened correlated well $(0.845)$ with the inlet monitor in the range encountered $\left(<0.05 \mathrm{mg} / \mathrm{m}^{3}\right) .(3.9)$

6. The two total-particulate samples taken on either side of the target bay correlated well (0.818) with each other. The concentration at the inlet was usually no more than two times nigher than at the workplace position. $(3.6)$

In terms of the test objectives listed in Section 2.2, Table 4.1 gives the correlations obtained for the comparisons listed.

\subsection{SMEARABLE SURFACE CONTAMINATION}

1. The mean target bay smearable contamination varied by a factor of four from the least $(2,400$ counts/wipe) to the greatest (10,300 counts/wipe). In increasing order of contamination the surfaces are ranked as: front wall, x-ray wall, exhaust wall, rear wall, exhaust inlet, and floor equipment. (3.10) 
TABLE 4.1. Correlations for Comparisons of Major Interest

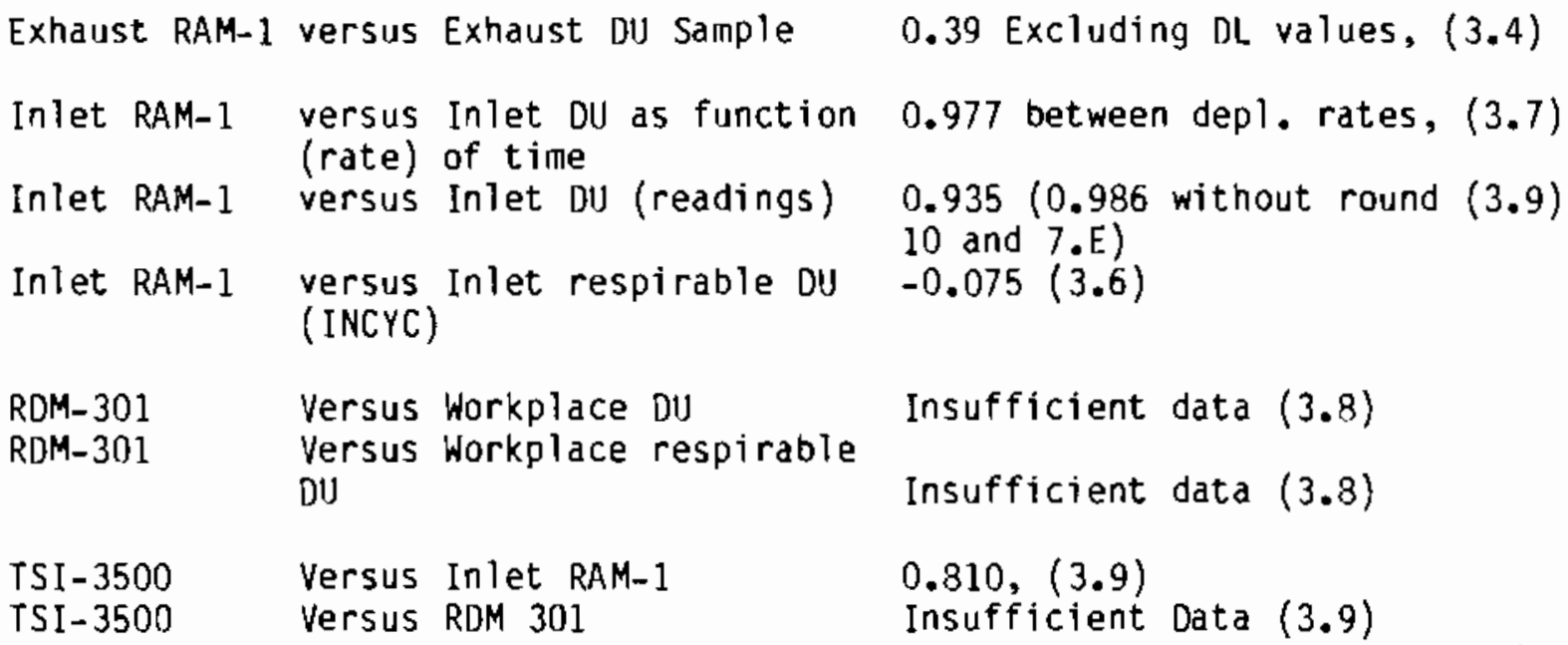

2. A low-pressure, water-spray decontamination after three test shots decreased the smearable surface contamination by a factor of 5 . Contamination increased to almost twice predecontamination levels after the following shot and stayed there for the next five shots. $(3.10)$

\subsection{RECOMMENDATIONS}

Recommendations for performing target bay and ventilation exhaust sampling are based on the above conclusions.

- Discontinue use of the RDM-301 because of its lack of sensitivity, slow response, and time-consuming maintenance.

- Implement weekly air samples in the workplace at two or more locations to better determine occupational exposure.

- Implement ways to reduce the labor required to operate the air sampling system such as airflow controls, easier data recording, and monitor maintenance. 
Some additional experiments are recommended:

- After workplace air sampling is implemented, monitor exposure of a subject in the target bay using a personal sampler to collect weekly samples.

- Compare these samples with the fixed samplers to test how well fixed samplers alone would routinely estimate exposures.

- Test target bay monitor and sampler responses using artificially generated surrogate aerosols.

A lower priority experiment would be to determine how accurately the exhaust monitor indicates a release exceeding the control level. This could be done by collecting air samples in the exhaust ducts for no more than 30 min after a test shot. Several sequential samples or a single sample could be taken. If sequential sampling is done it is important to use consistent exposure intervals. A better method for determining monitor readings accounting for zero drift would be useful for this experiment.

Finally, particle-size measurements in the unfiltered exhaust duct would be useful if upgrading the ventilation filtration system is contemplated. Aerodynamic particle-size distribution for DU and total particles is needed for selecting air-cleaning equipment. Cascade impactors or a device using a laser velocimetry would be the methods of choice. 


\subsection{REFERENCES}

Application for Amendment of Aberdeen Proving Ground License Sub-834. 1980. U.S. Army Material Testing Directorate, Aberdeen Proving Ground, Maryland.

Gl issmeyer, J. A., and M. A. Halverson. 1980. Operating Manual for Ford's Farm Range Air Samplers. PNL-3361, Pacific Northwest Laboratory, Richland, Washington. 

APPENDIX A

BASIC DATA FOR FORD'S FARM 


\section{APPENDIX A}

\section{BASIC DATA FOR FORO'S FARM}

TABLE A.1. Exhaust Monitor and Sampler Concentrations(a)

\begin{tabular}{|c|c|c|c|}
\hline \multirow[b]{2}{*}{ Round } & \multirow{2}{*}{$\begin{array}{l}\text { Monitor } \\
\mathrm{mg} / \mathrm{m}^{3} \\
\mathrm{EXH} . \mathrm{M}\end{array}$} & \multicolumn{2}{|c|}{$\begin{array}{c}\text { Uranium Concentration } \\
\text { By Fluorimetry } \\
\text { Ci } \times 10^{-18} / \mathrm{ml}\end{array}$} \\
\hline & & EXY.L & $E X Y . R$ \\
\hline 1 & 0.0024 & 1.900 & 2.600 \\
\hline 2 & 0.0010 & 0.413 & 0.267 \\
\hline 3 & 0.0020 & -0.520 & -0.680 \\
\hline 4 & 0.0035 & 1.500 & 1. $\mathrm{B} 00$ \\
\hline 5 & 0.0030 & 1.400 & 1.500 \\
\hline 6 & -0.0010 & 0.190 & 0.710 \\
\hline 7 & -0.0010 & 0.290 & 0.370 \\
\hline 8 & 0.0010 & 1.100 & 0.660 \\
\hline 9 & -0.0010 & 0.210 & 0.290 \\
\hline 10 & 0.0029 & 1.700 & 1.800 \\
\hline
\end{tabular}

TABLE A.2. Average Monitor Aerosol Concentration In Workplace, $\mathrm{mg} / \mathrm{m}^{3}$ (Concurrent with Temporary Samplers)

\begin{tabular}{|c|c|c|c|}
\hline Round & RDM & INLET & TSI \\
\hline 1 & $-\cdots$ & 0.030 & 0.015 \\
\hline 2 & 0.0 & 0.045 & 0.049 \\
\hline 3 & 0.010 & 0.017 & 0.010 \\
\hline 4 & 0.008 & 0.140 & 0.059 \\
\hline 5 & 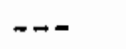 & 0.034 & 0.030 \\
\hline 6 & 0.140 & 0.015 & 0.013 \\
\hline 7 & 0.0 & 0.017 & 0.014 \\
\hline 8 & 0.020 & 0.025 & 0.036 \\
\hline 9 & 0.0 & 0.020 & 0.018 \\
\hline 10 & 0.0 & 0.019 & 0.010 \\
\hline
\end{tabular}


TABLE A.3. Uranium Concentration Analyses by Fluorimetry, Temporary Samplers

\begin{tabular}{|c|c|c|c|c|}
\hline \multirow[b]{2}{*}{ Round } & \multicolumn{4}{|c|}{ Uranium $\mathrm{Ci} \times 10^{-18} / \mathrm{m} \mathrm{l}$} \\
\hline & INF ILT & INCYCL & WKFILT & WKCYCL (a) \\
\hline 1 & 0.264 & 0.260 & $-0 . \overline{790}$ & 19.000 \\
\hline 2 & 3.030 & 0.350 & 1.870 & -32.000 \\
\hline 3 & 6.830 & 0.852 & 4.050 & -6.250 \\
\hline 4 & 6.830 & 0.852 & 4.050 & -6.250 \\
\hline 5 & 24.600 & 0.686 & 17.900 & 25.100 \\
\hline 6 & 24.600 & 0.686 & 17.900 & 25.100 \\
\hline 7 & 0.992 & 0.620 & 0.400 & 30.000 \\
\hline 8 & 27.000 & 8.300 & 16.000 & -0.640 \\
\hline 9 & 2.400 & 0.910 & 0.820 & -13.000 \\
\hline 10 & 8.100 & 0.200 & 20.000 & 58.000 \\
\hline
\end{tabular}

(a) A minus sign indicates a "detection limit" value.

TABLE A.4. Average Inlet Mogjtgr Aerosol Concentration by Sequence
After Shot, $\mathrm{mg} / \mathrm{m}$

\begin{tabular}{|c|c|c|c|c|c|}
\hline Round & SEO.A & SEח. B & SEQ.C & SEQ.0 & SEQ.E \\
\hline 1 & - & $\cdots$ & $-\cdots$ & $\cdots$ & -- \\
\hline 2 & $-\ldots$ & 0.022 & -- & -.- & $-\cdots$ \\
\hline 3 & $\ldots$ & 0.017 & --- & $-\ldots$ &..- \\
\hline 4 & -.. & --- & 13.100 & 1.990 & 0.090 \\
\hline 5 & -.. & 77.000 & 41.000 & 22.000 & 2.700 \\
\hline 6 & --- & 5.700 & 1.500 & 0.260 & 0.032 \\
\hline 7 & -.- & 9.100 & 1.050 & 0.055 & 0.017 \\
\hline 8 & 30.600 & 11.400 & 4.100 & 0.890 & 0.050 \\
\hline 9 & 37.000 & 4.200 & 0.380 & 0.060 & 0.020 \\
\hline 10 & --- & 34.000 & 6.000 & 0.170 & 0.024 \\
\hline
\end{tabular}

(a) A minus sign indicates a "detection limit" value. 
TABLE A.5. Temporary Sequential Sampler(a) by Fluorimetry

\begin{tabular}{|c|c|c|c|c|c|}
\hline \multirow[b]{2}{*}{ Round } & \multicolumn{5}{|c|}{ Uranium Ci $\times 10^{-15} / \mathrm{m} 1$} \\
\hline & SEQ.A & SEQ.B & SEQ.C & SEQ.D & SEO.E \\
\hline 1 & -- & -- & --- & --- & -- \\
\hline 2 & 2.700 & 0.0037 & $-\ldots$ & --- & --- \\
\hline 3 & 1.800 & 0.0058 & -- & --- & --- \\
\hline 4 & 100.000 & 24.000 & 3.400 & --- & -- \\
\hline 5 & 120.000 & 33.000 &.-- & 11.000 & 1.8000 \\
\hline 6 & 64.000 & 7.1000 & --- & 0.085 & 0.0048 \\
\hline 7 & 64.000 & 4.4000 & 0.590 & 0.014 & -0.0012 \\
\hline 8 & --- & --- & --- & -- & \\
\hline 9 & 25.000 & 1.8000 & 0.230 & 0.048 & 0.0023 \\
\hline 10 & 130.000 & 18.0000 & 15.200 & 0.764 & 0.2910 \\
\hline
\end{tabular}

(a) A minus sign indicates a "detection-limit" value. 



\section{APPENDIX B}

BLANK ADJUSTMENT FOR TEMPORARY SAMPLERS 
IABLE B.1. $x_{i j}$, Basic Data, Ci/ml, Iranium by Fluorimetry(a)

\begin{tabular}{|c|c|c|c|c|c|c|c|c|c|c|c|}
\hline \multirow[b]{2}{*}{ Round } & \multicolumn{6}{|c|}{$\mathrm{Ci} \times 10^{-18} / \mathrm{m} 1$} & \multicolumn{5}{|c|}{$\mathrm{Ci} \times 10^{-15} / \mathrm{ml}$} \\
\hline & $\overline{E X H . L}$ & EXH.R & INF & INC & WKF & WKC & SEQ.A & SEO.B & SEO.C & SEQ.D & SEQ.E \\
\hline 1 & 1.900 & 2.600 & 0.264 & 0.260 & $(0.790)$ & 19.000 & -- & - & - & - - & - \\
\hline 2 & 0.413 & 0.267 & 3.030 & 0.350 & 1.870 & $(32.000)$ & 2.700 & 0.003 & -- & $\ldots$ & - \\
\hline 3 & $(0.520)$ & $(0.680)$ & 6.830 & 0.853 & 4.050 & $(6.250)$ & 1.800 & 0.005 & -- & $\ldots$ & -- \\
\hline 4 & 1.500 & 1.800 & 6.830 & 0.853 & 4.050 & $(6.250)$ & 100.000 & 24.000 & 3.400 & - & - \\
\hline 5 & 1.400 & 1.500 & 24.600 & 0.686 & 17. & 25.100 & 120.000 & 33.000 & -- & 11.000 & 1.800 \\
\hline 6 & & & 24.600 & 0.686 & & & 64.000 & 7.100 & -- & 0.085 & 0.005 \\
\hline 7 & 0.290 & 0.370 & 0.992 & 0.620 & & 900 & 64.000 & 4.400 & 0.590 & 0.014 & $(0.001)$ \\
\hline 8 & 1.100 & 0.660 & 27.000 & 8.300 & 16.000 & $(0.640)$ & -- & 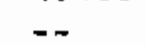 & -- & $\ldots$ & - \\
\hline 9 & 0.210 & 0.290 & 2.400 & 0.910 & 0.820 & $(13.000)$ & 25.000 & 1.800 & 0.230 & 0.048 & 0.002 \\
\hline 10 & 1.700 & 1.800 & 8.100 & 0.200 & 20.000 & 58.000 & 130.000 & 18.000 & 15.200 & 0.764 & 0.291 \\
\hline
\end{tabular}

(a) Parentheses indicates detection limit values.

TABLE B.2. V V

\begin{tabular}{|c|c|c|c|c|c|c|c|c|c|c|c|}
\hline & \multicolumn{6}{|c|}{$\left.\mathrm{Ci} \times 10^{-18} / \mathrm{m}\right\}$} & \multicolumn{5}{|c|}{$\mathrm{Ci} \times 10^{-15} / \mathrm{ml}$} \\
\hline Round & EXH.L & EXH. R & INF & INC & WKF & WKC & SEO.A & SEQ.B & SEO.C & SEQ.D & SEO.E \\
\hline 1 & 4.9850 & 4.9850 & 1.5900 & 2.4000 & 1.6300 & 0.0640 & -- & - & -- & -- & - \\
\hline 2 & 10.3000 & 10.3000 & 1.7300 & 2.6199 & 1.7800 & 0.0700 & 0.2760 & 0.9729 & -- & - & - \\
\hline 3 & 8.6999 & 8.6999 & 3.6500 & 5.4800 & 3.5100 & 0.1440 & 0.2460 & 0.8060 & -- & - & -- \\
\hline 4 & 500 & 500 & 3.6500 & 5.4800 & 100 & 0.1440 & 0.1350 & 0.1350 & 0.1350 & 0.3240 & 0.3780 \\
\hline 5 & 999 & 999 & 3.5399 & 5.2500 & 399 & 0.1199 & 0.1350 & 0.1350 & 0.1350 & 0.0540 & 1.6200 \\
\hline 6 & 8.3500 & 8.3500 & 3.5399 & 5.2500 & 3.0399 & 0.1199 & 0.1620 & 0.1080 & -- & 0.1620 & $\$ 400$ \\
\hline 7 & 7.4000 & 7.4000 & 1.5200 & 2.2500 & 1.4600 & 0.0579 & 0.1350 & 0.1350 & 0.1350 & 0.4320 & 1.2699 \\
\hline 8 & 7.5000 & 7.5000 & 1.5200 & 2.2500 & 1.5200 & 0.0599 & 350 & 0.1350 & 0.1350 & 0.3240 & 0.3200 \\
\hline 9 & 8.1499 & 8.1499 & 1.5200 & 2.5200 & 200 & 0.0599 & 0.1350 & 0.1350 & 0.1080 & 0.1620 & 1.3700 \\
\hline 10 & 8.6499 & 8.6499 & 3.4800 & 5.1799 & 3.3800 & 0.1340 & 0.1350 & 0.1350 & 0.2700 & 0.4050 & 0.4050 \\
\hline
\end{tabular}

(a) Table B.3 is calculated by dividing the blank filter analysis by the figures in Table B.2. 
TABLE B.3. $b_{i j}^{-}, B l a n k \mathrm{Ci} / m 1$

\begin{tabular}{|c|c|c|c|c|c|c|c|c|c|c|c|c|}
\hline \multirow[b]{2}{*}{ Round } & \multicolumn{6}{|c|}{$\mathrm{Cl} \times 10^{-18} / \mathrm{ml}$} & \multicolumn{5}{|c|}{ Cl $\times 10^{-15} / \mathrm{ml}$} & \multirow{2}{*}{$\begin{array}{l}\mathrm{b}_{1}, \text { Blank } \\
\text { Cil/Ftlitar } \\
\end{array}$} \\
\hline & EXH.L & EXH.R & INF & $\operatorname{INC}$ & WKF & WKC & SEQ.A & SEQ.B & SEQ,C & SEQ.D & SEQ.E & \\
\hline$\uparrow$ & 0.2122 & 0.2122 & 0.6654 & 0.4408 & 0.6490 & 16.5312 & -- & -- & - & -- & $=$ & $(9.058)$ \\
\hline 2 & 0.1027 & 0.1027 & 0.6115 & 0.4038 & 0.5943 & 15.1142 & 0.0038 & 0.0010 & -- & - & -- & $\{1.058\}$ \\
\hline 3 & 0.1216 & 0.1216 & 0.2898 & 0.1930 & 0.3014 & 7.3472 & 0.0043 & 0.0013 & -- & $=$ & -- & $(1.058)$ \\
\hline 4 & 0.2330 & 0.2330 & 0.3287 & 0.2189 & 0,3418 & 8.3333 & 0.0088 & 0.0088 & 0.0088 & 0.0037 & 0.0031 & 1.2 \\
\hline 5 & 0.0380 & 0.0380 & 0.0988 & 0.0666 & 0.1151 & 2.9166 & 0.0025 & 0.0025 & 0.0025 & 0.0064 & 0.0002 & 0.35 \\
\hline 6 & 0.3832 & 0.3832 & 0.9039 & 0.6095 & 1.0526 & 26.6666 & 0.0197 & 0.0296 & -- & 0.0197 & 0.0059 & 3.2 \\
\hline 7 & 0.0324 & 0.0324 & 0.1578 & 0.1066 & 0.1643 & 4.1379 & 0.0017 & 0.0017 & 0.0017 & 0.0005 & 0.0001 & 0.24 \\
\hline 8 & 0.1733 & 0.1733 & 0.8552 & 0.5777 & 0.8552 & 21.6666 & 0.0096 & 0.0096 & 0.0096 & 0.0040 & 0.0009 & 1.3 \\
\hline 9 & 0.0073 & 0.0073 & 0.0394 & 0.0238 & 0.0394 & 1.0000 & 0.0004 & 0.0004 & 0.0005 & 0.0003 & 0.0000 & 0.06 \\
\hline 10 & 0.1223 & 0.1223 & 0.3040 & 0.2042 & 0.3130 & 7.8956 & 0.0078 & 0.0078 & 0.0039 & 0.0026 & 0.0026 & $(1.058)$ \\
\hline
\end{tabular}

(a) Parenthesized value is average of rounds 4 through 9.

TABLE B.4. $\quad x_{j j}$, Adjusted $\mathrm{C} i / m l(a, b, c)$

\begin{tabular}{|c|c|c|c|c|c|c|c|c|c|c|c|}
\hline \multirow[b]{2}{*}{ Round } & \multicolumn{6}{|c|}{$\mathrm{Ci} \times 10^{-18} / \mathrm{mi}$} & \multicolumn{5}{|c|}{$\mathrm{cl} \times 10^{-15} / \mathrm{ml}$} \\
\hline & EXH.L & $\mathrm{EXH}, \mathrm{R}$ & $\mathrm{INF}$ & $I N C$ & $\mathrm{WKF}$ & WKC & SEQ.A & SEQ.B & $A C . C$ & SEQ.D & SEQ.E \\
\hline 1 & 1.687 & 2.387 & -0.401 & -0.180 & $(0.140)$ & 2.468 & -- & -- & -- & -- & -- \\
\hline 2 & 0.310 & 0.164 & 2.418 & -0.053 & 1.275 & $(16.885)$ & 2.696 & 0.002 & -- & - & -- \\
\hline 3 & $(0.398)$ & $(0.558)$ & 6.546 & 0.659 & 3.748 & $(-1.097)$ & 1.795 & 0.004 & -- & -- & -- \\
\hline 4 & 1.266 & 1.566 & 6.501 & 0.634 & 3.708 & $(-2.083)$ & 99.991 & 23.991 & 3.391 & -- & - \\
\hline 5 & 1.361 & 1.461 & 24.501 & 0.619 & 17.784 & 22.183 & 119.997 & 32.997 & -- & 10.993 & 1.799 \\
\hline 6 & -0.193 & 0.326 & 23.696 & 0.076 & 16.847 & -1.566 & 63.980 & 7.070 & -- & 0.065 & -0.001 \\
\hline 7 & 0.257 & 0.337 & 0.834 & $0.5 \uparrow 3$ & 0.235 & 25.862 & 63.998 & 4.398 & 0.588 & 0.013 & $(0.001)$ \\
\hline 8 & 0.926 & 0.486 & 26.144 & 7.722 & 15.144 & $(-21.026)$ & -- & -- & -- & $=-$ & -- \\
\hline 9 & 0.202 & 0.282 & 2.360 & 0.886 & 0.780 & 12.000 & 24.999 & 1.799 & 0.229 & 0.047 & 0.002 \\
\hline 10 & 1.577 & 1.677 & 7.795 & -0.004 & 19.686 & 50.104 & 129.992 & 17.992 & 15.196 & 0.761 & 0.288 \\
\hline
\end{tabular}

(a) The results in Table B.4 are obtalned by subtracting the results in Table B.3 from those of Table B. 1 . (b) Parentheses Indicate detection IImit values.

(c) A minus sign indicates samples for which blank correction was greater than sample result. 
TARLE B.5. $P_{i j}$, Blank as a Percentage of the Unadjusted Data $(a)$

\begin{tabular}{|c|c|c|c|c|c|c|c|c|c|c|c|}
\hline Round & EXH.L & EXH.R & INF & INC & WKF & WKC & SEN.A & SEQ.B & SEN.C & SEO. 0 & SEQ.E \\
\hline 1 & 11.17 & 8.16 & 252.04 & 169.55 & 82.16 & 87.00 & -- & - & - & -- & - \\
\hline 2 & 24.87 & 38.47 & 20.18 & 115.37 & 31.78 & 47.23 & 0.14 & 29.38 & -- & $\ldots$ & -- \\
\hline 3 & 23.38 & 17.88 & 4.24 & 22.63 & 7.44 & 117.55 & 0.23 & 22.63 & -- & -- & -- \\
\hline 4 & 15.53 & 12.94 & 4.81 & 25.67 & 8.44 & 133.33 & 0.00 & 0.03 & 0.26 & -- & -- \\
\hline 5 & 2.71 & 2.53 & 0.40 & 9.71 & 0.64 & 11.62 & 0.00 & 0.00 & -- & 0.05 & 0.01 \\
\hline 6 & 201.70 & 53.97 & 3.67 & 88.85 & 5.88 & 106.24 & 0.03 & 0.41 & -- & 23.23 & 123.45 \\
\hline 7 & 11.18 & 8.76 & 15.91 & 17.20 & 41.09 & 13.79 & 0.00 & 0.04 & 0.30 & 3.96 & 15.74 \\
\hline 8 & 15.75 & 26.26 & 3.16 & 6.96 & 5.34 & 3385.41 & -- & -- & $\ldots$ & -- & -- \\
\hline 9 & 3.50 & 2.53 & 1.64 & 2 & 4.81 & & 0.00 & 0.02 & 0.24 & 0.77 & 1.90 \\
\hline 10 & 7.19 & 6.79 & 3.75 & 102.12 & 1.56 & 13.61 & 0.00 & 0.04 & 0.02 & 0.34 & 0.89 \\
\hline
\end{tabular}

(a) Table B.5 is calculated by taking the values in Table $R .3$ as a percentage of corresponding values in Table B.l.

TABLE R.6. U U $U_{i j}$, Grams DU per Cubic Meter of Air (a)

\begin{tabular}{|c|c|c|c|c|c|c|c|c|c|c|c|}
\hline \multirow[b]{2}{*}{ Round } & \multicolumn{6}{|c|}{$\mathrm{g} / \mathrm{m}^{3}$} & \multicolumn{5}{|c|}{$\mathrm{mg} / \mathrm{m}^{3}$} \\
\hline & EXH.L & EXH.R & INF & INC & WKF & WKC & SEQ.A & SEQ.B & SEQ.C & SEQ.D & SEQ.E \\
\hline 1 & 4.688 & 6.632 & -1.115 & -0.502 & 0.391 & 6.857 & $\ldots$ & 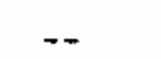 & -- & - & - \\
\hline 2 & & & & -0.1 & 3.5 & 46. & 7.489 & 0.007 & -- & $\ldots$ & -- \\
\hline 3 & 106 & 1.551 & 18.167 & 1.833 & 10.412 & -3 & 4.988 & 0.012 & $\ldots$ & $\ldots$ & $\ldots$ \\
\hline 4 & 3.519 & 4.3 & 18.058 & 1.761 & 10.300 & -5.787 & 277.753 & 66.641 & 9.419 & $\ldots$ & -- \\
\hline 5 & 3.783 & 4.060 & 68.056 & 1.720 & 49.402 & 61.620 & 333.326 & 91.659 & -- & 30.537 & 4.999 \\
\hline 6 & -0.536 & 0.907 & 65.822 & 0.212 & 46.798 & -4.351 & 177.722 & 19. & -- & 0. & -0.003 \\
\hline 7 & 0.715 & 0.937 & 2.316 & 1.425 & 0.654 & & 177.772 & 12.217 & 1.633 & 0.037 & 0.002 \\
\hline 8 & 2.574 & 1.351 & 72.624 & 21.450 & 42.068 & -58.407 & -- & -- & - & -- & -- \\
\hline 9 & & 0.785 & & & & & 69.443 & 4.998 & 0.637 & 0.132 & 0.006 \\
\hline 10 & 4.382 & 4.660 & 21.655 & -0.011 & 54.686 & 139.179 & 361.089 & 49.978 & 42.211 & 2.114 & 0.801 \\
\hline
\end{tabular}

(a) Mass units were calculated by converting units from Table B.4. 
TA8LE B.7. $\log _{e}\left(U_{i j}\right)$, Natura T Logarithm of Adjusted Grams DU per $m^{3(a)}$

\begin{tabular}{|c|c|c|c|c|c|c|c|c|c|c|c|}
\hline Round & EXH.L & $\mathrm{EXH} . \mathrm{R}$ & INF & INC & WKF & WKC & SEQ.A.A & SEO.B & SEQ.C & SEO.D & SEQ.E \\
\hline 1 & 1.5450 & 1.8920 & -- & - & -0.9379 & 1.9253 & -- & -- & -- & -- & $=$ \\
\hline 2 & -0.1486 & -0.7845 & 1.9047 & -- & 1.2650 & $3.84 \mathrm{~B} 1$ & 2.0134 & -4.9257 & -- & -- & -- \\
\hline 3 & 0.1013 & 0.4389 & 2.8996 & 0.6060 & 2.3430 & -- & 1.6070 & -4.3848 & - & -- & -- \\
\hline 5 & 1.3305 & 1.4014 & 4.2203 & 0.5425 & 3.8999 & 4.1209 & 5.8091 & 4.5180 & -- & 3.4189 & 1.6093 \\
\hline 6 & - & -0.0968 & 4.1869 & -1.5491 & 3.8458 & -- & 5.1802 & 2.9775 & -- & -1.7079 & -- \\
\hline 7 & -0.3348 & -0.0643 & 0.8402 & 0.3548 & -0.4238 & 4.2744 & 5.1805 & 2.5028 & 0.4910 & -3.2875 & -5.8751 \\
\hline 8 & 0.9454 & 0.3014 & 4.2852 & 3.0657 & 3.7393 & -- & -- & - & - & -- & -- \\
\hline
\end{tabular}

(a) Results are natural logarithms of values in Table B.6. 
APPENDIX C.I

LISTING OF BETA-GAMMA DATA FROM WIPES 
LISTING OF BETA-GAMMA DATA FROM WIPES

TABLE C.1. Wipe Data for X-Ray Wall, cPm

\begin{tabular}{|c|c|c|c|c|c|c|c|}
\hline Round & $\begin{array}{l}\text { LOC22.B } \\
\text { Mean }\end{array}$ & $\begin{array}{l}\text { LOC23.B } \\
\text { Mean }\end{array}$ & $\begin{array}{l}\text { LOC24. B } \\
\text { Mean }\end{array}$ & $\begin{array}{l}\text { LOC25. B } \\
\text { Mean }\end{array}$ & $\begin{array}{l}\text { LOC26. } \\
\text { Mean }\end{array}$ & $\begin{array}{l}\mathrm{LBC} 27.8 \\
\text { Mean }\end{array}$ & $\begin{array}{l}\text { LOC28. } \\
\text { MEAN }\end{array}$ \\
\hline 1 & -- & -- & -- & - & 144 & - & - \\
\hline 2 & 119 & 214 & -- & 161 & 747 & 1119 & 133 \\
\hline 3 & - & 3281 & -- & 3688 & -- & 4474 & 5172 \\
\hline 4 & 2411 & -- & -- & 4550 & -- & 2194 & $\cdots$ \\
\hline 5 & - & 5186 & -- & 7578 & -- & 1744 & -- \\
\hline 6 & -- & 5928 & -- & 4861 & -- & 1683 & -- \\
\hline 7 & 3922 & -- & -- & -. & -- & 3284 & 2422 \\
\hline 8 & 1725 & -. & -- & 1394 & -. & 2511 & 1105 \\
\hline 9 & 8216 & -- & -- & 4300 & -- & 9516 & 4033 \\
\hline 10 & 1792 & -- & -. & 9786 & -. & 6450 & 3888 \\
\hline Decon & - & -- & - & -- & -- & 144 & 272 \\
\hline$\overline{\text { Mean }}$ & $\overline{3030.8}$ & $\overline{3652.2}$ & $\overline{-}$ & $\overline{4539.7}$ & $\overline{445.5}$ & $\overline{3311.8}$ & $\overline{2432} .1$ \\
\hline & 6 & 4 & 0 & 8 & 2 & 10 & 7 \\
\hline
\end{tabular}

TABLE C.2. Wipe Data for Front Wall, cpm

\begin{tabular}{|c|c|c|c|c|c|}
\hline Round & $\begin{array}{l}\text { LOC29.B } \\
\text { Mean } \\
\end{array}$ & $\begin{array}{l}\text { LOC } 30 . B \\
\text { Mean } \\
\end{array}$ & $\begin{array}{l}\text { LOC } 31 . B \\
\text { Mean } \\
\end{array}$ & $\begin{array}{l}\text { LOC 32. B } \\
\text { Mean }\end{array}$ & $\begin{array}{l}\text { LOC33. B } \\
\text { Mean }\end{array}$ \\
\hline 1 & -- & 112 & -- & -- & -- \\
\hline 2 & 200 & 235 & 232 & -- & 109 \\
\hline 3 & 368 & 5367 & -- & 358 & 1172 \\
\hline 4 & -- & 3467 & -- & -- & -- \\
\hline 5 & -- & 3467 & 1633 & 1584 & 1695 \\
\hline 6 & 2078 & -- & 1394 & 1578 & -- \\
\hline 7 & & 2811 & 3744 & 2639 & 2167 \\
\hline 8 & 3684 & -- & 6230 & 6127 & 2355 \\
\hline 9 & 1300 & -- & 4317 & 2994 & 678 \\
\hline 10 & 1715 & -- & 3658 & 6427 & 3442 \\
\hline Decon & & - & $\cdots$ & -- & \\
\hline Mean & 1557.5 & 2743.1 & $\overline{3029.7}$ & $\overline{3101.0}$ & 1659.7 \\
\hline$N$ & 6 & 6 & 7 & 7 & 7 \\
\hline
\end{tabular}




\begin{tabular}{|c|c|c|c|c|c|c|c|c|}
\hline Round & $\begin{array}{l}\text { LOC } 1 . B \\
\text { Mean }\end{array}$ & $\begin{array}{l}\text { LOC2.B } \\
\text { Mean } \\
\end{array}$ & $\begin{array}{l}\text { LOC 3. B } \\
\text { Mean } \\
\end{array}$ & $\begin{array}{l}\text { LOC4.B } \\
\text { Mean } \\
\end{array}$ & $\begin{array}{l}\text { LOC5. B } \\
\text { Mean }\end{array}$ & $\begin{array}{c}\text { L0C6.B } \\
\text { Mean }\end{array}$ & $\begin{array}{l}\text { LOC7.B } \\
\text { Mean }\end{array}$ & $\begin{array}{c}\text { LOCS.B } \\
\text { Mean }\end{array}$ \\
\hline 1 & -- & -- & - & 400 & -- & -- & -- & - \\
\hline 2 & 204 & - & -- & 125 & 747 & 425 & 877 & 1656 \\
\hline 3 & 10800 & 1242 & 9505 & 1684 & - & - & - & 10291 \\
\hline 4 & 48.34 & $=$ & 2150 & - & - & 4678 & -- & 233 \\
\hline 5 & 39611 & -- & 11250 & -- & - & $-\infty$ & 25472 & 987 \\
\hline 6 & 7772 & 10044 & 11711 & -- & $=$ & - & - & 4711 \\
\hline 7 & 7361 & - & 4478 & 6394 & -- & -- & -- & 5161 \\
\hline 8 & 1016 & 11639 & 7205 & - & - & $=$ & - & 499 \\
\hline 9 & 10505 & 11538 & 7111 & - & - & -- & 4184 & 3567 \\
\hline 10 & 25840 & 62569 & 7619 & -- & -- & - & 1323 & 8300 \\
\hline Decon & 361 & 1155 & -- & -- & 50 & -- & - & 1544 \\
\hline Mean & $\overline{10830}$ & 16364 & $\overline{7628}$ & $\overline{2150.7}$ & $\overline{398.50}$ & $\overline{2551.5}$ & $\overline{7964}$ & 3694.8 \\
\hline$N$ & 10 & 6 & 8 & 4 & 2 & 2 & 4 & 10 \\
\hline
\end{tabular}


TABLE C.4. Wipe Data for Exhaust Wall, cpm

\begin{tabular}{|c|c|c|c|c|c|c|c|c|c|}
\hline Round & $\begin{array}{l}\text { LOC9.B } \\
\text { Mean } \\
\end{array}$ & $\begin{array}{l}\text { LOC } 10 . B \\
\text { Mean }\end{array}$ & $\begin{array}{l}\text { LOC11. B } \\
\text { Mean }\end{array}$ & $\begin{array}{l}\text { LOC12. B } \\
\text { Mean }\end{array}$ & $\begin{array}{l}\text { LOC } 13 . R \\
\text { Mean }\end{array}$ & $\begin{array}{l}\text { LOC14.B } \\
\text { Mean }\end{array}$ & $\begin{array}{l}\text { LOC } 15 . B \\
\text { Mean }\end{array}$ & $\begin{array}{c}\text { LOC16.B } \\
\text { Mean }\end{array}$ & $\begin{array}{l}\text { L0C17. B } \\
\text { Mean }\end{array}$ \\
\hline 1 & -- & -- & -- & -- & $-\pi$ & - & -- & -- & -- \\
\hline 2 & 109 & 586 & 361 & 1825 & 575 & 274 & 137 & -- & 211 \\
\hline 3 & 1950 & - & 1652 & -- & - & - & 3410 & 20750 & 2154 \\
\hline 4 & 2678 & -- & 4125 & 6011 & - & -- & 6594 & -- & 4083 \\
\hline 5 & 2583 & -- & 9894 & 14011 & - & 5794 & -- & 38994 & -- \\
\hline 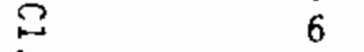 & - & - & 464 & 19227 & -- & 5383 & -- & 10266 & -- \\
\hline 7 & 1786 & -- & 1277 & - & - & 10350 & - & 12922 & -- \\
\hline 8 & -- & - & - & 8500 & -- & 1885 & $=-$ & 11622 & -- \\
\hline 9 & 3133 & -- & 1510 & 2255 & - & 4300 & -- & 12443 & -- \\
\hline 10 & 21905 & $\sim$ & 5942 & 1172 & -- & 7356 & -- & 7908 & -- \\
\hline Decon & -- & -- & -- & 972 & -- & 222 & 2461 & 1077 & $\ldots$ \\
\hline Mean & $\overline{4877}$ & 586 & $\overline{3153.5}$ & 6746 & 575 & $\overline{4445.5}$ & 3150.5 & 14497 & $\overline{2149.3}$ \\
\hline N & 7 & 1 & 8 & 8 & 1 & 8 & 4 & 8 & 3 \\
\hline
\end{tabular}


IABLE C.5. Wipe Data for Rear Wall, cpm

\begin{tabular}{|c|c|c|c|c|}
\hline Round & $\begin{array}{l}\text { LOC18.B } \\
\text { Mean }\end{array}$ & $\begin{array}{l}\text { LOC19.B } \\
\text { Mean }\end{array}$ & $\begin{array}{l}\text { LOC20.B } \\
\text { Mean }\end{array}$ & $\begin{array}{l}\text { LOC21. B } \\
\text { Meann }\end{array}$ \\
\hline 1 & -- & -- & -- & -- \\
\hline 2 & -- & 175 & 337 & 204 \\
\hline 3 & -- & 393 & 3180 & 1849 \\
\hline 4 & 1333 & 2678 & -- & 3294 \\
\hline 5 & 2394 & 4756 & 9750 & 577 \\
\hline 6 & 4106 & 3411 & 16033 & 2711 \\
\hline 7 & 2272 & 2605 & 5228 & 1628 \\
\hline 8 & 3705 & 1605 & 11183 & 2700 \\
\hline 9 & 39433 & 9999 & 12966 & 7422 \\
\hline 10 & 4119 & 8650 & 19669 & 5346 \\
\hline Decon & -- & -- & 627 & -- \\
\hline Mean & 8194 & $\overline{3808.0}$ & 8774 & 2859.0 \\
\hline $\mathrm{N}$ & 7 & 9 & 9 & 9 \\
\hline
\end{tabular}

C1.4 


\section{APPENDIX C.2}

PLOTS OF BETA-GAMMA DATA FROM WIPES BY ROUNO NATURAL LOGARITHM OF DATA 


\section{APPENDIX C.2}

\section{PLOTS OF BETA-GAMMA DATA FROM WIPES BY ROUND}

NATURAL LOGARITAM OF DATA
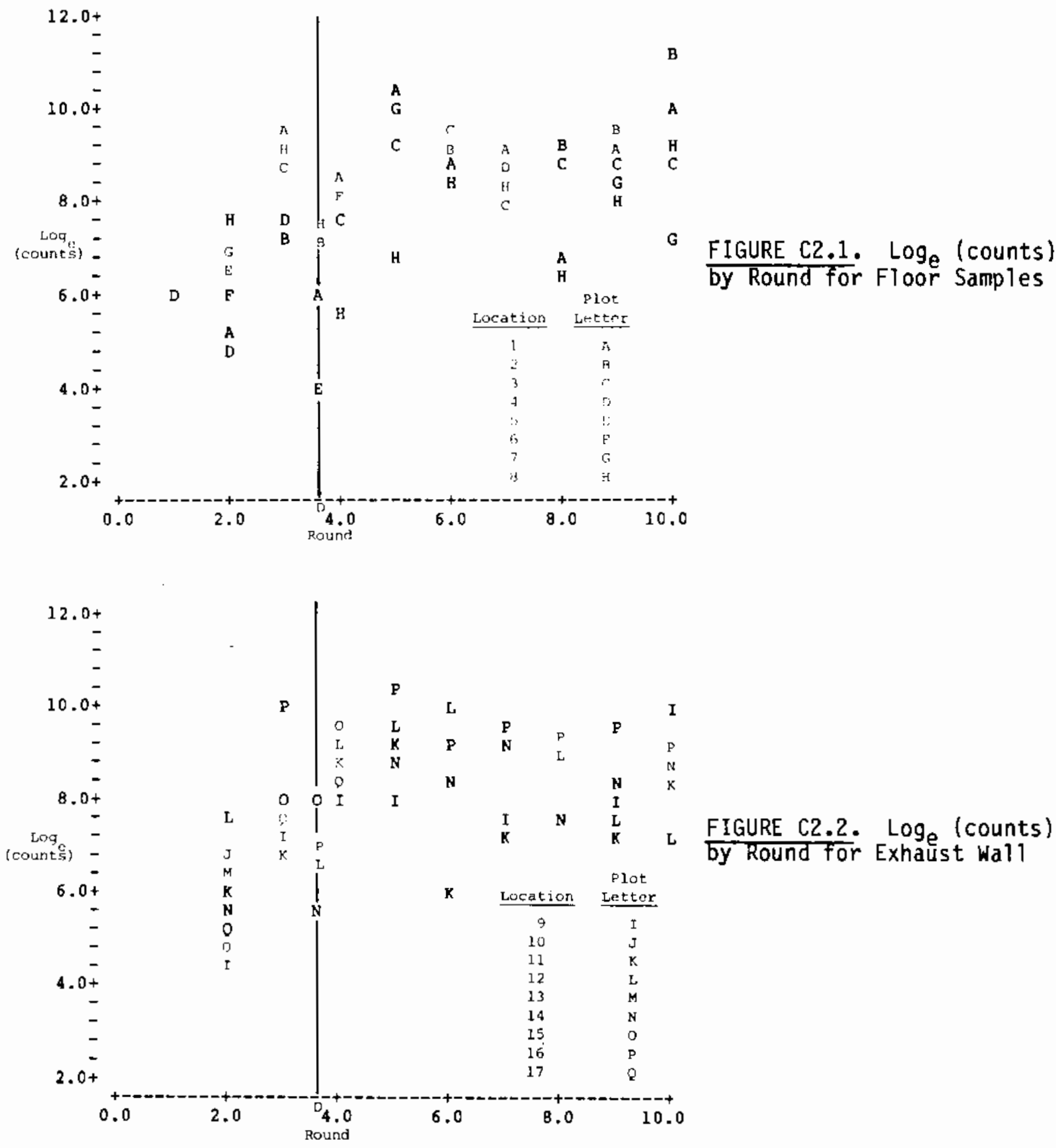

NOTE: Vertical line indicates time at which building was decontaminated. 

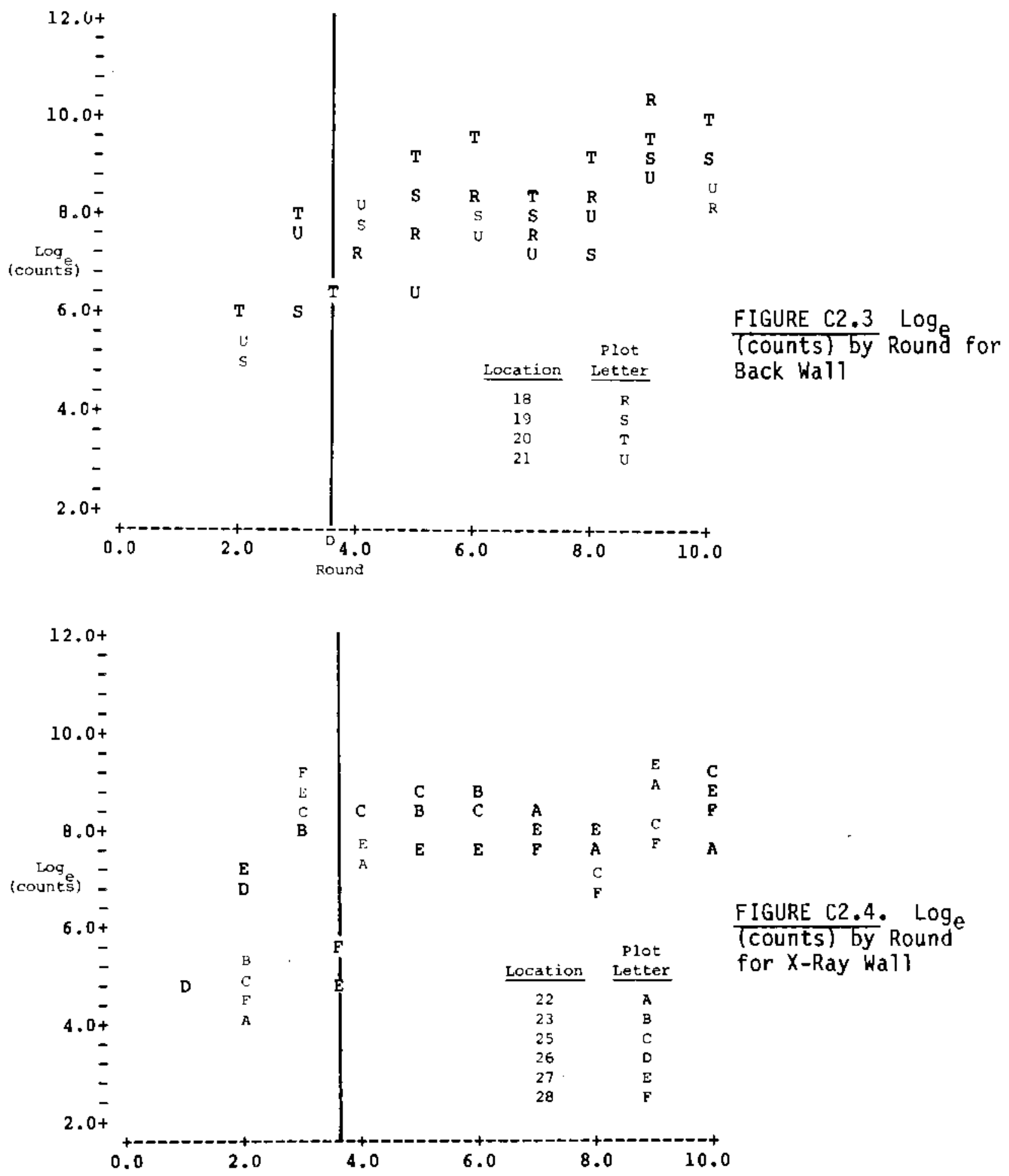

NOTE: Vertical line indicates time at which building was decontaminated. 


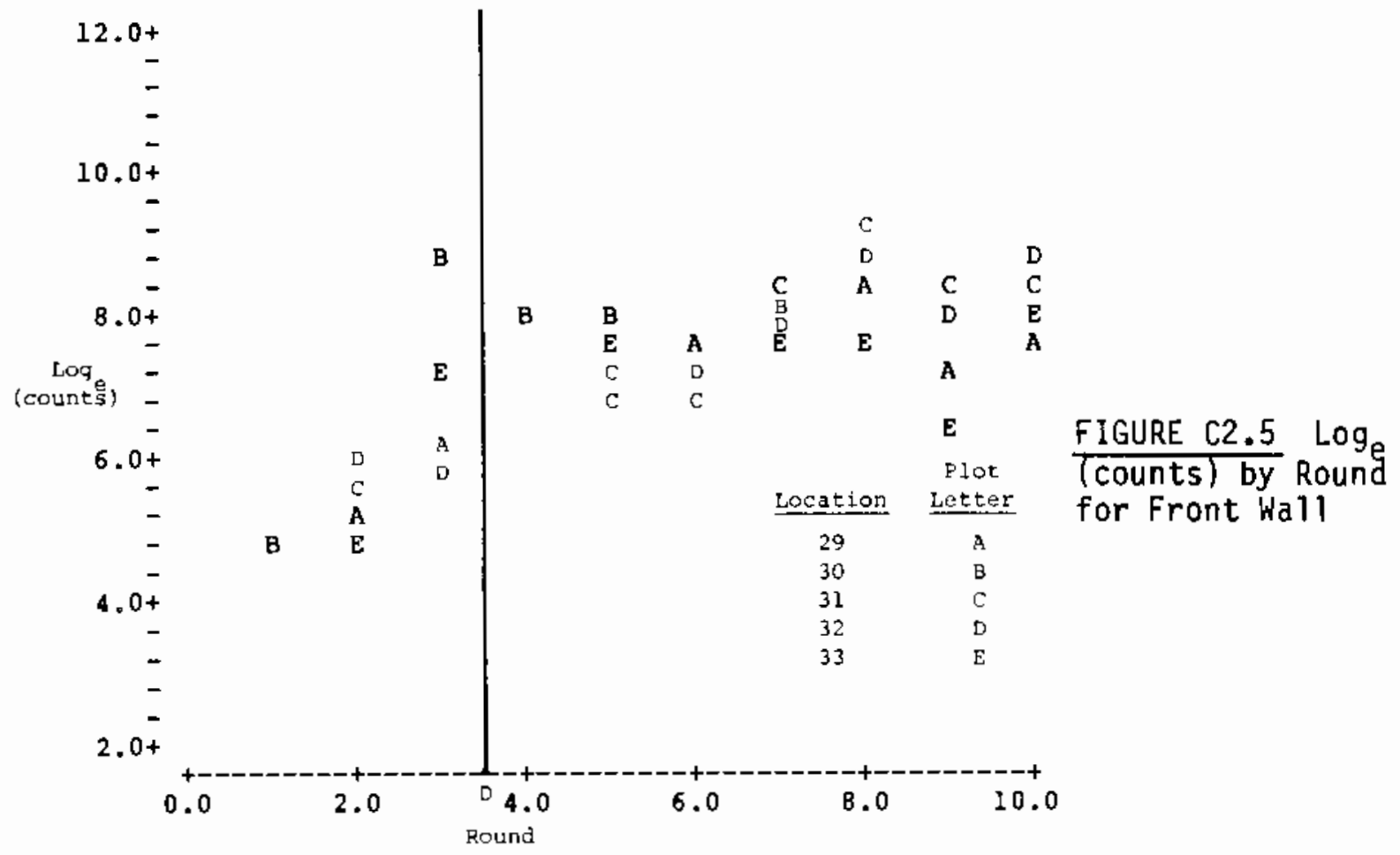

NOTE: Vertical line indicates time at which building was decontaminated. 



\section{DISTRIBUTION}

No. of

Copies

OFFSITE

25 Commander

Material Testing Directorate

STEAP-MT-A

$M r$. Ken Ruff

Aberdeen Proving Ground, MD 21005

27 DOE Technical Information Center

1 GCA Corporation

Technology Division

Environmental Instruments

$\mathrm{Mr}$. N. Ortolino

213 Burlington Road

Bedford, MA 01730
No. of

Copies

ONSITE

DOE Richland Operations Office

H. E. Ransom

25 Pacific Northwest Laboratory

D. W. Dragnich

C. E. Elderkin

J. A. Glissmeyer (8)

P. C. Hays

R. K. Hadlock

M. Halverson

J. W. Johnston (3)

N. S. Laulainen

J. Mishima

Technical information (5)

Publishing Coordination (2) 


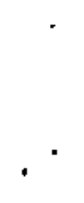

. 